NBSIR 85-3221

\title{
An Assessment of the NBS 1-m Guarded-Hot-Plate Limits
}

Brian G. Rennex

U.S. DEPARTMENT OF COMMERCE

National Bureau of Standards

National Engineering Laboratory

Center for Building Technology

Gaithersburg, MD 20899

August 1985

Prepared for:

U.S. Department of Energy

$\begin{array}{cc}-\mathrm{AC} & \text { Building Energy } \\ 100 & \text { and Development } \\ \text { on, DC } 20585\end{array}$

.1156

$85-3221$ 


\section{AN ASSESSMENT OF THE NBS 1-m GUARDED-HOT-PLATE LIMITS}

Brian G. Rennex

U.S. DEPARTMENT OF COMMERCE

National Bureau of Standards

National Engineering Laboratory

Center for Building Technology

Gaithersburg。MD 20899

August 1985

Prepared for:

U.S. Department of Energy

Office of Building Energy

Research and Development

Washington, DC 20585

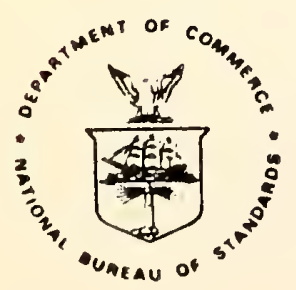

U.S. DEPARTMENT OF COMMERCE, Malcolm Baldrige, Secretary NATIONAL BUREAU OF STANDARDS, Ernest Ambler. Director 


\section{PREFACE}

This report is one of a series documenting NBS research and analysis efforts to support the Department of Energy/National Bureau of Standards' Measurements Technology Program. The work reported in this document was sponsored by Department of Energy through DOE/ORO/NBS Interagency Agreement No. DE-AI05-850R21513, Task C-85/1, Guarded Hot Plate Assessment.

\section{PRODUCT DISCLAIMER}

Because of the nature of this report, to assess the limits of a particular apparatus, there is an occasional use of a trade name or a manufacuturer's name. This in no way represents an endorsement of a particular product or manufacturer. 



\begin{abstract}
The report evaluates the National Bureau of Standards 1-meter Guarded Hot Plate in terms of the range of values of operating parameters. The ranges of operation arediscussed according to three kinds of limiting factors. The first is the limits of temperature over which the various apparatus components can be used without damage. The second kind is the limits of plate temperatures, specimen thickness, atmospheric pressure, and relative humidity achievable with the existing control systems. The third kind is any limits on the values of apparent thermal conductivity, thermal resistance, or specimen thickness due to measurement error considerations.

The current operating range is documented by data of apparent thermal conductivity versus specimen mean temperature and thickness. The current temperature 1 imits for the specimen mean temperature are $-3^{\circ} \mathrm{C}$ to $55^{\circ} \mathrm{C}$. $M$ inor improvement $c$ an extend this range to $-30^{\circ} \mathrm{C}$ to $190^{\circ} \mathrm{C}$. There are no serious limits on thermal resistance or apparent thermal conductivity for typical specimens. There is no pressure control, and to provide such control would be a major expense. The thickness limits are $19 \mathrm{~mm}$ to $381 \mathrm{~mm}$. The current 1 imits on relative humidity are from $2 \%$ to $35 \%$ at $24^{\circ} \mathrm{C}$. The upper limit can easily be extended. An estimate of apparatus uncertainty is made over the ranges of specimen mean temperature, apparent thermal conductivity, and thickness.
\end{abstract}

Keywords: apparent thermal conductivity, calibration, error analysis, guarded hot plate, operating ranges, standard reference material (SRM), thermal insulation, thermal resistance. 
PREFACE ........................ . . $i i$ ABSTRACT . . . . . . . . ......... . i ii LIST OF FIGURES . . . . . . . . . . . . . . . . . v v LIST OF TABLES. . . . . . . . . . . . . . . . . vii LIST OF APPENDICES. . . . . . . . . . . . . . . . . viii ACKNOWLEDGMENTS . . . . . . . . . . . . . . . . . ix LIST OF SYMBOLS . . . . . . . . . . . . . . . . . . x

1. INTRODUCTION. . . . . . . . . . . . . . . 1

1.1 objectives ................... 1

1.2 Background ...................... 1

1.3 Scope. . . . . . . . . . . . . . . 2

2. TEMPERATURE LIMITS OF APPARATUS COMPONENTS . . . . . . . 2

2.1 Apparatus Description . . . . . . . . . . . 2

2.2 Component Materials Difficult to Replace........ 2

2.3 Component Materials Easy to Replace . . . . . . . 5

3. PARAMETER CONTROL LIMITS . . . . . . . . . . . . 6

3.1 Temperature Control .............. 6

3.2 Plate-Temperature Limits Due to Control Circuity. . . . 6

3.3 Ambient Temperature Control . . . . . . . . . . 7

3.4 Thickness Constraints . . . . . . . . . . . . 7

3.5 Ambient Gas Pressure... . . . . . . . . . . 8

3.6 Relative Humidity Control ............. 8

4. PARAMETER LIMITS DUE TO APPARATUS UNCERTAINTY CONSIDERATIONS 9

4.1 Introduction. . . . . . . . . . . . . . 9 9

4.2 Lower Limit for Apparent Thermal Conductivity ..... 9

4.3 Opper Limit for Apparent Thermal Conductivity . . . . . 11

4.4 Thickness Limit ............... 13

4.5 Temperature Limits. . . . . . . . . . . . 15

4.6 Apparatus Uncertainty as a Function of $\mathrm{k}_{\mathrm{s}}$ and $\mathrm{T}_{\mathrm{m}}$. . . . 15

5. APPARENT THERMAL CONDUCTIVITY DATA OVER THE CURRENT OPERATING TEMPERATURE RANGE. . . . . . . . . . . . . 16

6. SUMMARY OF PARAMETER LIMIT AND ESTIMATES OF COST IMPROVEMENTS 17

6.1 Temperature Limits. . . . . . . . . . . 17

6.2 Other Apparatus Limits............ 19

REFERENCES . . . . . . . . . . . . . . . . . 21 APPENDICES 
Figure 1. Drawing of the NBS $1-m$ Guarded Hot Plate Showing the Support System of the Hot and Cold Plate and Showing the Rotatable Enclosure for Environmental Control......................

Figure 2. Temperature Control Circuit for the NBS 1-m Guarded-Hot-P late Apparatus. . . . . . . . .

Figure 3. Resistance-Temperature Characteristics for Temperature Control Thermistors. . . . . . . . . 24

Figure 4. Control Circuit for the Guard Heaters for the NBS I-m Guarded Hot Plate. . . . . . . . . . .

Figure 5. View of the NBS 1-m Guarded-Hot-P late Apparatus Walls and Doors..................

Figure 6. Latch of the NBS 1-m Guarded-Hot-Plate Apparatus Door-Lock Bar. . . . . . . . . . . . . .

Figure 7. Cross Section of the NBS 1-m Guarded-Hot-Plate Apparatus Walls.................

Figure 8. Plot of Edge-Effect Coefficient "A" as a Function of Specimen Thickness for the NBS 1-m Guarded Hot Plate, Showing the Parametrical Dependence on the Ratio of the Effective Surface Film Coefficient, $h_{e}$, over the Specimen Apparent Thermal Conductivity, $\mathrm{k}_{\mathrm{s}}$. . . . •

Figure 9. Plot of Edge-Effect Coefficient " $B$ " as a Function of Specimen Thickness for the NBS 1-m Guarded Hot Plate, Showing the Parametrical Dependence on the Ratio of the Effective Surface Film Coefficient, $h_{e}$, over the Specimen Apparent Thermal Conductivity, $\mathrm{k}_{\mathrm{s}}$...... 30

Figure 10. The Edge-Effect Percent Uncertainty, Due to the A Coefficient $(0.25 A)$ and the $B$ Coefficient (B $\Delta X$, where $\Delta \mathrm{X}=0.036)$, as a Function of Specimen Thickness, L, for the NBS 1-m Guarded Hot Plate....

Figure 11. The Total Edge-Effect Percent Uncertainty, $0.25 \mathrm{~A}+$ $0.036 \mathrm{~B}$, as a Function of Thickness, L, for the NBS 1-m Guarded Hot Plate. . . . . . . . . . . 
Figure 12. Relationship between temperature at edge of metering section and the average temperature over the metering section area as a function of specimen thermal conductivity for the geometry indicated [3].......

Figure 13. Correction Term, DD, for the NBS Guarded-Hot-Plate Thickness Readout Based on an In Situ Measurement. . . 34

Figure 14. Apparent Thermal Conductivity versus Specimen Mean Temperature Points Showing the Ranges Measured on the NBS 1-m Guarded Hot Plate. . . . . . . . . .

Figure 15. Apparent Thermal Conductivity versus Specimen Mean Temperature for Insulation Materials ..........

Figure 16. Apparent Thermal Conductivity versus Specimen Thickness, L, for Insulation Materials. . . . . . . . . .

Figure 17. Temperature Limits for the NBS 1-m Guarded-Hot-Plate Apparatus ...................... 
Table 1. Relative Magnitudes of Contact Resistance and the Thermal Resistance of a $25.4 \mathrm{~mm}$ Thick Specimen for a Range of Specimen k-value.... 39

Table 2. Difference Between NBS 1-m Guarded Hot Plate Thickness Readout and In Situ Thickness Readout • 40

Table 3. Percentage Estimate of Uncertainties in the Measured Apparent Thermal Conductivity for the NBS Guarded Hot Plate . . . . . . . 41

Table 4. Total Apparatus Uncertainty for a Specimen Thickness, $L$, of $25.4 \mathrm{~mm}$, as a Function of Specimen Mean Temperature, $\mathrm{T}_{m}$, and Specimen Apparent Thermal Conductivity, $k_{s} \ldots . . . .42$

Table 5. Total Apparatus Uncertainty for a Specimen Thickness, L, of $152.4 \mathrm{~mm}$, as a Function of Specimen Mean Temperature, $\mathrm{T}_{\mathrm{m}}$, and Specimen Apparent Thermal Conductivity, $\mathrm{k}_{\mathrm{s}}$. . . . . . 43

Table 6. Total Apparatus Uncertainty for a Specimen Thickness, L, of $304.8 \mathrm{~mm}$, as a Function of Specimen Mean Temperature, $\mathrm{T}_{\mathrm{m}}$, and Specimen Apparent Thermal Conductivity, $\mathrm{k}_{\mathrm{s}}$. . . . . . 44

Table 7. Total Apparatus Uncertainty for a Specimen Thickness, L, of $381 \mathrm{~mm}$, as a Function of Specimen Mean Temperature, $\mathrm{T}_{\mathrm{m}}$, and Specimen Apparent Thermal Conductivity, $\mathrm{k}_{\mathrm{s}}$. . . . . 45

Table 8. Apparent Thermal Conductivity as a Function of Specimen Mean Temperature, $\mathrm{T}_{\mathrm{m}}$. . . . . . . 46

Table 9. Apparent Thermal Conductivity as a Function of Specimen Mean Temperature, $\mathrm{T}_{\mathrm{m}}$, Data Measured on the NBS 1-m Guarded Hot Plate....... 47

Table 10. Apparent Thermal Conductivity as a Function of Specimen Thickness, L, Data Measured on the NBS $1-m$ Guarded Hot Plate, at a Mean Temperature of $23.9^{\circ} \mathrm{C}$ and a Temperature Difference of $27.8^{\circ} \mathrm{C} \cdot .48$

Table 11. Percent Difference Between the average $k-v a l u e$ of the Individual Layers in a Stacked Specimen and the Actually Measured k-value of the Stacked Specimen............ 49 
Appendix I Copy of Reference [4]............ 1-1

Appendix 2 Positive Pressure Inside Chamber . . . . . . 2-1

Appendix 3 Vacuum Inside Chamber. . . . . . . . . . 3-1

Appendix 4 Calculation of Percentage Uncertainty in the Measured Metered-Area Heater Power for a $152.4 \mathrm{~mm}$ Thick, Low k-value Insulation Specimen [5] ............ 4-1

Appendix 5 Test Thickness Limitations Due to Edge Effect Uncertainties........... . . 5-1

Appendix 6 Contact Resistance ........... . 6-1 


\section{ACKNOWLEDGEMENTS}

The author expresses appreciation to the Department of Energy whose sponsorship made this effort possible. Programatic and technical coordination was provided by Bill Gerken, Program Manager, Materials Program, Building Systems Division, Office of Energy $R \& D$, Department of Energy, and Dr. David McElroy of the Oak Ridge National Laboratory. The author wishes to thank William Stone, of Structures Division, CBT, NBS, for the calculations in appendices 2 and 3 , Brad Peavy, retired from the Building Physics Division, CBT, NBS, for his help on the edge-effect calculations and Carmen Gracia for her help in the preparation of this document. 



\section{LIST OF SYMBOLS}

a radius of circular line-heat-source in the hot-plate metered area

A intercept of edge effect curve

b radius of metered area of the hot plate

B slope of edge effect curve

C maximum fiber axis from neutral axis for calculation of bending stress

d area centroid distance from neutral axis for calculation of I

DD difference between DT and DF

DF thickness change with temperature referenced to a mean temperature of $24^{\circ} \mathrm{C}$ as measured by the Farrand thickness transducers

DT thickness change with temperature referenced to a mean temperature of $24^{\circ} \mathrm{C}$ as measured by the in-situ thickness transducer

e height of heater in hot plate

$F(T)$ thickness, as measured by the Farrand thickness transducers at temperature $T$

h surface film coefficient between the edge insulation and the ambient

$h_{e}$ effective surface film coefficient including edge insulation

I composite moment of inertia for I" strip

$k$ apparent thermal conductivity

ka gas conductivity of air

$k_{p}$ plate thermal conductivity

$k_{s}$ specimen apparent thermal conductivity

L specimen thickness

$\mathrm{L}_{\mathrm{g}}$ air-gap thickness

m hot-plate thickness

$M_{\text {MAX }}$ maximum bending moment

$\mathrm{P}_{\text {INT GHP apparatus internal pressure }}$ 
Ptotal total force imparted to the GHP apparatus door due to the internal pressure

$Q_{m}$ power produced by the metered-area heater

$q$ heat flow per unit area

Q shear area moment

R thermal resistance

$R_{\text {ed }}$ thermal resistance of edge insulation

$R_{\text {heater metered-area heater resistance }}$

$R_{F}$ reaction forces for 1 " strip analysis

$R_{m}$ measured thermal resistance of stack

$R_{0}$ thermal resistance that would result given perfect one-dimensional heat flow across a specimen, as approximated by the sum of the thermal resistance values of the component specimens in a stack

$R_{S}$ shunt resistance

$r$ contact resistance

$\mathrm{S}_{1}$ reaction force which must be resisted by shear bars in the GHP apparatus

$T(T)$ thickness measured by the in-situ thickness transducer at a temperature $T$

$\overline{\mathrm{T}}$ average air-gap temperature

$\mathrm{T}_{\mathrm{a}}$ ambient temperature

$T_{c}$ cold-plate temperature

$\mathrm{T}_{\mathrm{h}}$ hot-plate temperature

$\mathrm{T}_{\mathrm{m}}$ mean temperature $=\left(\mathrm{T}_{\mathrm{h}}+\mathrm{T}_{\mathrm{c}}\right) / 2$

$\nabla$ maximum shear force

$\mathrm{V}_{\mathrm{h}}$ heater voltage

$\mathrm{V}_{\mathrm{s}}$ shunt voltage

$\mathrm{X}=2\left(\mathrm{~T}_{\mathrm{m}}-\mathrm{T}_{\mathrm{a}}\right) /\left(\mathrm{T}_{\mathrm{h}}-\mathrm{T}_{\mathrm{c}}\right)$

$Y=\left(R_{0}-R_{m}\right) / R_{m}=A+B X$ 
$\beta$ extinction coefficient

$\Delta \mathrm{T}$ temperature difference

$\Delta v$ voltage uncertainty

$\Delta \mathrm{X}$ uncertainty in $\mathrm{X}$

$\epsilon$ plate emittance

$\sigma$ Stefan-Boltzmann constant

$\sigma_{\text {ult }}$ ultimate shear stress

$\sigma_{s}$ shear stress

- optical depth

Subscripts

b bottom side of the two-sided apparatus

$t$ top side of the two-sided apparatus 


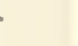




\section{INTRODUCTION}

\subsection{Objectives}

Accurate measurement of the thermal resistance of insulation and building materials is a matter of national interest. A viable national calibration program must consist of accurate apparatuses, appropriate test methods, and calibration specimens available over the needed ranges of test and material parameters, such as temperature and apparent thermal conductivity. The apparatuses are operated according to the test methods to provide these calibration specimens. It is necessary to know the apparatus accuracy over the entirety of the operating ranges over which the calibration specimens are measured.

The objective of this report is to evaluate the operating capability of the NBS 1-m Guarded-Hot-Plate (GHP) apparatus according to three kinds of limiting factors. The first kind is the limits of temperature over which the various apparatus components can be used without suffering damage. The second kind is the limits of plate temperatures, specimen thickness, atmospheric pressure, and relative humidity that $c$ an be achieved with the existing control systems. The third kind is any limits on the values of apparent thermal conductivity, thermal resistance, or specimen thickness due to measurement error considerations.

\subsection{Background}

The issues related to the need for calibration test measurements over a wider range of test conditions were discussed in detail in previous papers. Reference [1], published by an ASTM Working Group in 1978, gave information on many candidate materials. In addition, it recommended (1) a search for new Standard Reference Materials (SRM's) and (2) the development of a long-range priority scheme to provide these SRM's.

Reference [2] presented the rationale for a calibration program which would minimize calibration errors by making available calibration points over the entirety of the ranges of test parameters. It also assessed the need for calibration points at various ranges of test parameters, and it recommended a priority scheme for the development of new calibration standards.

This report gives parameter ranges of operation, and apparatus accuracies over these ranges, for the 1-m GHP apparatus at NBS, Gaithersburg. This device provides calibration specimens for thermal testing of insulation materials. Its design was based on work by Hahn, Robinson and Flynn [3] at NBS in the $1970^{\prime} s$, and its construction by Hahn was completed in 1981 . The salient design feature was a line-heat source for the hot plate heaters. A description of this apparatus is given in reference [4], and a detailed error analysis is presented in reference [5]. This error analysis indicated an upper limit for apparatus uncertainty of less than 0.5 percent for thermal resistance measurement at $24^{\circ} \mathrm{C}$. 


\subsection{Scope}

The primary purpose of this report is to provide documentation on the current operating capability of the 1-m NBS GHP apparatus, No changes have been made to extend the operating range. However, brief discussions are given to indicate the amount of effort that would be required to extend the various ranges. This NBS internal report will be made available to parties interested in NBS measurement capability, and it is intended to assist other researchers in similar evaluations of their apparatuses.

\section{TEMPERATURE LIMITS OF APPARATUS COMPONENTS}

\subsection{Apparatus Description}

Reference [4] contains a brief description and a summary error analysis of the 1-m GHP apparatus, and it is included as appendix 1. A more detailed discussion of the error analysis is presented in reference [5]. This apparatus was designed to conform to the ASTM C 177-76 Test Method for the absolute measurement of thermal resistance of insulation specimens [6].

Figure 1 is a drawing of the apparatus. The hot plate is maintained in position between the two cold plates by a support system which in turn is suspended within the ambient chamber $(1.6 \mathrm{~m}$ on a side). The plates are $1 \mathrm{~m}$ in diameter and are made of type 6061-T6 aluminum; the support system and the metal parts of the ambient chamber are also made of aluminum. The plates contain temperature sensors, heater wire, and epoxy; and they are insulated with polystyrene. The ambient chamber walls contain polyurethane.

\subsection{Component Materials Difficult to Replace}

This section documents the temperature limits to which the various nonmetallic components of the apparatus can be subjected without damage.

\section{Hot Plate Epoxy}

An epoxy was used in the hot plate to keep thermocouple and heater leads in grooves milled in the plate surfaces and to ensure a flat plate surface by filling these grooves. The epoxy used was Eccobond 285 with catalyst produced by Emerson and Cummings, Inc.* The manufacturer recommended a safe lower temperature 1 imit of $-40^{\circ} \mathrm{C}$, and a possible lower temperature 1 imit of $-48^{\circ} \mathrm{C}$, since below this 1 imit the epoxy becomes brittle and can crack. Because the epoxy is not used for mechanical support, it might be possible to go to lower temperatures and tolerate any cracks that might develop. Such cracks would not result in a measurable difference in test results because they would comprise a very small percentage of the metered area. Furthermore, the manufacturer does produce another catalyst (非4LV) which can be safely used at cryogenic temperatures, and this could be used to repair or replace the existing epoxy. The biggest risk at lower

*Because this report purports to specifically describe the existing apparatus, there will be an occasional use of a manufacturer's name. This in no way represents an endorsement of the various manufacturers. 
temperatures is that the silver leads, which connect to the one heater in the metered area and the two heaters in the guard area, might break due to strain resulting from the epoxy cracking. The on ly way to know for sure whether the lead would break would be to subject the actual hot plate to temperatures below $-40^{\circ} \mathrm{C}$. If the wires were to break, it would be necessary to disassemble the hot plate, mill out the old epoxy and leads, and replace these with the new leads and the cryogenic epoxy. This epoxy $(\# 24 \mathrm{LV})$ has an upper temperature limit that is $28^{\circ} \mathrm{C}$ lower than the existing epoxy.

The upper temperature limit of the existing epoxy (with catalyst 非1) is $177^{\circ} \mathrm{C}$ for long-term use, according to the manufacturer. Oven tests between $85^{\circ} \mathrm{C}$ and $315^{\circ} \mathrm{C}$ were made on $34 \mathrm{specimens}$ of a similar epoxy (using the same


limit of use that is $24^{\circ} \mathrm{C}$ lower than that with the catalyst oven tests indicated that the epoxy exhibited no changes up to $150^{\circ} \mathrm{C}$ for tests as long as 16 hours. Between $150^{\circ} \mathrm{C}$ and $250^{\circ} \mathrm{C}$ the epoxy finish became duller, and there was a progressive discoloration. According to the manufacturer, the discoloration has no deleterious effect on mechanical performance of the epoxy. Above $250^{\circ} \mathrm{C}$ the epoxy was damaged in that it expanded, softened, and became extremely brittle when re-cooled to lower temperatures. Finally, it crumbled at $300^{\circ} \mathrm{C}$.

The conclusion of the experimental work is that the hot-plate epoxy could be used at least up to temperatures of $250^{\circ} \mathrm{C}$. However, a lower more conservative value of $200^{\circ} \mathrm{C}$ is recommended to avoid any chance of accidental increase to the unsafe higher temperature. This value of $200^{\circ} \mathrm{C}$ is higher than the original NBS design temperature of $150^{\circ} \mathrm{C}$ or the manufacturer's recommended upper limit of $177^{\circ} \mathrm{C}$.

\section{Cold-Plate Epoxy}

The same epoxy, Eccobond 285 with catalyst 111 , as that used in the hot plate was alsoused in the cold plate, but for a different purpose. The cold plate is type 6061-T6 aluminum and consists of a $6.4 \mathrm{~mm}$ thick cover plate bonded with the epoxy to a $19.0 \mathrm{~mm}$ thick base plate. The base plate contains milled grooves which form channels in a double-spiral configuration. It is important that these channels remain leak-proof to ensure a uniform temperature distribution over the cold-plate surface and to prevent leaks from the cold plate itself. Cooling below $-40^{\circ} \mathrm{C}$ could result in leaks or even actual separation of the base and cover plates. The same limit of $200^{\circ} \mathrm{C}$ as for the hot plate applies for the cold plate. Any failure of the cold-plate epoxy would be more serious than in the case of the hot plate. Since the hot plate is 1 imited to use below $200^{\circ} \mathrm{C}$, it is unlikely that the cold plate would be used above $190^{\circ} \mathrm{C}$, as the cold plate is typically more than $10^{\circ} \mathrm{C}$ colder than the hot plate.

\section{Plate Temperature Sensors}

The two cold plates and the hot plate contain a single temperature sensor each. These are Platinum Resistance Thermometers (PRT's), model number S1059-2, produced by the Minco Corporation. The manufacturer claims that these devices can be used over a temperature range from $-269^{\circ} \mathrm{C}$ to $220^{\circ} \mathrm{C}$. Their uncertainty value for 20 temperature cycles between plus and minus $200{ }^{\circ} \mathrm{C}$ is $0.001 \Delta \mathrm{T}\left({ }^{\circ} \mathrm{C}\right) . *$ Thus it is not expected that temperature cyc 1 ing between $-40^{\circ} \mathrm{C}$ and $200^{\circ} \mathrm{C}$ would add a significant error contribution to the

* In this report the $\Delta \mathrm{T}\left({ }^{\circ} \mathrm{C}\right)$ notation is used to indicate a temperature difference as opposed to an absolute temperature. 
p late temperature measurement. The low temperature 1 imit is due to the presence of helium gas in the encapsulated PRT device, and the high temperature limit is due to the Teflon insulation for the lead wires. The other temperature sensors in the hot plate are thermistors used for temperature control. The upper limit for these, due to the Teflon insulation, is $220^{\circ} \mathrm{C}$.

The four PRT leads in the cold-plate are insulated from each other by Torr Seal epoxy, manufactured by Varian Associates. This prevents any current leakage that might result if the leads became wet. According to the manufacturer, at temperatures above $120^{\circ} \mathrm{C}$, the binder is driven out of the epoxy, and it will crumble under stress. This would seem to 1 imit the operating temperature to $120^{\circ} \mathrm{C}$, but it would be easy to remove the coldplate PRT's and protect them with higher-temperature epoxy.

If a PRT were damaged in a cold plate, it would be relatively easy to replace because the PRT can be pulled out of its bore hole, which was drilled from the edge of the cold plate to the center of the cold plate. On the other hand, it would be necessary to disassemble the hot plate to remove its PRT, which is located in the gap between the metered area and the guard area. This would be a very time-consuming task.

It is not clear that it would be necessary to remove the hot-plate PRT to replace the Torr Seal, for two reasons. First, moisture is normal1y driven away from the hot plate, so there would be no current leakage because the PRT leads could not get wet. The exception would be the case when the hotplate is below the ambient dew-point temperature. The relative humidity of the ambient could be controlled, to avoid this case. The second reason is that the hot-plate PRT is encased in a metallic holder. This means that there is no requirement for structural integrity of the PRT-wire epoxy. The epoxy's bulk would be expected to continue to provide protection from moisture intrusion even with the binder removed.

A final argument in favor of attempting a high temperature for the hotplates is that, if moisture should collect at cold temperatures, it could be driven off, simply by raising the hot-plate temperature.

\section{Plate Warpage}

The two components of the cold plates were epoxied together and then the plate surfaces were machined. There is no reason to expect significant warpage of these plates over the temperature range allowed by the fabricating epoxy, $-40^{\circ} \mathrm{C}$ to $200^{\circ} \mathrm{C}$.

The hot plate was also designed to have very little warpage. It is made of 6061-T6 aluminum, and is constructed in such a way that there is a pressure fit between the different parts of the hot plate. The inner and outer parts of the metered area are separated by the metered-area heater. These two parts were pressure fit, to expand and contract the same amount, with temperature changes. The support between the metered area and the guard region of the hot $p$ late is accomplished with three stainless steel pins, and the guard section itself is a single piece of aluminum. There is no reason to expect significant warpage of the hot plate over the indicated temperature range of $-40^{\circ} \mathrm{C}$ to $200^{\circ} \mathrm{C}$. 


\section{Ambient Chamber Wall Insulation}

The ambient chamber is shown in figure 1. The purposes of this chamber are (1) to support the plates so that they can be rotated and (2) to control the temperature, gas composition, and relative humidity of the air surrounding the GHP specimen. The chamber walls are composed of two sheets of aluminum, 1-mm thick, around a 76-mm thick layer of molded polyurethane, which is glued to the aluminum sheets. The polyurethane is not a limiting factor on the low-temperature side, as it can be used at temperatures be 1 ow $-40^{\circ} \mathrm{C}$; but it is a 1 imiting factor on the high-temperature side to temperatures below $100^{\circ} \mathrm{C}$. To be on the safe side, the ambient-chamber temperature should not be allowed above $90^{\circ} \mathrm{C}$.

This restriction would not result in upper-temperature 1 imits for specimens less than $150 \mathrm{~mm}$ in thickness, because the edge effects are negligible at these thicknesses; hence, the ambient temperature need not to be maintained equal to the mean temperature of the hot and cold plates.

To run at mean temperatures higher than $90^{\circ} \mathrm{C}$, the following two methods could be used. The first would be to put extra high-temperature insulation on the inside wal1s. Assuming that the air temperature outside the ambient temperature is $24^{\circ} \mathrm{C}$ and that $50 \mathrm{~mm}$ of typical insulation could be added, the mean ambient temperature could be raised to approximately $134^{\circ} \mathrm{C}$, before the polyurethane insulation would reach $90^{\circ} \mathrm{C}$. Another method would be to put an insulated or water-cooled heater jacket around the edges of the specimen. This would maintain a small layer of air at much higher temperatures than the ambient chamber air, but the chamber walls would not be subjected to these higher temperatures.

\subsection{Component Materials Easy to Replace}

\section{Cold-Plate Polystyrene Insulation}

Molded polystyrene having a thickness of $76 \mathrm{~mm}$ is used around both cold plates. This material can be used at temperatures of $-40^{\circ} \mathrm{C}$ or below, but it is restricted on the high-temperature side to use below $85^{\circ} \mathrm{C}$. The purpose of this insulation is to enhance the uniformity of temperature over the cold plate surface. It would be straightforward to replace the polystyrene with another insulating material, such as high-density molded glass-fiber board which can be used up to temperatures of $150^{\circ} \mathrm{C}$ or layers of flexible Min-K material which can be used at temperatures much higher than $200^{\circ} \mathrm{C}$.

\section{Tef lon Tubing}

Teflon plastic tubing is used to contain the thermistor, PRT, and thermistor wires and hold them in place. Pieces of this tubing are in direct contact with the cold plates and the hot plates. This tubing is manufactured by Norton Plastics and Synthetics. The manufacturer did not know the upper temperature 1 imit for this tubing. Tests at NBS indicated that the upper temperature 1 imit for the tubing is $170^{\circ} \mathrm{C}$, at which point the tubing melts. Between $55^{\circ} \mathrm{C}$ and $170^{\circ} \mathrm{C}$ the tubing shrinks slight 1 y in length but not in diameter; this does not affect the tubing's function. This tubing could be easily replaced. 


\section{PARAMETER CONTROL LIMITS}

\subsection{Temperature Control}

The ranges of temperature, at which the cold plates, the hot plate, and the ambient can be controlled, depend on the capabilities of the cold baths, the power supplies, and feedback-control circuity, as well as the heating and cooling loads. The cold-plate bath is a Tamson, model number TCZ-45, produced by NESLAB Instruments, Inc. This circulating bath has the power capability to go up to $230^{\circ} \mathrm{C}$, but in practice it is 1 imited to $80^{\circ} \mathrm{C}$ because the heating unit must oppose the existing cooling unit. The cooling capacity of this unit could be reduced, to allow the bath heater to reach a temperature of $200^{\circ} \mathrm{C}$. However, the " $\mathrm{"} \mathrm{(force} \mathrm{and} \mathrm{suction)} \mathrm{circulation}$ pump, cannot be used with foam-forming liquids such as oils, and, thus, the bath is limited to temperatures below $110^{\circ} \mathrm{C}$. The acquisition of a highertemperature pump for use with oil would permit the extension of the bath circulator temperature capability to $230^{\circ} \mathrm{C}$.

The cold-temperature 1 imit is determined by the NESLAB PBC-2 portable bath coolers which can cool the baths down to $-30^{\circ} \mathrm{C}$. Other baths such as the NESLAB LT-50 low temperature bath circulator could lower the limit to $-50^{\circ} \mathrm{C}$, or lower. The cooling fluid currently used is ethylene glycol. This can be used up to temperatures of $110^{\circ} \mathrm{C}$ and down to temperatures of $-48^{\circ} \mathrm{C}$. If colder temperatures were desired, a solution of methylene chloride could be used down to $-73^{\circ} \mathrm{C}$.

The hot plate does not have any temperature 1 imit within the range of $-40^{\circ} \mathrm{C}$ to $200^{\circ} \mathrm{C}$, but the power output from the metered area of $0.1299 \mathrm{~m}^{2}$ is limited to $40 \mathrm{~W}$. This limits the temperature difference possible across the various specimens.

\subsection{Plate-Temperature Limits Due to Control Circuitry}

The plate temperatures are controlled by the feedback control circuits shown in figure 2. The amplifier labeled "A" does the fine temperature control utilizing a thermistor in the plate as the feedback resistor. The amplifier labeled "B" is used in conjunction with a computer-generated digital signal to automatically bring the plates to the approximate desired temperature. The power supply and resistance bank labeled " $C$ " is used, in effect, to null the coarse control signal from "C", so that the " $A$ " amplifier can do the fine control. The current-summed output of these three components is, in turn, the input to a summing amplifier, "D", the output of which drives the plate-heater power supplies.

Thermistors are used for the feedback because they have a large resistancetemperature coefficient. The resistance of the plate-installed thermistors changes by a factor of about 4000 between $-50^{\circ} \mathrm{C}$ and $200^{\circ} \mathrm{C}$ (Figure 3 ). This is an advantage for fine control at a particular temperature, but it results in difficulties when the operating range is large. If the thermistor resistance becomes too large, as the plate temperature decreases, the "A" amplifier will saturate. For the existing circuit components this occurs below $-17^{\circ} \mathrm{C}$ for the hot and cold plates. It would be straightforward to change a few circuit components in " $A$ " and " $B$ " by less than a factor of 2, to control all plates down to temperatures of $-40^{\circ} \mathrm{C}$. 
At higher temperatures the resistance-temperature coefficient of the control thermistors decreases, resulting in a larger control band. This can be compensated by reducing the input resistor value in " $A$ " to increase the amplifier gain or by changing the thermistors. It would be straightforward to change the cold-plate thermistors, but it would require a major disassembly of the hot plate to change the hot-plate thermistors.

The control band of the hot $\mathrm{p}$ late is very sma $11,0.001 \Delta T\left({ }^{\circ} \mathrm{C}\right)$. It could increase by a factor of 10 to 100 , before the control stability would become a problem. Thus, it should be possible to control the hot plate up to $100^{\circ} \mathrm{C}$ with minor circuit changes. The control between $100^{\circ} \mathrm{C}$ and $200^{\circ} \mathrm{C}$ must be tried experimentally to be sure that the control stability is adequate.

The two guard heaters in the hot plate are controlled by the circuits shown in figure 4. Two thermistors, one on either side of the gap, are used to control the inner guard heater, and another two thermistors, located between the two guard heaters, are used to control the outer guard heater. These thermistor pairs are used in a Wheatstone bridge to provide an input to a differential amplifier. This input is a function of the resistance difference, and hence the temperature difference, between the pair of thermistors. Since both thermistors remain at the same temperature, there is no problem with saturation. At temperatures above $100^{\circ} \mathrm{C}$ it may be necessary to modify the amplifier to increase the gain as the sensitivity to temperature change decreases, due to the decreasing resistancetemperature coefficient of the thermistors.

\subsection{Ambient Chamber Temperature Contro 1}

The ambient chamber temperature control is accomplished with a heat exchanger, a fan, and a heater. The current low-temperature limit is determined by the cooling capacity of a single NESLAB PCB-2 cooling unit. The lowest ambient temperature achieved was $2^{\circ} \mathrm{C}$. Another cooling unit could be added to attain an ambient temperature of $-30^{\circ} \mathrm{C}$. However, the instrument used to control the ambient, a Versa-Therm 2155 temperature controller made by the Cole-Parmer Instrument Company, is capable of controlling only down to $-20^{\circ} \mathrm{C}$. This would have to be replaced.

The $500 \mathrm{~W}$ power supply for the heater is capable of maintaining the ambient temperature at $128^{\circ} \mathrm{C}$, based on a calculation of heat loss through the existing ambient chamber walls to an outside temperature of $24^{\circ} \mathrm{C}$. A higher ambient temperature would require a larger power supply. Also the existing heater and fan would need to be redesigned to ensure a uniform temperature in all parts of the ambient chamber. A more stringent limit is that the ambient controller is 1 imited to $120^{\circ} \mathrm{C}$. The alternative method mentioned earlier would be to use an insulated heater jacket at the specimen edges.

\subsection{Thickness Constraints}

Physical constraints determine the upper and lower thickness measurements. The upper limit of $381 \mathrm{~mm}$ is the distance the cold plates can move from the hot plate before the plates physically touch the ambient walls. The lower limit of $19 \mathrm{~mm}$ is the thickness at which the hot-plate support structure touches the cold-plate insulation. Smaller thicknesses could be achieved with modification of either the cold-plate insulation or the hot-plate support structure. 


\subsection{Ambient Gas Pressure}

There was no attempt to include a control capability of the ambient pressure in the original apparatus design. Pressurization control would require that the ambient chamber be air-tight and that the structure be strong enough to resist deformation. To satisfy the first requirement, it would be necessary (1) to provide a feed-through interface for the wires that enter the chamber and (2) to change the existing door gaskets to an 0-ring design. The capability of the structure to withstand pressurization was estimated by considering the weakest part of the structure for both positive and negative pressurization.

The ambient chamber is much stronger for positive pressurization than for negative pressurization because of the wall cross beams. These beams are on the outside of the wal1s; thus, they provide structural support to prevent outward movements of the wal1. Referring to figures $5 a$ and $5 b$, for each of the walls there are 12 aluminum square beams (26 mm $x 26 \mathrm{~mm}$ ) which go from the center of the wall to the center of a side or to a corner. For each of the four doors (two on each side), there are $10 \mathrm{such}$ beams. These beams provide considerably more support for pressurization than the weakest part of the structure. The weakest structural parts are the bars which lock the four doors closed (see Figure 6). The calculation in appendix 2, made by Dr. William Stone of NBS, estimates that this bar would shear when the inside pressure is $193 \mathrm{kPa}$ ( $28 \mathrm{psi}$ or 2 atmospheres) greater than the outside pressure. These locking bars are on the outside of the structure, so it would be feasible to add more of these to constrain the doors from opening.

The structure is much weaker to support vacuum. Figure 7 shows a crosssection of the walls, which consists of two aluminum sheets, $1 \mathrm{~mm}$ thick, with $76 \mathrm{~mm}$ of molded polyurethane $\left(32 \mathrm{~kg} / \mathrm{m}^{3}\right)$ sandwiched between. The polyurethane was bonded to the aluminum sheets. There is nothing in the center of the door section (the weakest part) to constrain the wall from bowing inward under negative pressurization. This sandwich structure will eventually fail in a delamination shear mode as the bond between the outer a luminum sheet and the polyurethane breaks. Or, the failure could occur between successive layers of polyurethane near the outside aluminum sheet. The calculation in appendix 3, made by Dr. William Stone of NBS, indicates that this failure would occur for a pressure differential of $14.1 \mathrm{kPa}(2.05$ psi), or roughly one-seventh of an atmosphere.

A critical uncertainty in this calculation is that there was no documentation of the adhesive used to bond the polyurethane to the aluminum sheets. The assumption made was that this bond was at least as strong (in the delamination shear mode) as the polyurethane itself. Even so, the calculation shows that the structure could, at best, barely support a pressure of 86 percent of a standard atmosphere, which is greater than the typical atmospheric pressure ( 80 percent) in Denver, Colorado.

\subsection{Relative Bumidity Control}

The relative humidity ( $R H)$ within the ambient chamber can be controlled in several ways. The first way takes advantage of the ambient temperature control system, which consists of condensing coils, a fan, and a heater. 
This system is capable of reducing the initial relative humidity of the ambient chamber, 35 percent at $24^{\circ} \mathrm{C}$ which corresponds to the 1 aboratory environmental condition, down to 23 percent at $24^{\circ} \mathrm{C}$. With this moisture content, condensation will occur on surfaces within the ambient chamber, which are at temperatures below $1^{\circ} \mathrm{C}$. Thus, there is not any problem with condensation as long as the cold plates are above $1^{\circ} \mathrm{C}$.

In order to operate the cold plates or the ambient chamber at temperatures below $0^{\circ} \mathrm{C}$, it is desirable and sometimes necessary to reduce the moisture content of the ambient air. This prevents the formation of ice on the condensing coils, on the internal parts of the ambient chamber, on the apparatus itself, and within the specimen. One way to reduce the moisture content in the ambient chamber is to flush the ambient chamber with a gas such as nitrogen or dry air. Using nitrogen, it was possible to reduce the relative humidity to 2 percent at $24^{\circ} \mathrm{C}$. A drawback is that the ambient chamber is not very airtight, and thus it would be necessary to use relatively large amounts of bottled gas to maintain the low relative humidity condition. Another method to remove moisture from the ambient air would be to use a desiccant within the chamber.

Moisture can be removed from the specimen, as opposed to the ambient air, by baking until the specimens come to a constant weight. The specimen will eventually condition to the humidity condition of the ambient chamber, unless it is sealed. Currently, there is no humidifying equipment in the ambient chamber. It would be a simple matter to purchase a humidifier for the ambient chamber.

\section{PARAMETER LIMITS DUE TO APPARATUS UNCERTAINTY CONSIDERATIONS}

\subsection{Introduction}

The following sections discuss the apparatus uncertainty as operating conditions are varied over their entire ranges. NBS researchers will use this information to determine the operating limits which correspond to a desired measurement tolerance.

\subsection{Lower Limit for Apparent Thermal Conductivity}

The question of whether there is a lower limit on k-value is considered first. The procedure will be to assume the lowest $k-v a l u e$ that would be expected for a GHP specimen, and to calculate the error for this low kvalue. A value of $0.0086 \mathrm{~W} / \mathrm{m}{ }^{\circ} \mathrm{K}$ is chosen for the lower 1 imit of $\mathrm{k}-\mathrm{value}$. This corresponds to a type of evacuated panel insulation material.

The first contribution to the error for a low k-value specimen is due to the fact that the metered-area power is considerably smaller than for most building insulation materials. As a result, any fixed systematic uncertainty is a larger percentage of this smaller power. Appendix 4, based on information in reference [5], contains a calculation of the uncertainty expected for low k-value specimens. It shows that the most important contribution to uncertainty in the measurement of the meter power is due to the measurement of the voltage across the metered-area-heater shunt resistor. For a $152 \mathrm{~mm}$ specimen with a temperature difference of $27.8 \Delta T\left({ }^{\circ} \mathrm{C}\right)$ and for a $\mathrm{k}-\mathrm{value}$ of $0.0086 \mathrm{~W} / \mathrm{m}^{\circ} \mathrm{K}$, the uncertainty due to the shunt resistor is 0.03 percent. For a $305 \mathrm{~mm}$ specimen, the value would be 0.06 percent and for a $381 \mathrm{~mm}$ specimen, the value would be 0.08 percent. This error is negligible. 
The other contribution to uncertainty [5] in the measurement of the metered-area power is due to the uncertainty in the measurement of power generated by thermistors located within the hot plate metered area, $0.4 \mathrm{~mW}$, and the uncertainty due to the measurement of the gap heat flow, $0.3 \mathrm{~mW}$. For the 152 specimen just described, the combined uncertainty of $0.7 \mathrm{~mW}$ results in an uncertainty in power measurement of 0.2 percent. For the 305 mm specimen this is 0.36 percent, and for the $381 \mathrm{~mm} s p e c i m e n$ the value is 0.46 percent.

Thus there is a combined uncertainty in the measurement of the metered heater power of approximately 0.5 percent for a worst-case specimen with a thickness of $381 \mathrm{~mm}$ and a $\mathrm{k}-\mathrm{val}$ ue of $0.0086 \mathrm{~W} / \mathrm{m} \cdot \mathrm{K}$. For a more typical thickness of $152 \mathrm{~mm}$ and the same $k-v a l u e$, the combined uncertainty in the metered area power totals to 0.23 percent.

The conclusion is that the NBS 1-m GHP is not practically 1 imited in its operation with regard to low $k-v a l u e$, due to the heat-flow measurement.

The other factor that could limit the operating range for the NBS apparatus in terms of low $k$-value is the edge effect. The edge effect is larger for lower k-value specimens. One way to see this is to use the parameter $h_{e} / k_{s}$, the ratio of the surface $f i l m$ coefficient to the specimen k-value. The conductance to the edge of the specimen is proportional to the surface film coefficient, and the conductance across the specimen is proportional to the k-value. Thus, the larger the ratio of $h_{e}$ to $k_{s}$, the greater the edge effect.

The edge effect is defined in equation 1 .

$$
\mathrm{Y}=\left(\mathrm{R}_{\mathrm{o}}-\mathrm{R}_{\mathrm{m}}\right) / \mathrm{R}_{\mathrm{m}}
$$

The term $R_{0}$ is the thermal resistance that would result, given onedimensional heat flow across the specimen. It is approximated experimentally by the sum of thermal resistance values of the components of a thick stack. These component specimens are measured at small enough thicknesses so that the edge heat flow is negligible. The term $R_{m}$ is the actual measured thermal resistance of a thick stack of specimens which includes some heat flow to or from the edge of the specimen. Equation 2 defines the $A$ and $B$ coefficients, shown in figures 8 and 9 , and these coefficients indicate the magnitude of the edge effect [3].

$$
Y=A+B X
$$

The $X$ term is a dimensionless temperature term which indicates the unbalance, or difference, between the specimen mean temperature, $T_{m}$, and the ambient temperature, $T_{a}$.

$$
X=2\left(T_{m}-T_{a}\right) /\left(T_{h}-T_{c}\right)
$$

$T_{h}$ and $T_{c}$ are the hot-plate and cold-plate temperatures. The $T_{m}$ is approximated experimentally as the average of $T_{h}$ and $T_{c}$. As the ambient temperature is varied above and below the mean temperature, the edge heat flow changes, and the amount of this change is predicted by the magnitude of the coefficients $A$ and $B$ in figures 8 and 9. 
These figures are for the case of the NBS 1-m GHP which has a metered-area radius of $0.20326 \mathrm{~m}$ [4] and a guard radius of $0.508 \mathrm{~m}$. Assuming there is extra edge insulation around the specimen, a typical value of $h$ is 0.57 $\mathrm{W} / \mathrm{K} \cdot \mathrm{m}^{2}$, and a typical value for $\mathrm{k}$ is $0.03 \mathrm{~W} / \mathrm{m} \cdot \mathrm{K}$; these give a value of $18.9 \mathrm{~m}^{-1}$ for $\mathrm{h} / \mathrm{k}$. Figures 8 and 9 show the $A$ and $B$ coefficients as a function of $\mathrm{h} / \mathrm{k}$ for values on either side of this typical value. Inspection of the equations associated with the curves in these figures shows that as the k-value decreases, the A and B curves asymptotically approach a particular curve. The value of $\mathrm{h} / \mathrm{k}$ that corresponds to the low $\mathrm{k}-\mathrm{val}$ ue of $0.0086 \mathrm{~W} / \mathrm{m} \cdot \mathrm{K}$ is $66.3 \mathrm{~m}^{-1}$. The figures show that the greater value of $\mathrm{h} / \mathrm{k}$ does not significantly change the thickness at which the edge effect exceeds a particular tolerance level. This greater value of $\mathrm{h} / \mathrm{k}$ does result in an edge effect that is perhaps 30 percent larger, but, again, this does not significantly change the maximum thickness for the apparatus.

To estimate the uncertainty in measured thermal resistance due to edge effect, one must include the contributions of both the $A$ and $B$ terms. As a working hypothesis, assume that $A$ is predicted by the edge mode 1 within \pm 25 percent of its value. To determine the $B$ contribution, assume a value of 0.036 for $\Delta \mathrm{X}$, which corresponds to $\left(\mathrm{T}_{\mathrm{h}}-\mathrm{T}_{\mathrm{c}}\right)=27.8 \Delta \mathrm{T}\left({ }^{\circ} \mathrm{C}\right)$ and an uncertainty of $1 \Delta \mathrm{T}\left({ }^{\circ} \mathrm{C}\right)$ in $\left(\mathrm{T}_{\mathrm{m}}-\mathrm{T}_{\mathrm{a}}\right)$.

Assume an edge insulation resistance value, $R_{e d}$, of $1.75 \mathrm{~K}^{\cdot} \mathrm{m}^{2} / \mathrm{W}$. For these parameter values, the contributions to uncertainty of the $A$ and $B$ terms are shown in figure 10, and the sum of these is shown in figure 11. These are shown for a range of specimen apparent thermal conductivity values, $k_{s}$, between 0.0577 and $0.00045 \mathrm{~W} / \mathrm{m}^{\circ} \mathbb{R}$.

Appendix 5 shows how the range of operation is affected by a lower $k-v a l u e$ assuming an edge érror tolerance of 0.5 percent. A typical k-value of 0.033 $\mathrm{W} / \mathrm{m}^{\circ} \mathrm{K}$ results in an upper 1 imit on operating thickness of $350 \mathrm{~mm}$, whereas a $\mathrm{k}-\mathrm{value}$ of $0.0086 \mathrm{~W} / \mathrm{m}^{\circ} \mathrm{R}$ results in an upper 1 imit on thickness of $320 \mathrm{~mm}$. This demonstrates that operation at a significantly lower value of apparent thermal conductivity does not significantly change the thickness range of the apparatus.

\subsection{Upper Limit for Apparent Thermal Conductivity}

The first factor that determines the upper limit in thermal conductivity value is the line-source heater design used in the metered area of the hot plate. This design and the corresponding temperature distribution over the metered area are described in references [3] and [5]. Part of the rationale for using this kind of heater is that, if the ratio of the gap radius to the 1 ine-heater radius is equal to $\sqrt{2}$, the temperature measured in the gap is approximately equal to the average temperature of the entire metered area. Reference [3] performs the calculation of the error associated with this approximation. This error is less than 0.01 percent for the following condition:

$$
\left(\frac{m k_{s}}{2 L k_{p}}\right)^{1 / 2}<0.03
$$

where $m$ and $L$ are the hot-p late and specimen thicknesses, and $k_{s}$ and $k_{p}$ are the specimen and the plate k-values. For the NBS apparatus, the term 
on the left side of equation (4) is equal to 0.03 , at specimen thickness of $25 \mathrm{~mm}$, when the specimen thermal conductivity is equal to $0.15 \mathrm{~W} / \mathrm{m}^{\circ} \mathrm{K}$. Figure 12 from reference [3] shows that if $k_{s}$ were greater than $0.4 \mathrm{~W} / \mathrm{m}^{\circ} \mathrm{K}$, the temperature error will be of the order of 0.1 percent. Above a value of $0.6 \mathrm{~W} / \mathrm{m} \cdot \mathrm{K}$ the error in the hot plate temperature exceeds 0.1 percent, and the correction based on the use of more terms in the Bessel function expansion would have to be made. The equation describing this correction is given in reference [3], and such a correction would not require any apparatus modification.

There is no restriction on $k$-value due to edge effect considerations, since the edge effect becomes smaller as the k-value increases. The two factors that are more important in practice, for restricting the thermal conductivity of specimens, are the difficulty of obtaining large specimens of high $k$-value material and the problem of contact resistance between the specimen and the apparatus plate surface. The first problem is one of cost and of difficulty of specimen fabrication. Typically, testing of specimens with $\mathrm{k}$-values above $1 \mathrm{~W} / \mathrm{m} \cdot \mathrm{K}$ is performed on much smaller apparatuses. This is acceptable because the higher-conductivity specimens are generally much more uniform, and a smaller specimen can be representative of the material. Also, the requirements of guarding are not as stringent because the preferred path of heat flow is through the high conductivity specimen itself.

The second problem with high-k measurements is due to contact resistance between the specimen and the apparatus plates. This extra thermal resistance can lead to systematic errors in the measurement of the specimen therma 1 resistance. Even if the plate temperature is known very accurately, it is necessary to know the temperature of the specimen surface in order to calculate the specimen thermal resistance. One way to determine the actual specimen surface temperature is to place an appropriate number of thermocouples on the specimen surface. The personal communication given in reference [7] indicated that such a procedure is followed as a matter of course for specimens that have a thermal conductivity greater than $0.1 \mathrm{~W} / \mathrm{m} \cdot \mathrm{R}$. To estimate the error that could result if contact resistance were not taken into account, consider the example of a $25.4 \mathrm{~mm}$ thick specimen with a thermal conductivity of $0.14 \mathrm{~W} / \mathrm{m}^{\circ} \mathrm{K}$ which has an air gap on either side each with an average thickness of 25.4 microns. The thermal resistance of this air gap can be calculated by the expression $R=L_{g} / k$, ignoring thermal bridging considerations and noting that any radiation contribution to the thermal resistance for this order of magnitude of thickness is negligible (see Appendix 6). The $L_{g}$ term is the thickness of the air gap, 51 microns, and $\mathrm{k}_{\mathrm{a}}$ is the gas conductivity of air. Note that the convective heat transfer mode is not operative for thicknesses of this small order of magnitude. The R-value of this air gap is $2.0 \times 10^{-3} \mathrm{~K}^{\circ} \mathrm{m}^{2} / \mathrm{W}$, as compared with the Rvalue of the specimen itself, which is approximate 1 y $0.181 \mathrm{k} \cdot \mathrm{m}^{2} / \mathrm{W}$. Thus, the contact resistance is approximately 1 percent of the specimen resistance itself, in this example. The error could be of the same order of magnitude if contact resistance were ignored.

Table 1 shows the error in thermal resistance, due to contact resistance, as a function of specimen thermal conductivity. This table assumes an air gap of 51 microns and a specimen thickness of $25.4 \mathrm{~mm}$, and it demonstrates that contact resistance quickly becomes a significant source of uncertainty as the specimen $k$-value increases. The experimental problem is that the 
actual contact resistance will depend on the distribution of the air gap over the metered area; and this distribution is practically impossible to measure. Calculation of the effective contact resistance would take into account thermal bridging, since the contact resistance would vary over the metered area. The calculation would also depend on the temperature boundary conditions at the plate and specimen surfaces. Such a theoretical approach would be impractical, if not impossible.

An empirical approach is recommended, using thermocouples or thermopiles to measure the average temperature of the specimen surface. The number of thermocouples required to measure this average will depend on statistical criteria necessary to assure that the uncertainty in this average value is within a pre-selected tolerance.

\subsection{Thickness Limit}

The most significant factor 1 imiting the specimen thickness is the edge effect, which is nonnegligible at thicknesses above $229 \mathrm{~mm}$ for the NBS apparatus. A recent study of the edge effect indicated uncertainties of 0.5 percent at $285 \mathrm{~mm}, 1.0$ percent at $345 \mathrm{~mm}$, and 1.5 percent at $381 \mathrm{~mm}$. Appendix 5 shows how these uncertainties were derived. These values depend on the amount of change in the measured $k$-value as the ambient temperature changes, and on the uncertainty in this ambient temperature. In this estimate, the uncertainty in ambient temperature was $1^{\circ} \mathrm{C}$. Thus, if the other contributions to uncertainty were 0.5 percent and the tolerable total uncertainty were 1 percent, then the apparatus would be 1 imited to measurements below the $285 \mathrm{~mm}$.

Figures 8 and 9 show that if the ambient temperature cannot be controlled at the specimen mean temperature, the edge effect increases considerably. That is, the value of $X$ is proportional to the difference between the ambient temperature and the specimen mean temperature. If the slope, $B$, were determined empirically, it would be possible to make an adjustment of the measured thermal resistance value to the "true" value, corresponding to $X=0$. The uncertainty of such an adjustment would depend on the uncertainty in the curve as we 11 as the uncertainty in the value of $X$, which in turn depends upon the uncertainty in the value of the ambient temperature. Note that the specimen mean temperature will usually be known much more accurately than the ambient temperature.

There is another possible source of error in thickness, when the mean temperature is above or below $24^{\circ} \mathrm{C}$. To understand this possibility, it is necessary to examine the method of measuring and calibrating the specimen thickness. The thickness measurement is described in detail in reference [5]. Briefly, eight Farrand (produced by Farrand Industries, Inc.) thickness transducers, four for each cold plate, give an average value for the spacing between the hot plate and the two cold plates. The spatial reference points for these Farrand transducers are mounted on invar rods to minimize any change in position of these reference points. The average spacing between the plates over the metered area is determined by a mapping of the thickness using an in-situ thickness transducer; and this in-situ measurement is used to calibrate the eight Farrand thickness transducers. As long as there is no bowing or warping deformation of the plate, any change in thickness due to thermal expansion of the plates or the plate support system is indicated by the eight Farrand thickness transducers. As long as the plate spacings are calibrated at the same temperature 
conditions at which the specimen is measured, this plate deformation contribution to the error will be less than 51 microns, or 2 mils*.

Measurement difficulties arise at lower and higher temperatures (than $24^{\circ} \mathrm{C}$ ). It is not practical to calibrate the plate spacings (1) at low temperatures, because of ice formation in the interior of the ambient chamber and (2) at high temperatures, because of safety considerations and the difficulty of maintaining these high temperatures when the ambient chamber is open and the plates are exposed to the room temperature. A study was performed to measure the difference between (1) the thickness indicated by an in situ thickness transducer, located between the plates at their centers, and (2) the thickness indicated by the Farrand thickness transducers -- as the mean temperature was varied between $0^{\circ} \mathrm{C}$ and $57^{\circ} \mathrm{C}$. One would expect the plate spacings to change due to thermal expansion of the plate structure; the purpose of the study was to see if the change indicated by the Farrand thickness transducers corresponded to the change indicated by the in-situ thickness transducers.

Table 2 and figure 13 show the results of this study; the reference point, at which $D D=0$, is at the mean temperature of $24^{\circ} \mathrm{C}$. The DT term refers to the change in thickness as the mean temperature changes, as measured by the in-situ thickness transducer. The DF term refers to the change in thickness with the same change in mean temperature, as measured by the Farrand thickness transducers. The subscripts $t$ and $b$ refer to the top side and the bottom side of the two-sided apparatus. The DD term refers to the difference between DT and DF. This DD is a measure of the error in thickness that would result if plate deformation were ignored.

The points in figure 13 were taken in three sets. The slope of the average line is $0.22 \mathrm{mils} / \mathrm{K}$, and the scatter of the points about the average line is -1 mil. The difference between the two thickness readouts is systematic and repeatable. The in-situ detector is more reliable, because it is possible to calibrate it over the entire temperature range. The effective coefficient of thermal expansion of this aluminum in-situ detector was empirically determined, and the measured value agreed with the handbook value of $25 \times 10^{-6} \mathrm{~m} / \mathrm{m} \cdot \mathrm{R}$, within 1 percent. This coefficient was used to correct the in situ readings for thermal expansion.

The curve in figure 13 can be used to correct the readings of the Farrand thickness transducers. It should be possible to have a 20 percent confidence in the slope of this line with further repeats. For a $25.4 \mathrm{~mm}$ thick specimen, a thickness error of 1 mil corresponds to a percentage error of 0.1 percent. Thus, an error of $\sim 1.0$ percent would result over the temperature range indicated in the figure, if the plate deformation were not taken into account.

* The units of mils, or milli-inches are used since the size of the measured effect is $\sim 1 \mathrm{mil}$. The metric values can be obtained by noting that there are 25.4 microns in a mil. 


\subsection{Temperature Limits}

The three platinum resistance thermometers (PRT's) which measure the plate temperatures are capable of a temperature range from $-269^{\circ} \mathrm{C}$ to $220^{\circ} \mathrm{C}$. These were calibrated at NBS over a temperature range of $0^{\circ} \mathrm{C}$ to $50^{\circ} \mathrm{C}$, with a calibration bath uncertainty of $0.005 \Delta T\left({ }^{\circ} \mathrm{C}\right)$. Before NBS 1 -m GHP data for temperature points outside this calibrated range can be published, it will be necessary to calibrate the plate PRT's over the wider range of $40^{\circ} \mathrm{C}$ to $200^{\circ} \mathrm{C}$. This wou $1 \mathrm{~d}$ be easy for the two cold-plate PRT's because they are easily removed. It would require about a man-month of highly skilled technical labor for the hot-plate PRT, because the hot plate would have to be disassembled. A preferable and a feasible procedure would be to use the two cold-plate PRT's to perform an in-situ calibration of the hot-plate PRT.

The PRT manufacturer was contacted to obtain an order of magnitude for the uncertainty that would pertain if the PRT's would be used outside the calibrated range from $0^{\circ} \mathrm{C}$ to $50^{\circ} \mathrm{C}$ [9]. The manufacturer's estimate was that the extrapolation uncertainty would increase linearly from zero at $50^{\circ} \mathrm{C}$ to $-0.250^{\circ} \mathrm{C}$ at $200^{\circ} \mathrm{C}$, and the same slope could be used to estimate the uncertainty between $0^{\circ} \mathrm{C}$ and $-50^{\circ} \mathrm{C}$. For a temperature difference of 28 $\Delta T\left({ }^{\circ} \mathrm{C}\right)$, this method of estimation results in an additional uncertainty in $k_{s}$ of 0.35 percent at $\mathrm{T}_{\mathrm{m}}=-30^{\circ} \mathrm{C}, 0.55$ percent at $120^{\circ} \mathrm{C}$, and 1.55 percent at $180^{\circ} \mathrm{C}$.

Reference [5] discusses other contributions to the uncertainty of the average temperature over the surface of the metered area of the plates. An amount equal to $0.002 \Delta T\left({ }^{\circ} \mathrm{C}\right)$ was due to uncertainties in the measurement of the PRT resistance. The largest amount, $0.015 \Delta T\left({ }^{\circ} \mathrm{C}\right)$, was due to the difficulty in ascertaining by an independent in situ measurement that the surface temperature is constant over the metered area. This is important because the PRT measures the temperature in one location, and the accuracy with which this value at one location represents the average over the entire metered area must be considered. Neither of these two contributions will change when the temperature range is extended from $-50^{\circ} \mathrm{C}$ to $200^{\circ} \mathrm{C}$.

\subsection{Apparatus Uncertainty as a Function of $\mathrm{k}_{\mathrm{s}}$ and $\mathrm{T}_{\mathrm{m}}$}

Table 3 from reference [5] shows a summary of apparatus uncertainties as a function of specimen thickness, $L$, for the case of compressible specimens at a mean specimen temperature of $24^{\circ} \mathrm{C}$ and a plate temperature difference of $27.8^{\circ} \mathrm{C}$. This table will serve as the basis for the estimate of uncertainties as the specimen apparent thermal conductivity, $k_{s}$, and the specimen mean temperature, $\mathrm{T}_{m}$, are varied over the following ranges:

$$
\begin{aligned}
& \mathrm{k}_{\mathrm{s}}=0.0086 \text { to } 0.30 \mathrm{~W} / \mathrm{m}^{\circ} \mathrm{K} \\
& \mathrm{T}_{\mathrm{m}}=-30 \text { to } 180^{\circ} \mathrm{C}
\end{aligned}
$$

The total uncertainties are shown in tables 4 to 7 for L-values of 25.4, $152.4,304.8$, and $381 \mathrm{~mm}$. The additional uncertainty contributions (to Table 3) are due to contact resistance (see Section 4.3, Appendix 5, and Table 1), the thickness calibration uncertainty as the temperature varies away from $24^{\circ} \mathrm{C}$ (see Section 4.4 and Figure 11 ), the temperature extrapolation error as the sensor temperature varies from the calibrated range of $0^{\circ} \mathrm{C}$ to $50^{\circ} \mathrm{C}$ (see Section 4.5), and the edge effect (see Sections 
4.2 and 4.4, Appendix 4, and Figure 10). The effects of these four factors on the numbers in tables 4 to 7 will be discussed next.

The first factor, the contact-resistance estimate, is the same for all temperatures and was based on an assumption for the specimen-plate air gap which is reasonable but which would be difficult to verify. It also applies only to rigid specimens. That is, this factor would not apply for specimens of compressible material such as low-density, glass-fiber material. Assuming the specimens are not compressible, it is a significant term, even for typical insulation materials, 0.3 percent, for $I=25.4 \mathrm{~mm}$, but it is not significant at greater thicknesses because it is inversely proportional to the thickness. This term could be largely eliminated if the specimen surface temperature were independently measured. In this case, the specimen thickness would also have to be measured independently.

The second factor is due to plate deformation as the ambient and plate temperatures vary above and below $24^{\circ} \mathrm{C}$. This error estimate is based on the rather conservative estimate that the slope of the curve in figure 13 is known only to within \pm 50 percent. It is quite significant at $\mathrm{L}=25.4 \mathrm{~mm}$, having values of 0.5 percent at $\mathrm{T}_{\mathrm{m}}=-30^{\circ} \mathrm{C}$ and 0.9 percent at $\mathrm{T}_{\mathrm{m}}=120^{\circ} \mathrm{C}$. It too varies inversely with thickness, and is not as significant at large thicknesses.

The third factor is the estimate of extrapolation uncertainty due to the fact that the PRT's were calibrated on $1 \mathrm{y}$ between $0^{\circ} \mathrm{C}$ and $50^{\circ} \mathrm{C}$. This term can be as large as 0.5 percent, but it can be eliminated with further calibration.

The fourth factor is due to the edge effect. thicknesses above $200 \mathrm{~mm}$, and it is slightly

It is significant on 1 y for values of $\mathrm{k}_{\mathrm{s}}$.

In summary, tables 4 to 7 can be used to determine the current limits on operating values for thickness, temperature, and thermal conductivity that correspond to a given tolerance. For example, if this tolerance were \pm 1 percent, one would determine the acceptable range of $k_{s}$ by noting the range of values of $T_{m}$ and $L$ for which the table values are less than or equal to 1 percent.

5. APPARENT THERMAL CONDUCTIVITY DATA OVER THE CURRENT OPERATING TEMPERATURE RANGE

Figures 14 and 15 show the ranges of apparent thermal conductivity and specimen mean temperature over which the NBS 1-m GHP has been operated; and tables 8 and 9 contain the data used in these figures. The plate temperature difference was $\sim 27.8 \Delta \mathrm{T}\left({ }^{\circ} \mathrm{C}\right)$. Figure 15 shows a smaller $\mathrm{k}_{\mathrm{s}}$ range for typical insulation materials, while figure 14 shows a wider $k_{s}$ range. One indication of the measurement uncertainties at temperature extremes is the agreement between the data points and a curve that has been shown to be typical of a particular material. For example, for the glassfiber material of density equal to $114 \mathrm{~kg} / \mathrm{m}^{3}$, a straight line should fit the data within better than 0.1 percent between $0^{\circ} \mathrm{C}$ and $40^{\circ} \mathrm{C}$ [10]. Thus the variation of -1 percent about a straight-line fit for the high-density glass-fiber material is an indication of the consistency of the data. 
It is possible, however, that an error in slope could exist, such as that described in section 4.4 and shown in figure 13. Such a systematic error would not show up on a $k_{s}$ vs $T$ plot, and must be discovered by independent investigation of any systematic errors that might exist in the parameters that determine the calculated value of $k_{s}$.

Another feature of interest is that the polyisocyanurate data do not fit a straight line when a portion of the specimen is below $0^{\circ} \mathrm{C}$. This is probably because condensation of the fluorocarbon gas on the insulation cell walls results in a higher gas conductivity within the cells that make up this material. Also, at these lower temperatures the measured $\mathrm{k}_{\mathrm{s}}-\mathrm{value}$ was not as repeatable as at higher temperatures, presumably because the amount of condensation of the fluorcarbon gas depends on the past temperature history of the specimens [1].

The data for the Min-K material fits a quadratic expression within \pm 1 percent over the temperature range $0^{\circ} \mathrm{C}$ to $55^{\circ} \mathrm{C}$. The NBS measured value of $0.0254 \mathrm{~W} / \mathrm{m} \cdot \mathrm{K}$ at $24^{\circ} \mathrm{C}$ is between the two values quoted in a recent report [2], 0.020 and $0.030 \mathrm{~W} / \mathrm{m}^{\circ} \mathrm{R}$, and it is within 4 percent of the value of $0.0262 \mathrm{~W} / \mathrm{m}^{\circ} \mathrm{K}$ quoted in reference [1]. Since the $\mathrm{k}_{\mathrm{s}}-\mathrm{value}$ of $\mathrm{Min}-\mathrm{K}$ varies with atmospheric pressure, this parameter is included in table 9.

Figure 16 and table 10 show the variation in measured $k-v a l$ ue as the specimen thickness increases. The data for specimen $A$ is based on curve fits of data for a low-density, glass-fiber material. The k-value was plotted versus specimen density for a number of specimens [11], and the values in the figure represent the average curve value for a density of 9.6 $\mathrm{kg} / \mathrm{m}^{3}$ at three thicknesses. This data confirmed the thickness effect in this material. Specimen B was a glass-fiber material of density equal to $19.2 \mathrm{~kg} / \mathrm{m}^{3}$. No thickness effect is expected at this high density, and the scatter represents the variability from specimen to specimen - - as four $25.4 \mathrm{~mm}$ specimens were stacked to greater thicknesses.

Specimen C consisted of stacks of extruded polystyrene specimens, each of a thickness approximately equal to $51 \mathrm{~mm}$. If a constant value is used to fit this "ks vs $L$ " data up to the maximum thickness, the standard deviation is 0.4 percent. Part of this value is due to the variation in the $\mathrm{k}-\mathrm{value}$ of the layers of the stacked specimen. To remove this contribution to the scatter, the individual layers were measured. Table 11 presents data of the percent difference between the average $k-v a l u e$ of the individual layers in a stacked specimen and the actually measured k-value of the stacked specimen. This percent difference is an indication of the uncertainty in the measured k-value as a function of thickness. For thicknesses below 154 mm the average values are within 0.3 percent of the measured values; for larger thicknesses (205 to $381 \mathrm{~mm}$ ), the comparison was within 0.6 percent.

6. SUMMARY OF PARAMETER LIMITS AND ESTIMATES OF COSTS OF IMPROVEMENTS

\subsection{Temperature Limits}

The temperature limits are given in figure 17. A solid line indicates the current range for a particular factor; a dotted line indicates a possible extension of the range. The following discussion proceeds from the most restrictive to the least restrictive factor. Methods to increase the range are mentioned, along with an estimate of implementation costs. These costs 
are categorized as "low" when the estimate is less than $\$ 1 \mathrm{~K}$, "medium" when the estimate is between $\$ 1 \mathrm{~K}$ and $\$ 10 \mathrm{~K}$, and "high" if greater than $\$ 10 \mathrm{~K}$.

\section{Cold Plate}

Low limit $=-17^{\circ} \mathrm{C}$ Due to amplifier saturation in the plate temperature-control circuits. This circuit could be easily upgraded at a low cost by changing circuit components.

Next low limit $=-30^{\circ} \mathrm{C}$ Due to the cold-plate bath cooling capacity. A replacement bath that would achieve $-50^{\circ} \mathrm{C}$ could be purchased at a low cost.

Next low limit $=-40^{\circ} \mathrm{C}$ Due to the epoxy used to construct the cold plate. This is not extendable.

High limit $=50^{\circ} \mathrm{C}$ Due to limited capacity of the cold-plate heater power supply to oppose the existing cooling unit. This is extendable with the purchase of a power supply at a low cost.

Next high limit $=85^{\circ} \mathrm{C}$ Due to the cold-plate insulation. This could be easily replaced at a medium cost.

Next high limit $=100^{\circ} \mathrm{C}$ Due to a possible loss of sensitivity in the plate-temperature control circuits. This is because of low values of the temperatureresistance coefficient of the plate thermistors. This circuit could be upgraded at a medium cost by changing circuit components.

Next high limit $=110^{\circ} \mathrm{C}$ Due to the circulating pump in the cold-plate bath. This could be replaced at a medium cost.

Next high limit $=120^{\circ} \mathrm{C}$ Due to the PRT-wire epoxy. This could be easily replaced at a low cost.

Next high limit $=180^{\circ} \mathrm{C}$ Due to the epoxy used to construct the cold plates. This is not extendable.

Hot Plate

Low limit $=-17^{\circ} \mathrm{C}$ Due to amplifier saturation in the plate temperature-control circuits. This circuit could be upgraded at a low cost by changing circuit components.

Next low limit $=-48^{\circ} \mathrm{C}$ Due to the epoxy used to keep thermocouples and heater leads in place. This is not extendable.

High limit $=100^{\circ} \mathrm{C}$ Due to a possible loss of sensitivity in the plate-temperature control circuits.. This results from the low values of the temperatureresistance coefficient of the plate thermistors. This circuit could be upgraded at 
a medium cost by changing circuit components and testing the performance.

Next high limit $=170^{\circ} \mathrm{C}$ Due to Teflon tubing around the thermistor, PRT, and thermistor wires. This could be easily replaced at a low cost.

Next high limit $=200^{\circ} \mathrm{C}$ Due to the hot-p late epoxy. This is not extendable.

\section{Ambient Temperature}

Low limit $=\quad 2{ }^{\circ} \mathrm{C} \quad$ Due to the cooling capacity of the cold bath. A low-cost purchase of another bath would extend the limit to $-30^{\circ} \mathrm{C}$.

Next low limit $=-20^{\circ} \mathrm{C}$ Due to the ambient temperature controller. This could be easily replaced at a medium cost.

High limit $=90^{\circ} \mathrm{C}$ Due to the polyurethane in the ambient chamber walls. This could be extended at a medium cost to $120^{\circ} \mathrm{C}$ (the high-temperature 1 imit of the ambient controller), with extra insulation inside the ambient chamber. To extend to $190^{\circ} \mathrm{C}$, an insulated heater jacket would have to be designed, constructed, and tested -- at a high cost.

\subsection{Other Apparatus Limits}

\section{Thickness}

Low 1 imit $=19 \mathrm{~mm}$

High limit $=381$ mon

Thermal Resistance and Apparent Thermal Conductivity

The discussion in chapter 4 concluded that any practical insulation specimen could be tested in the apparatus. In this sense, there are no limits on these parameters.

Ambient Gas Pressure

There is no current control capability of the ambient gas pressure. At a very high cost, it might be possible to achieve a low limit of 80 percent of 1 atmosphere and high 1 imit of 3 atmospheres. 


\section{Relative Humidity}

Low 1 imit $=23$ percent at $24^{\circ} \mathrm{C}$ Next low limit $=2$ percent at $24^{\circ} \mathrm{C}$ High limit $=35$ percent at $24^{\circ} \mathrm{C}$
Using the existing condensing coils. Using nitrogen or dry air.

Due to the existing RH control in the laboratory room. This could be increased to a higher value with a low-cost humidifier. 


\section{REFERENCES}

1. ASTM Subcommittee C16.30, "Reference Materials for Insulation Measurement Comparisons," Thermal Transmission Measurements of Insulation, ASTM STP 660, R. P. Tye, Ed., American Society for Testing and Materials, 1978, Pp. 7-29.

2. Rennex, B. G., "An Assessment of Needs for New Thermal Reference Materials," National Bureau of Standards Interagency Report NBSIR 822538 (Washington, D.C., NBS, 1985).

3. Hahn, M. H., Robinson, H. E., and Flynn, D. R., "Rob inson Line-HeatSource Guarded-Hot-P late Apparatus," Heat Transmission Measurements in Thermal Insulations, ASTM STP 544, American Society for Testing and Materials, 1974, pp. 167-192.

4. Rennex, B. G. and Powe11, F. J., "The NBS Line-Heat-Source Guarded Hot Plate for Thick Materials," ASHRAE SP38, Thermal Performance of the Exterior Envelopes of Buildings - II, 657-672, (1983)

5. Rennex, B. G., "Error Analysis for the NBS 1016 mm Guarded Hot P late," Journal of Thermal Insulation, Vol. 7, Pp. 18-51 (July 1982).

6. 1984 Annual Book of ASTM Standards, Vol 04.06, ANSI/ASTM C 177-76, "Standard Test Method for STEADY-STATE THERMAL TRANSMISSION PROPERTIES BY MEANS OF THE GUARDED HOT PLATE," American Society for Testing and Materials, 1916 Race Street, Philadelphia, PA 19103, pp. 20-53.

7. Personal communication from Andre Desjarlais of Dynatech R\&D Corporation - Their policy, when measuring thermal resistance of

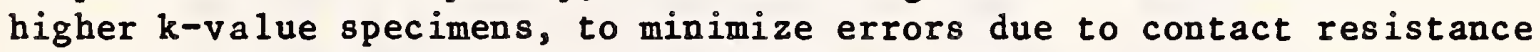
is to $p$ lace thermocouples on the specimen surfaces for $k-v a l u e s$ greater than $0.10 \mathrm{~W} / \mathrm{m} \cdot \mathrm{K}, 1985$.

8. Rennex, B. G., "Thermal Parameters as a Function of Thickness in LowDensity Insulation," Journal of Thermal Insulation, Vol. 3, pp. 37-61 (July 1985).

9. Personal communication from Dana Schurr of MINCO Products, Inc., Minneapolis, Minnesota, 1985.

10. Siu, M. C. I., J. G. Hust, National Bureau of Standards, Certificate of Standard Reference Material 1450b, Thermal Resistance - Fibrous Glass Board, May 21, 1982.

11. Rennex, B. G., "Low-Density Thermal Insulation Calibrated Transfer Samples -- a Description and a Discussion of the Material Variability," National Bureau of Standards Interagency Report NBSIR 82-2538 (Washington, DC, NBS, 1982). 


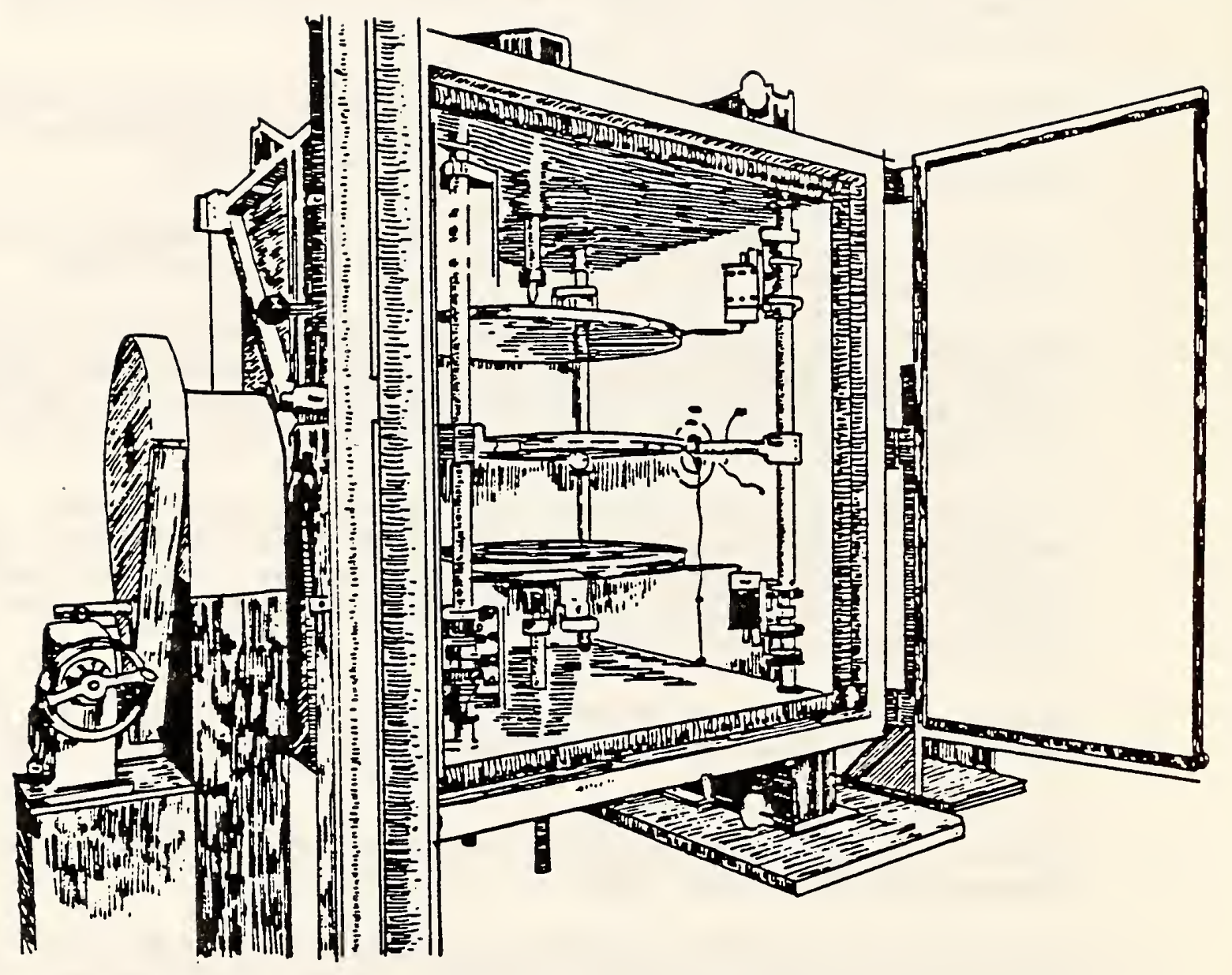

Figure 1 - Drawing of the NBS 1016 Guarded Hot Plate Showing the Support System of the Hot and Cold Plates and Showing the Rotatable Enclosure for Environmental Control. 




Figure 2 - Temperature Control Circuit for the NBS 1-m Guarded Hot Plate Apparatus. 


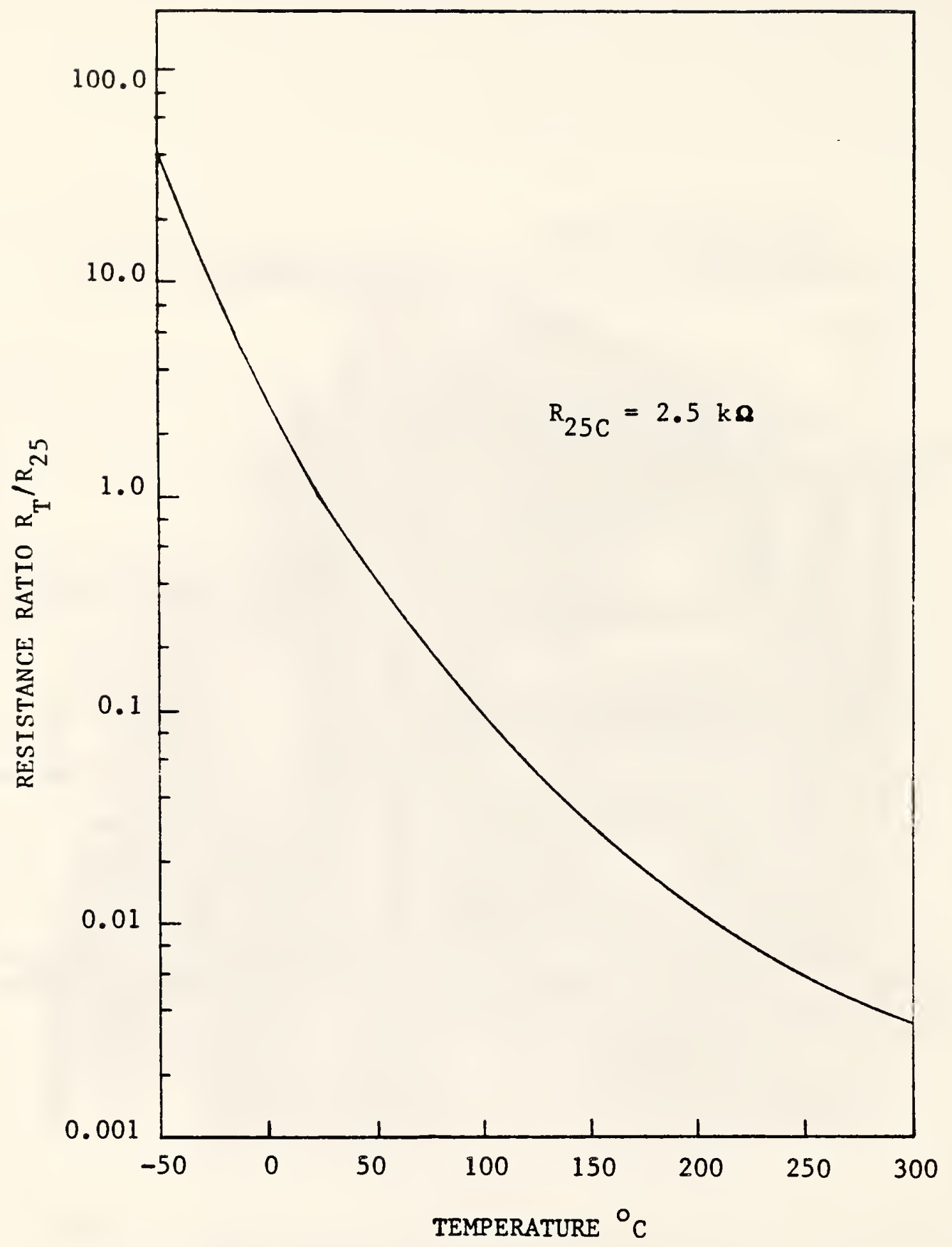

Figure 3 - Resistance-Temperature Characteristics for Temperature Control Thermistors 


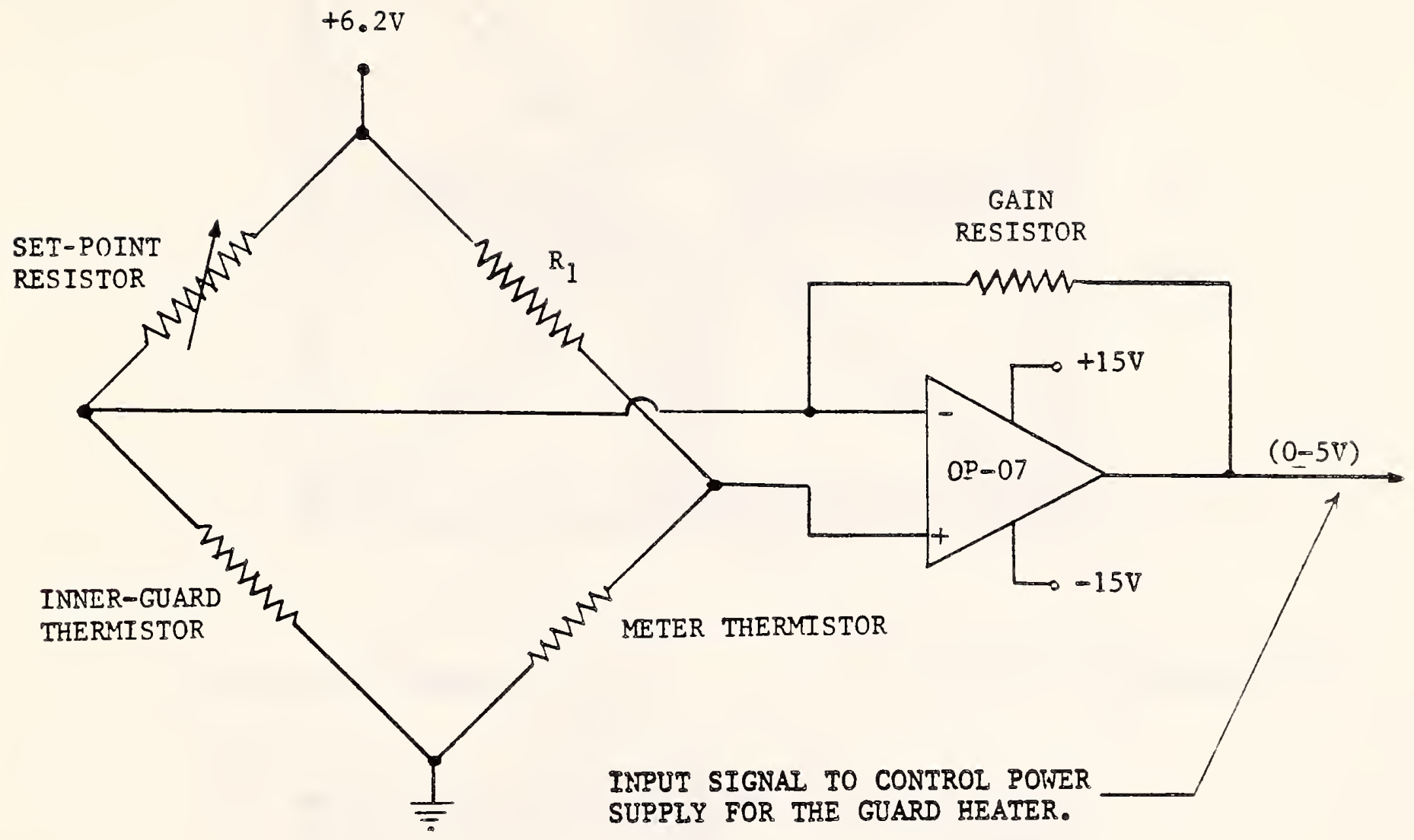

Figure 4 - Control Circuit for the Guard Heaters for the NBS $1-\mathrm{m}$ Guarded Hot Plate. 




Figure 5 - View of the NBS 1-m Guarded Hot Plate Apparatus walls and doors. 


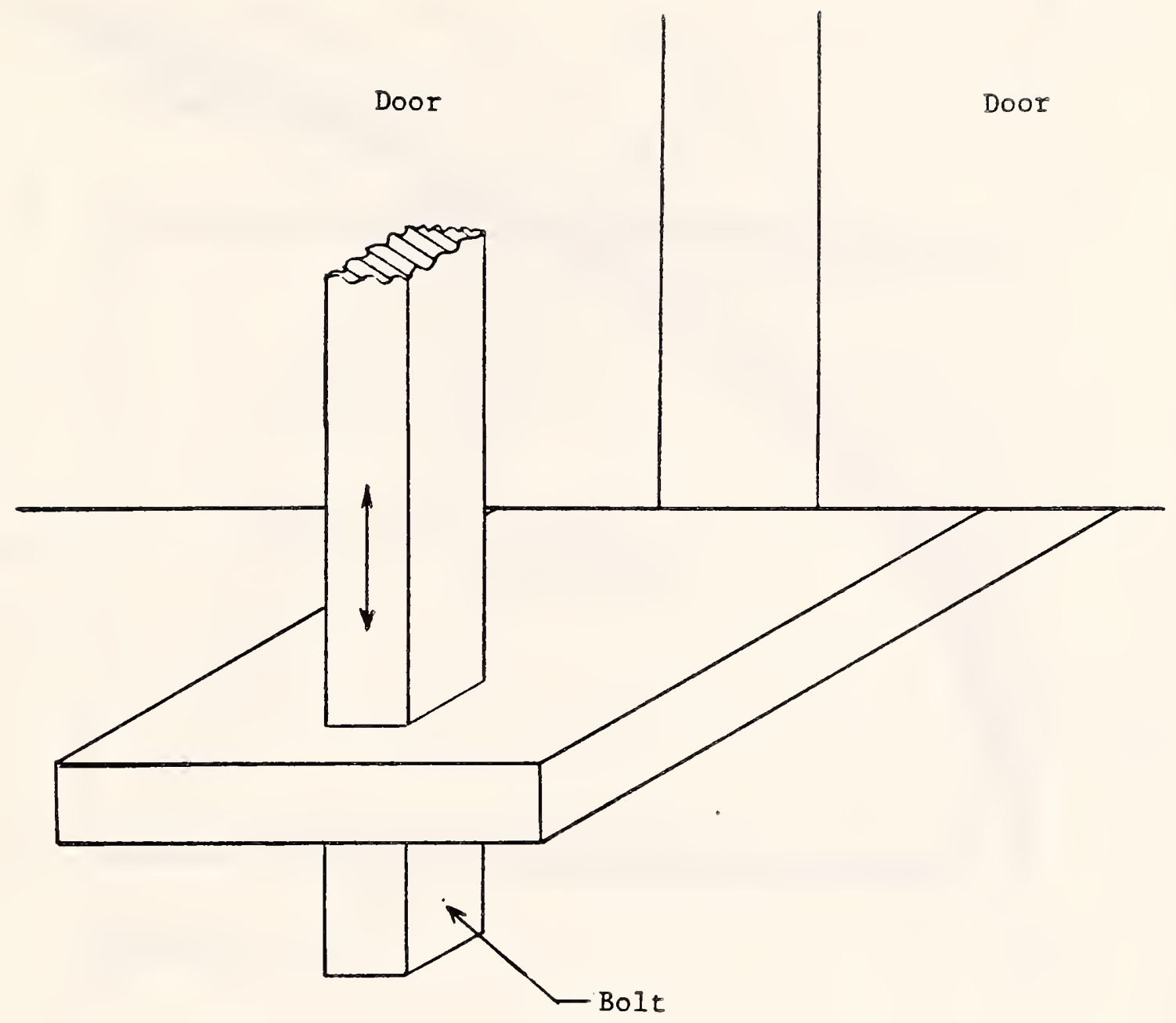

Figure 6 - Latch of the NBS 1-m Guarded Hot Plate Apparatus Door-Lock Bar. 


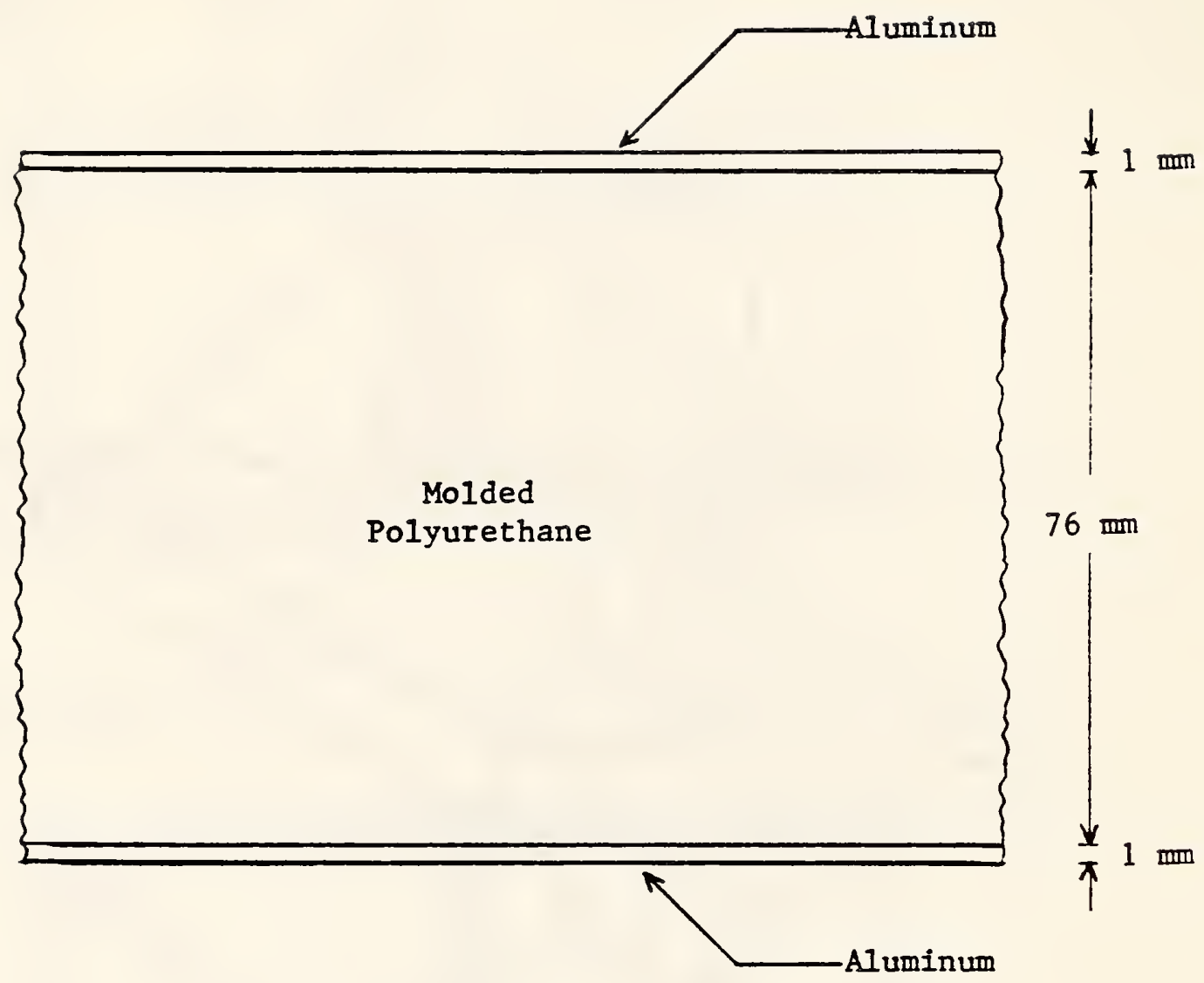

Figure 7 - Cross Section of the NBS 1-m Guarded Hot Plate Apparatus Walls. 







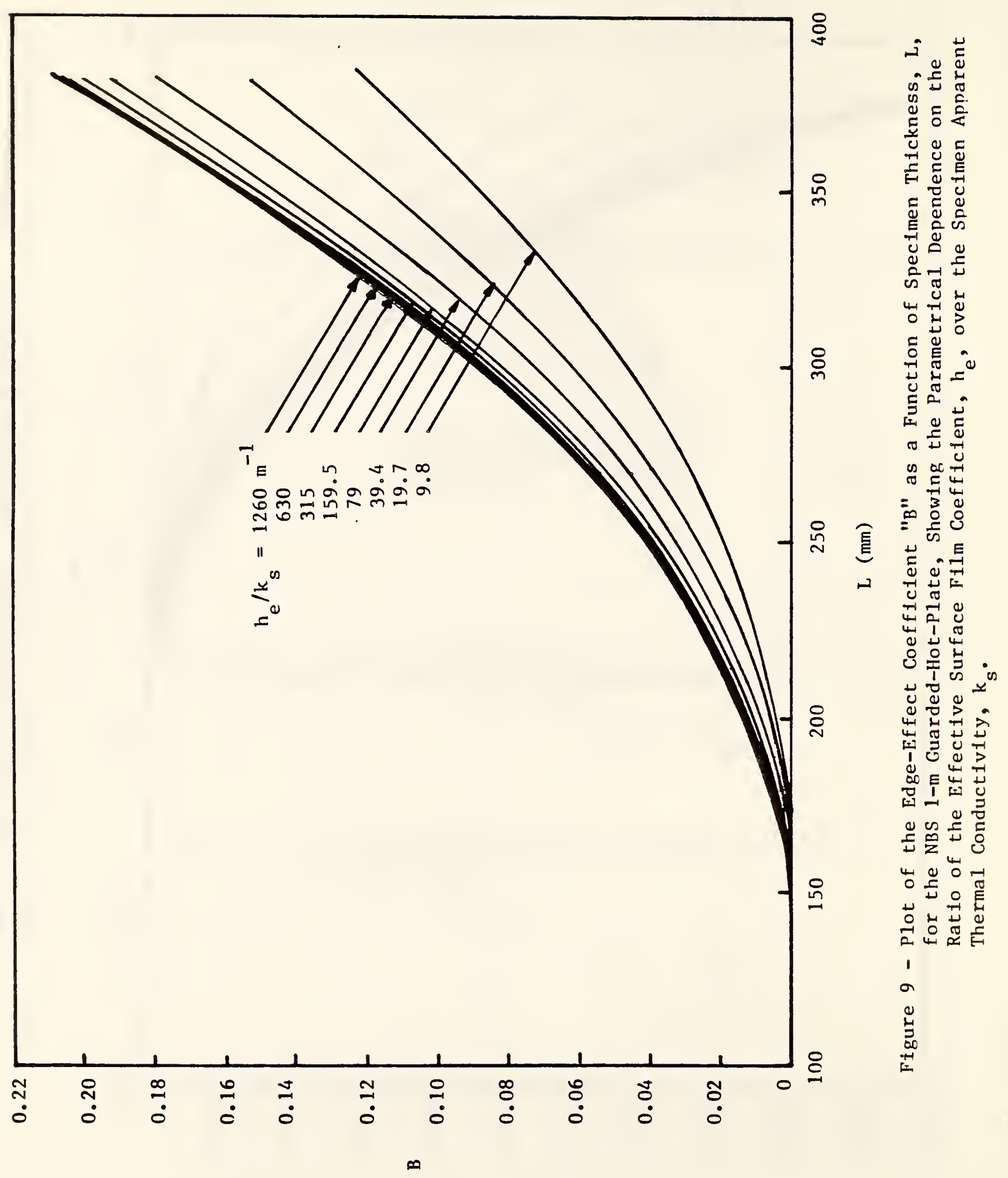









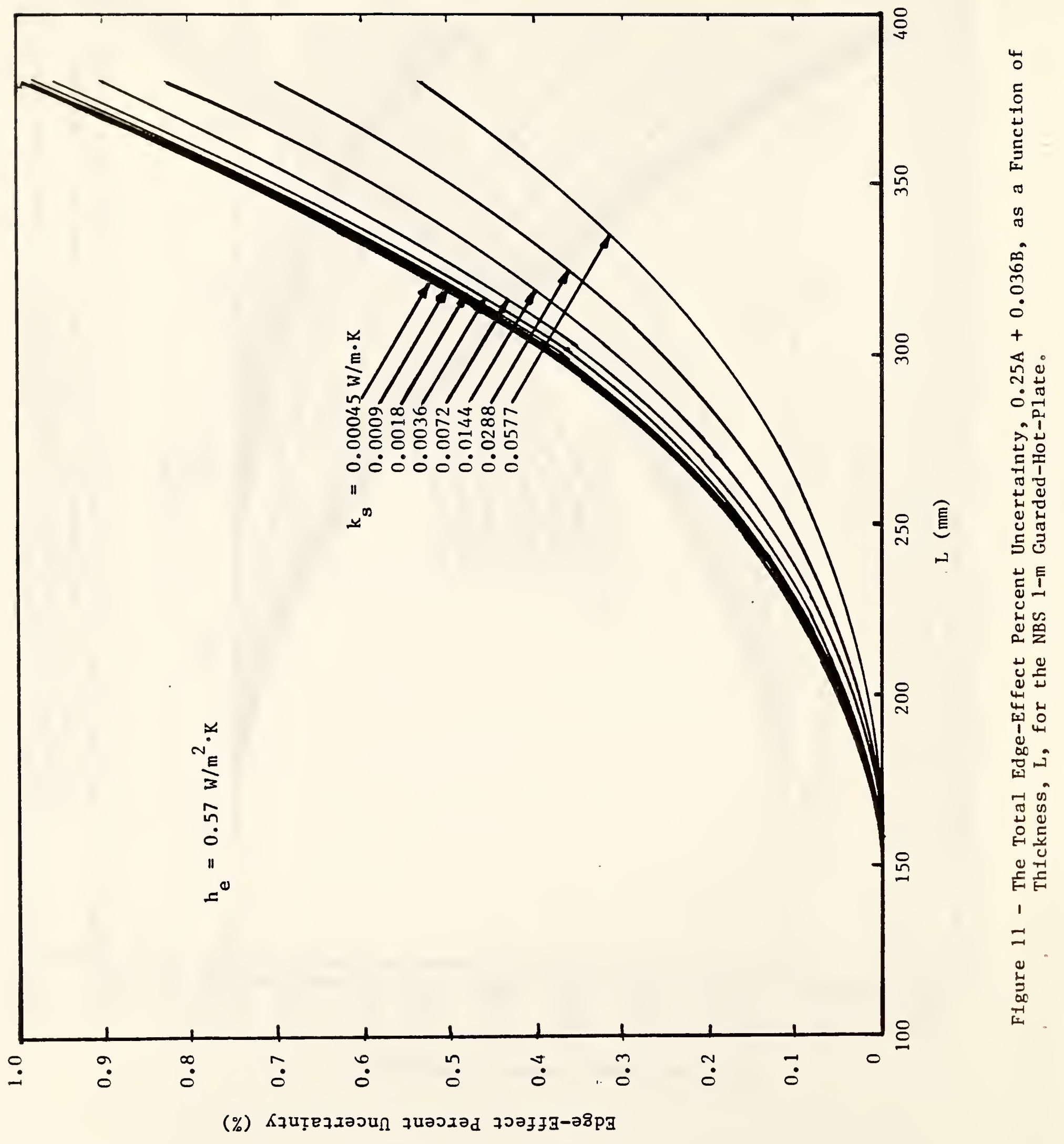




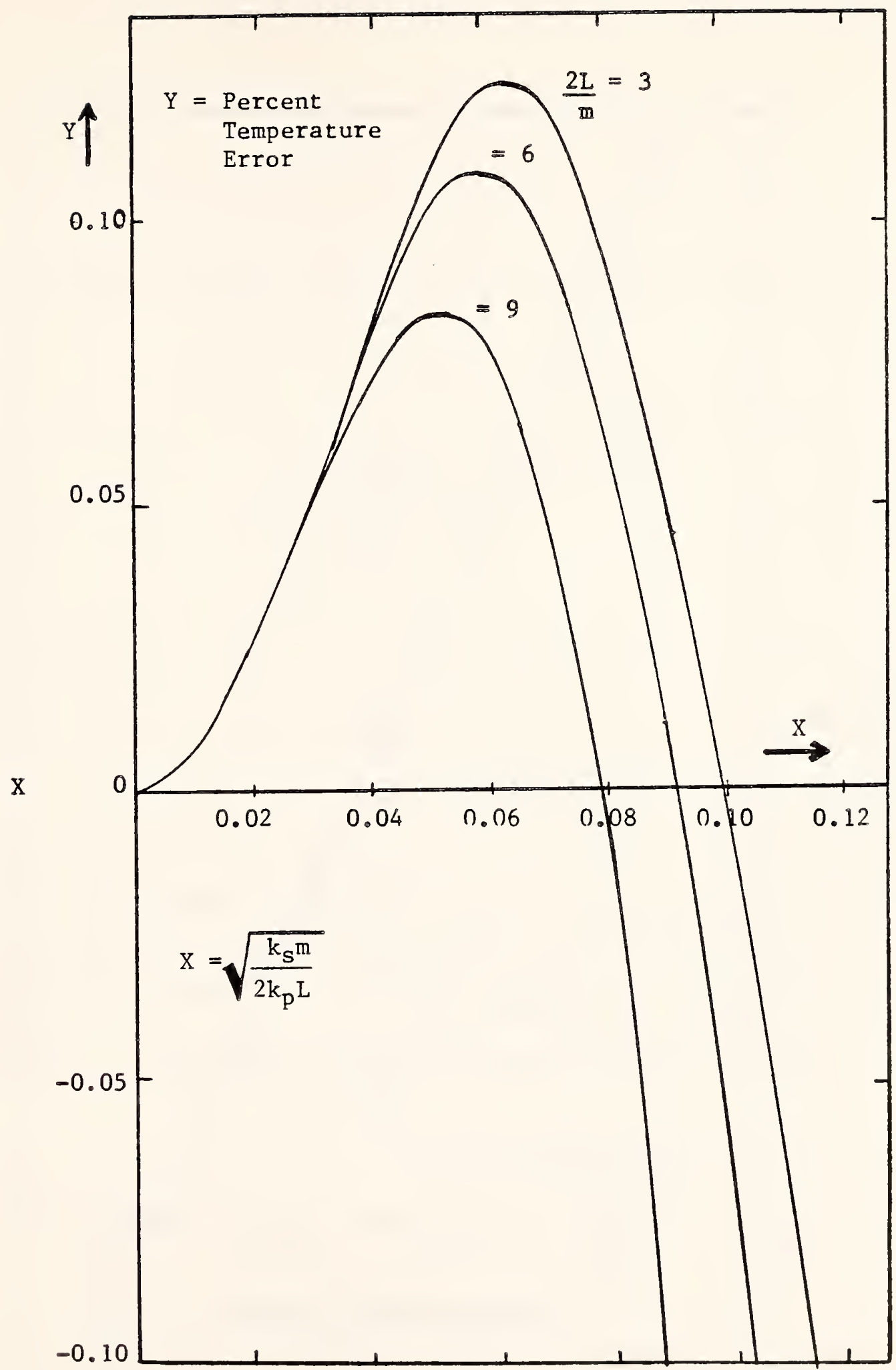

Figure 12 - Percentage difference between temperature at edge of metering section and the average temperature over the metering section area as a function of specimen thermal conductivity for the following parameters: $b / a=\sqrt{2}$ $2 \mathrm{~b} / \mathrm{m}=16$, and, $\mathrm{e} / \mathrm{m}=0.5$. 


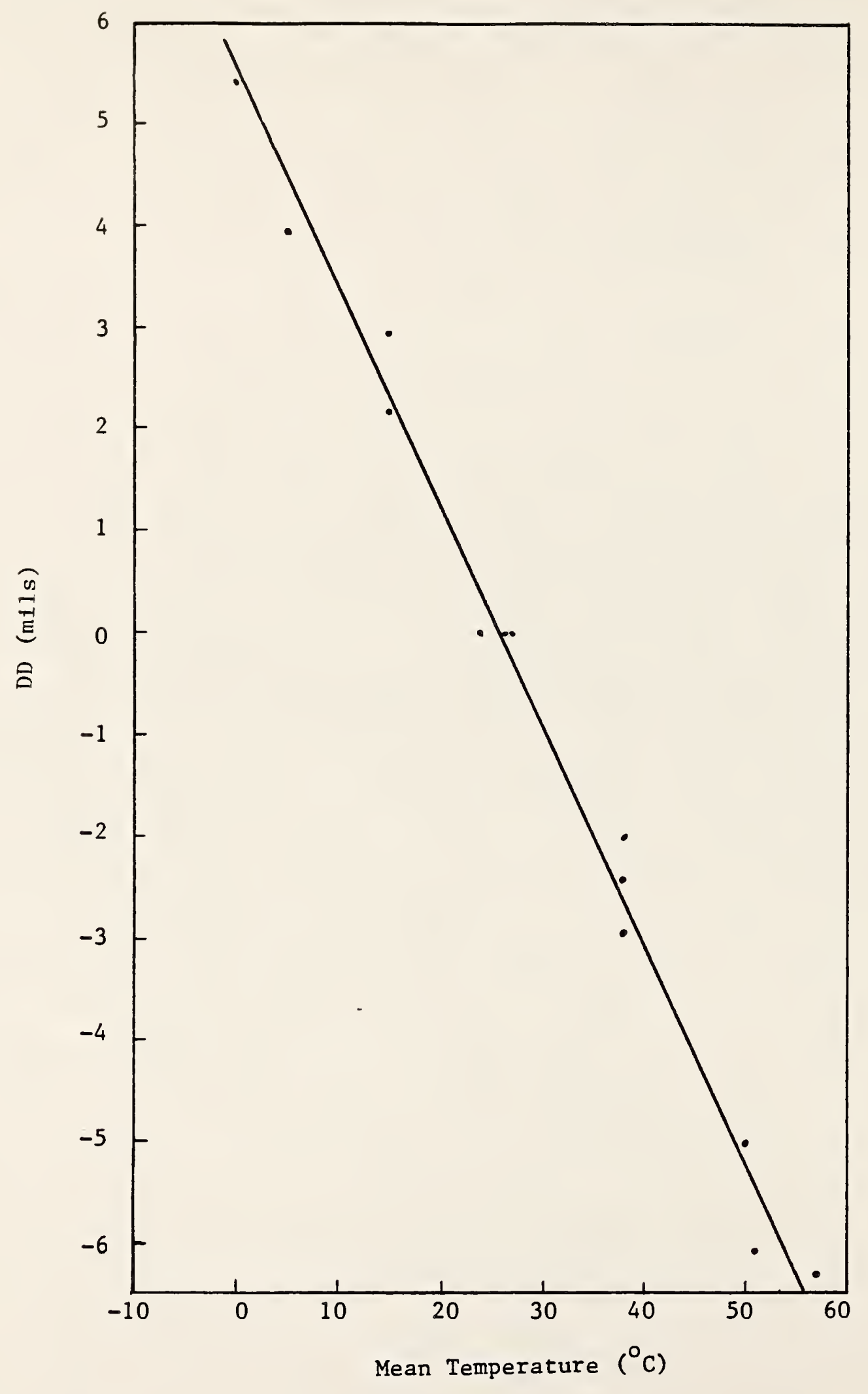

\footnotetext{
Figure 13 - Correction Term, DD, for the NBS GuardedHot-Plate Thickness Readout Based on an In-Situ Measurement.
} 




Figure 14 - Apparent Thermal Conductivity versus Specimen Mean Temperature Points Showing the Ranges Measured on the NBS $1-\mathrm{m}$ Guarded Hot Plate. 


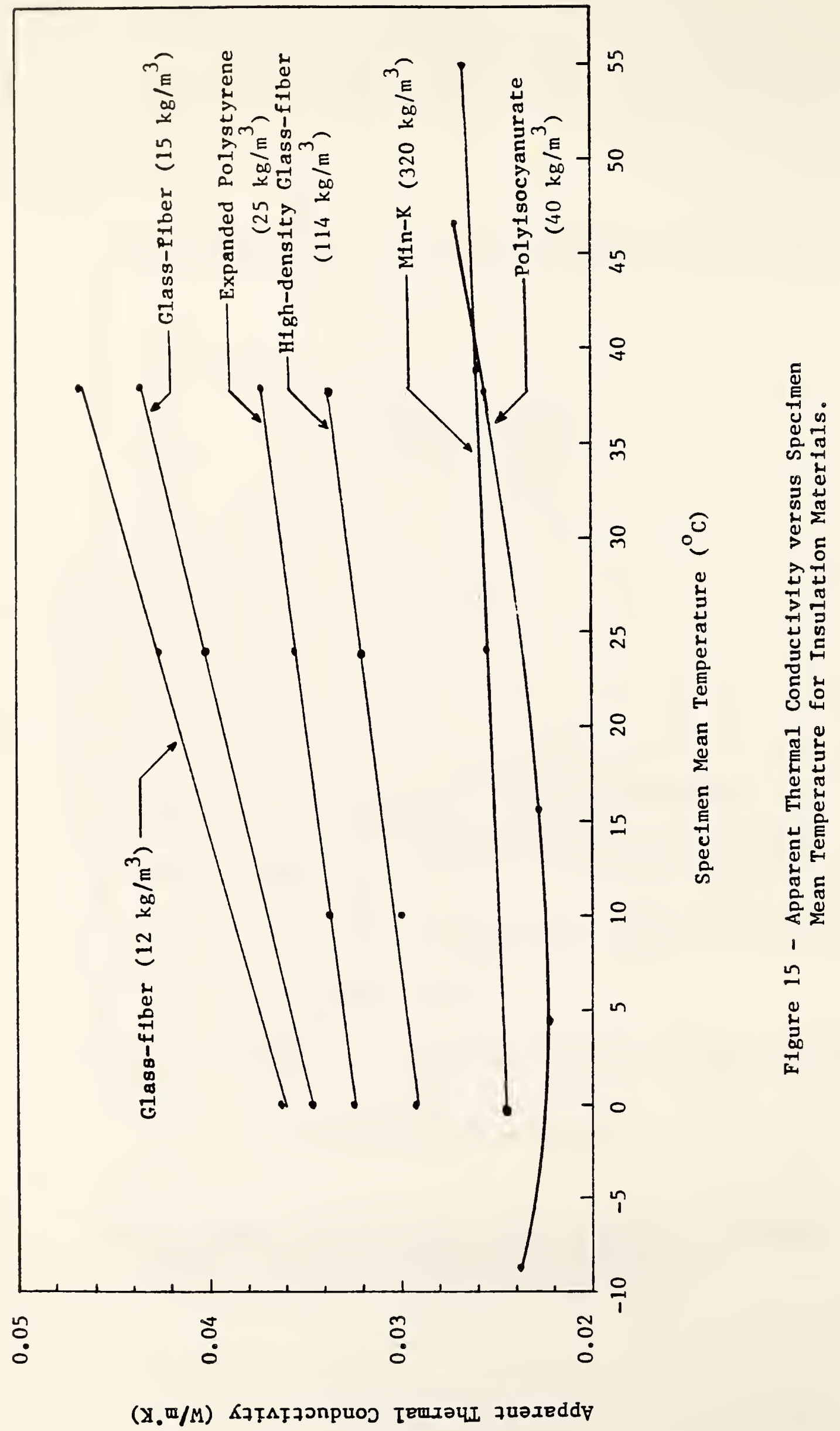




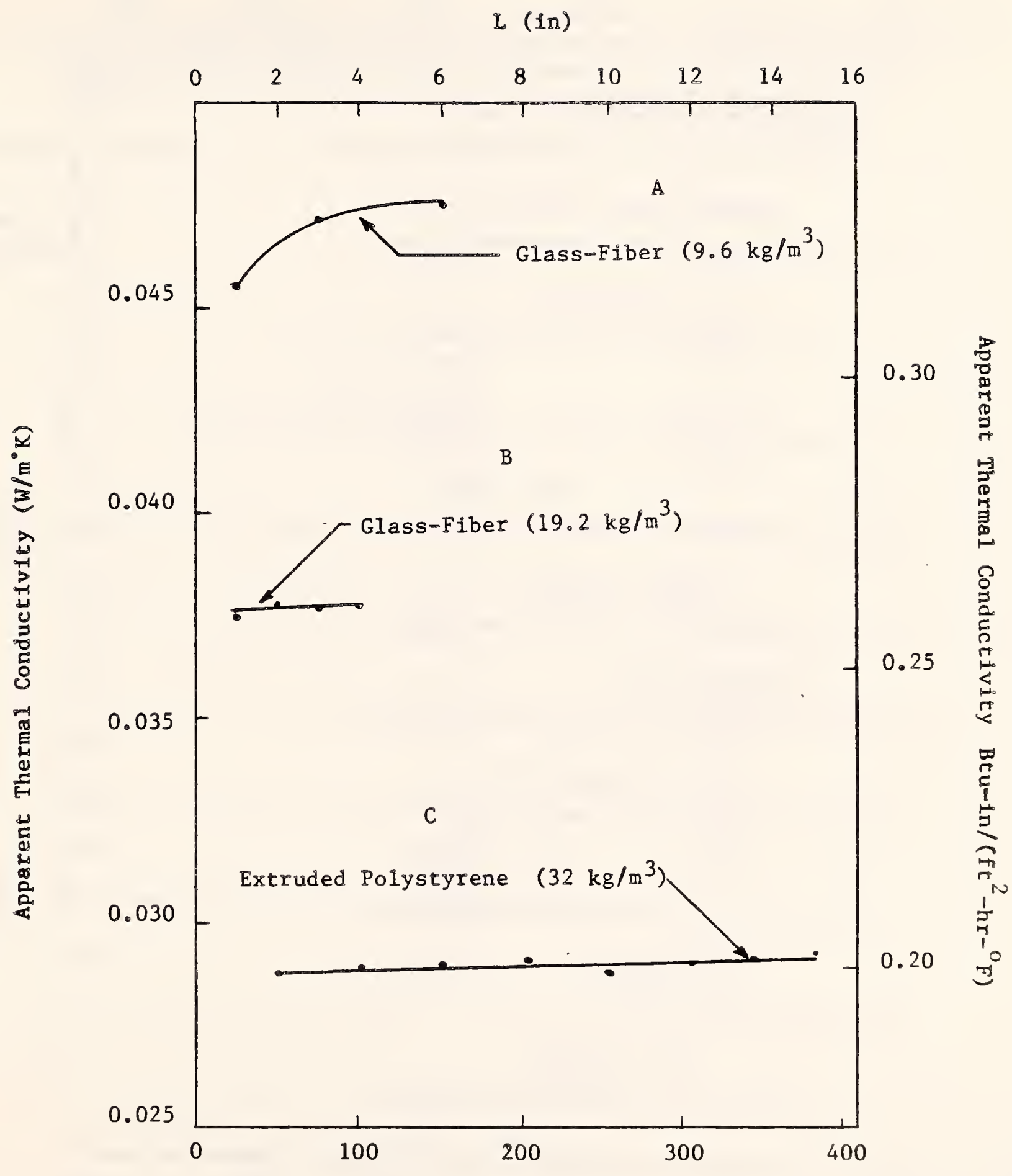

L (mm)

F1gure 16 - Apparent Thermal Conductivity versus Specimen Thickness, L, for Insulation Materials. 


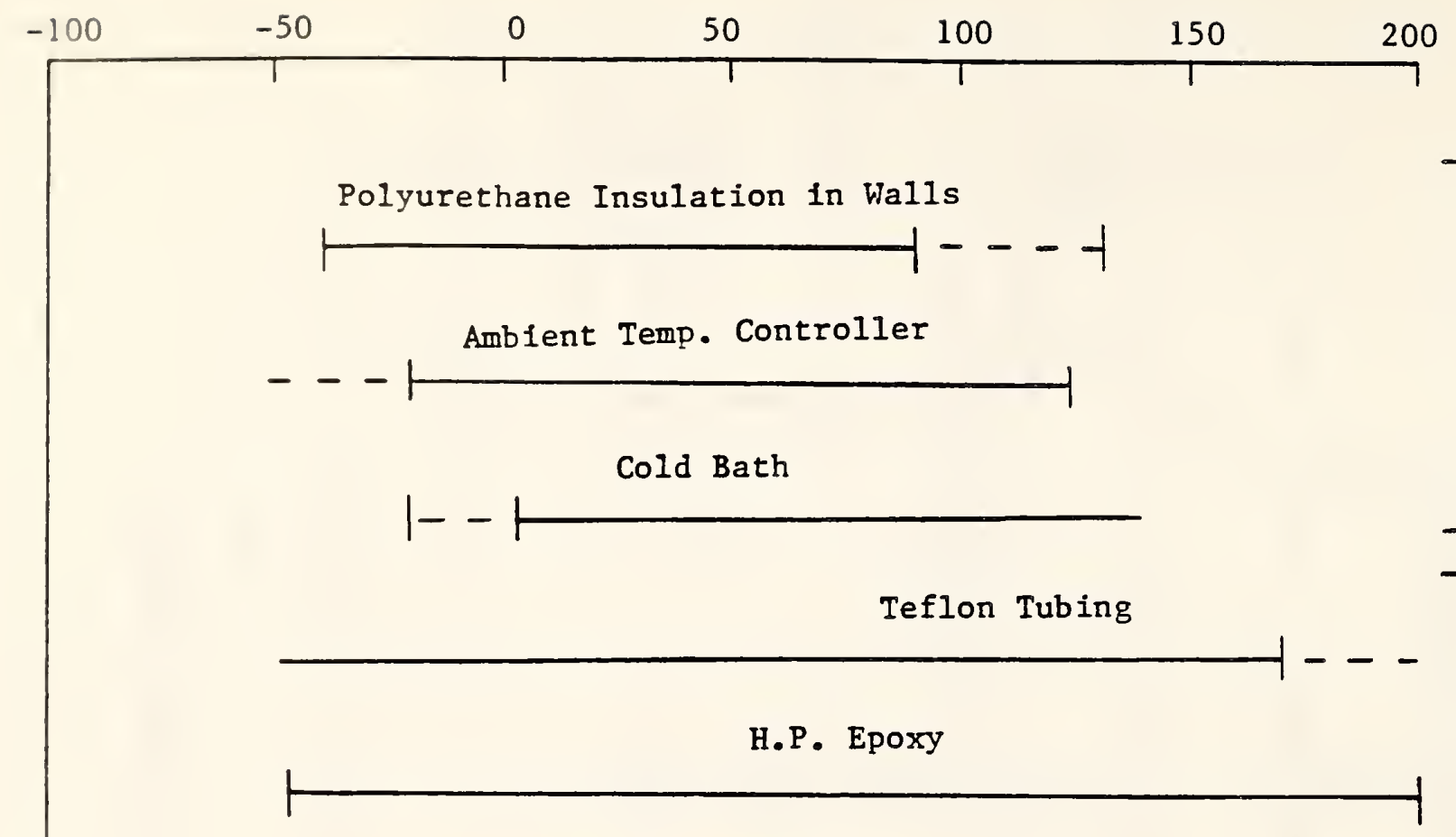

AMB IENT TEMPERATURE

H.P. Circuits

HOT

PLATE

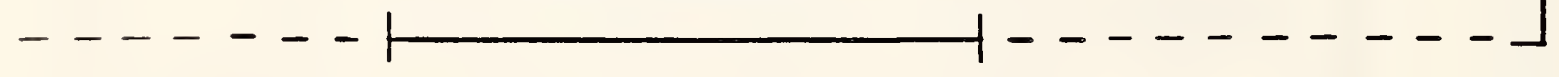

PRT-wire Epoxy

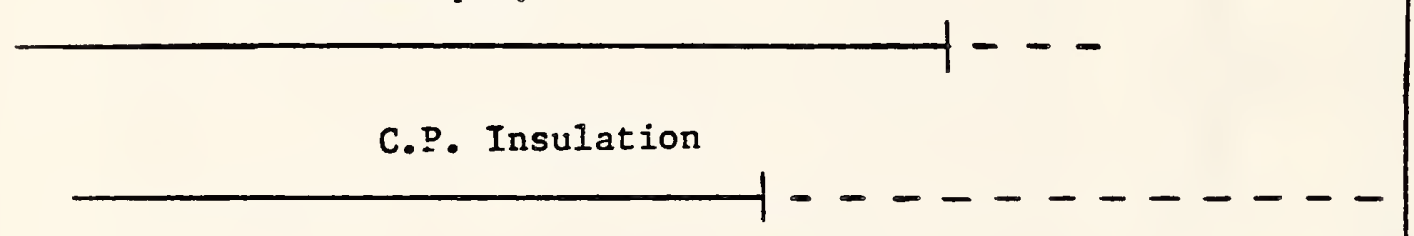

C.P. Epoxy



COLD

PLATES

C.P. Circuit

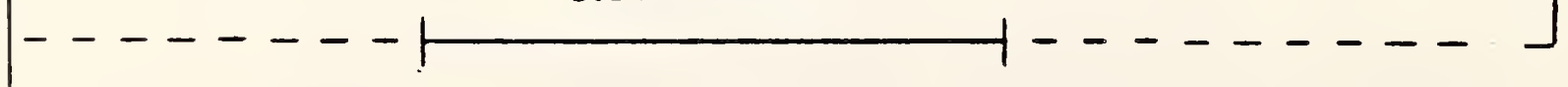

$\begin{array}{lllllll}-100 & -50 & 0 & 50 & 100 & 150 & 200\end{array}$

TEMPERATURE $\left({ }^{\circ} \mathrm{C}\right)$

Figure 17 - Temperature Limits for the NBS 1-m GuardedHot-Plate Apparatus. 
TABLE 1 - Relative Magnitudes of Contact Resistance, $r$, and the Thermal Resistance of a $25.4 \mathrm{~mm}$ Thick Specimen for a Range of Specimen k-value.

$\begin{array}{ccc}\mathrm{k} \text {-value }(\mathrm{W} / \mathrm{m} \cdot \mathrm{K}) & \mathrm{R} \text {-value }\left(\mathrm{m}^{2} \cdot \mathrm{K} / \mathrm{W}\right) & \text { Percent }(\mathrm{r} / \mathrm{R}) \\ 0.02 & 1.27 & 0.153 \% \\ 0.04 & 0.635 & 0.306 \% \\ 0.06 & 0.423 & 0.459 \% \\ 0.08 & 0.318 & 0.610 \% \\ 0.10 & 0.254 & 0.764 \% \\ 0.12 & 0.212 & 0.915 \% \\ 0.14 & 0.181 & 1.072 \% \\ 0.16 & 0.159 & 1.220 \% \\ 0.18 & 0.141 & 1.376 \% \\ 0.20 & 0.127 & 1.528 \% \\ 0.22 & 0.116 & 1.672 \% \\ 0.24 & 0.106 & 1.830 \% \\ 0.26 & 0.0977 & 1.986 \% \\ 0.28 & 0.0907 & 2.139 \% \\ 0.30 & 0.0847 & 2.290 \%\end{array}$




$$
\begin{aligned}
& \text { Table } 2 \text { - Difference Between NBS 1-m GHP Thickness } \\
& \text { Readout and In Situ Thickness Readout. }
\end{aligned}
$$

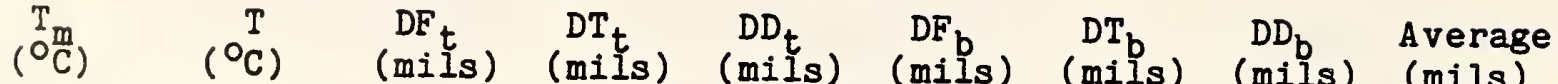

$$
\begin{aligned}
& 23.899 \quad 27.714 \\
& \begin{array}{lllllllll}
38.007 & 30.611 & -4.9 & -8.2 & -3.3 & -12.8 & -13.5 & -0.7 & -2.0
\end{array} \\
& \begin{array}{lllllllll}
56.976 & 31.133 & -12.8 & -18.7 & -5.9 & -19.0 & -25.7 & -6.7 & -6.3
\end{array} \\
& \begin{array}{lllllllll}
0.101 & 28.333 & 8.6 & 12.1 & 3.5 & 20.8 & 28.0 & 7.2 & 5.4
\end{array} \\
& 26.698 \quad 27.532 \\
& \begin{array}{lllllllll}
15.148 & 30.099 & 5.7 & 7.7 & 2.0 & 8.1 & 12 & 3.9 & 2.95
\end{array} \\
& \begin{array}{lllllllll}
37.954 & 28.031 & -3.3 & -4.7 & -1.4 & -7.7 & -11.1 & -3.4 & -2.4
\end{array} \\
& \begin{array}{lllllllll}
50.183 & 27.260 & -8.1 & -11.8 & -3.7 & -17.4 & -23.7 & -6.3 & -5.0
\end{array} \\
& 26.492 \quad 27 \cdot 988 \\
& \begin{array}{lllllllll}
5.087 & 28.173 & 9.5 & 12.6 & 3.1 & 21.8 & 26.6 & 4.8 & 3.95
\end{array} \\
& \begin{array}{lllllllll}
15.194 & 30.686 & 2.5 & 2.7 & 0.2 & 11.5 & 15.7 & 4.2 & 2.2
\end{array} \\
& \begin{array}{lllllllll}
38.125 & 27.623 & -5.8 & -8.1 & -2.3 & -5.1 & -8.7 & -3.6 & -2.95
\end{array} \\
& \begin{array}{lllllllll}
51.169 & 25.733 & -9.5 & -14.8 & -5.3 & -12.3 & -19.2 & -6.9 & -6.1
\end{array} \\
& D F_{t}=F_{t}(T)-F_{t}\left(24^{\circ} \mathrm{C}\right) \\
& D T_{t}=T_{t}(T)-T_{t}\left(24^{\circ} \mathrm{C}\right) \\
& D D_{t}=D T_{t}-D F_{t}
\end{aligned}
$$

The same for the bottom side of the two-sided apparatus, indicated by the subscript b. 
Table 3. Percentage Estimate of Uncertalntles in the Measured Apparent Thermal Conductivity for the NBS Guarded Hot Plate*

\begin{tabular}{|c|c|c|c|c|}
\hline \multirow{3}{*}{$\begin{array}{c}\text { Quantitative } \\
\text { Value }\end{array}$} & \multicolumn{4}{|c|}{ Thickness } \\
\hline & $\begin{array}{c}25 \mathrm{~mm} \\
(1 \mathrm{Inch})\end{array}$ & $\begin{array}{c}75 \mathrm{~mm} \\
(3 \text { Inches) }\end{array}$ & $\begin{array}{c}150 \text { min } \\
(6 \text { Inches })\end{array}$ & $\begin{array}{c}300 \mathrm{~mm} \\
(12 \text { Inches })\end{array}$ \\
\hline & \multicolumn{4}{|c|}{ Percent Uncertainty } \\
\hline $\begin{array}{l}\text { Area } \\
(12 \mu \mathrm{m} \text { or } 0.5 \mathrm{mil} \\
\text { In radius }\end{array}$ & 0.01 & 0.01 & 0.01 & 0.01 \\
\hline $\begin{array}{l}\text { Th1ckness } \\
(25 \text { m or } 1.0 \mathrm{mil})\end{array}$ & 0.1 & 0.03 & 0.02 & 0.01 \\
\hline Meter Power & 0.04 & 0.04 & 0.04 & 0.04 \\
\hline $\begin{array}{l}\text { Meter Resistive } \\
\text { Device }(0.4 \mathrm{~mW})\end{array}$ & 0.00 & 0.01 & 0.02 & 0.04 \\
\hline $\begin{array}{l}\text { Gap Heat Flow } \\
(0.3 \mathrm{~mW}, \text { or } 0.5 \mu \mathrm{V} \\
\text { 1n gap voltage })\end{array}$ & 0.00 & 0.01 & 0.02 & 0.03 \\
\hline Edge Heat Flow & 0.00 & 0.00 & 0.00 & 0.50 \\
\hline $\begin{array}{l}\text { Hot, cold-plate } \\
\text { Temperature } \\
\text { Difference ( } 44 \mathrm{mK})\end{array}$ & 0.16 & 0.16 & 0.16 & 0.16 \\
\hline
\end{tabular}
TOTAL
0.31
0.26
0.27
0.79

* These values are for compressible, low-density, glass-fiber insulation measured in the two-sided mode with a plate temperature difference of $28 \mathrm{~K}$. Uncertainty values of less than 0.01 percent are reported as zero. 


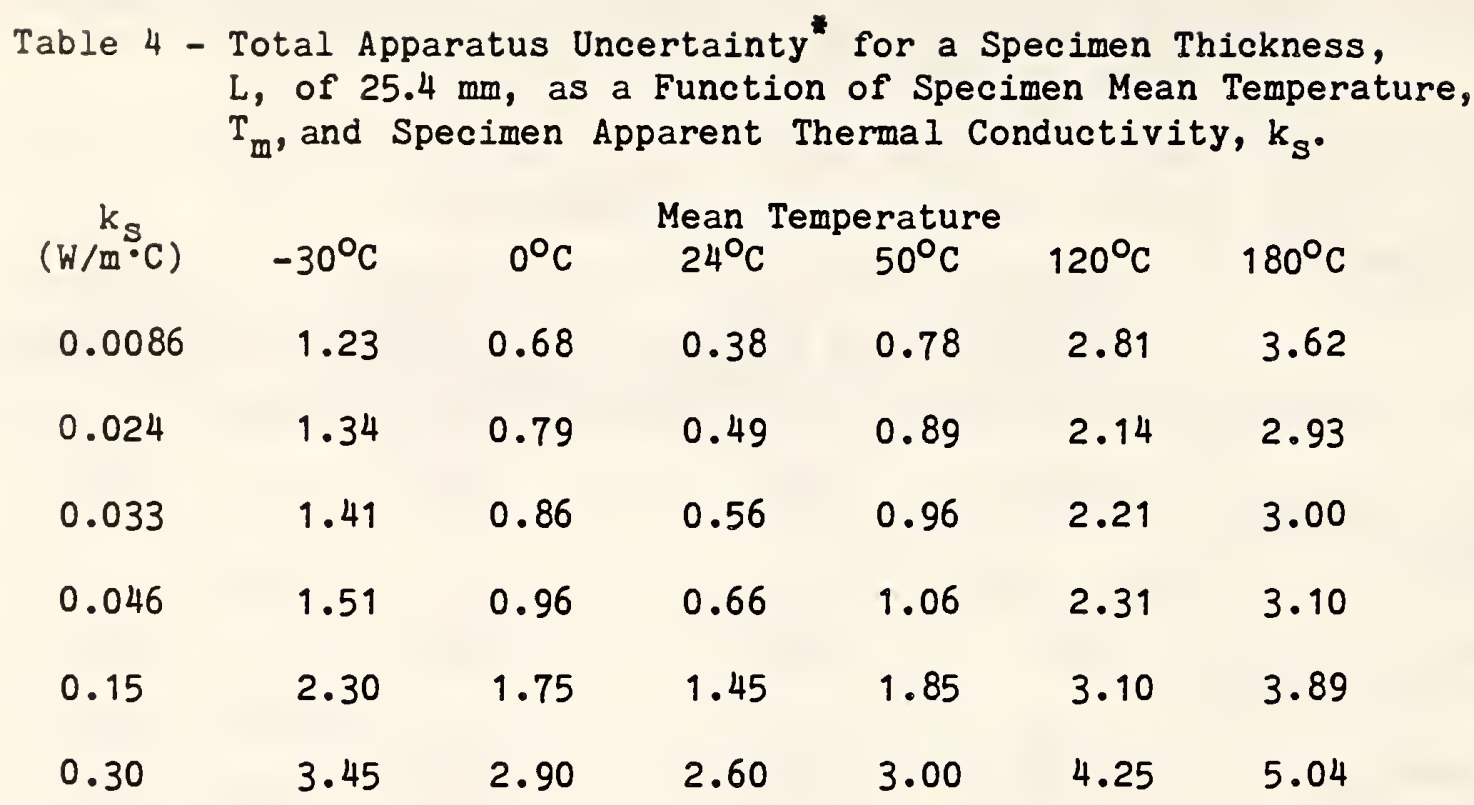

This is for a temperature difference across the specimen of $27.8^{\circ} \mathrm{C}$ and for two-sided operation of the NBS $1-\mathrm{m}$ Guarded Hot Plate. 
Table 5 - Total Apparatus Uncertainty for a Specimen Thickness, $\mathrm{L}$, of $152.4 \mathrm{~mm}$, as a Function of Specimen Mean Temperature, $\mathrm{T}_{\mathrm{m}}$, and Specimen Apparent Thermal Conductivity, $\mathrm{k}_{\mathrm{s}}$.

\begin{tabular}{ccccccc}
$\mathrm{k}_{\mathrm{S}}$ & \multicolumn{5}{c}{ Mean Temperature } \\
$\left(\mathrm{W} / \mathrm{m}^{\circ} \mathrm{C}\right)$ & $-30^{\circ} \mathrm{C}$ & $0^{\circ} \mathrm{C}$ & $24^{\circ} \mathrm{C}$ & $50^{\circ} \mathrm{C}$ & $120^{\circ} \mathrm{C}$ & $180^{\circ} \mathrm{C}$ \\
0.0086 & 0.71 & 0.41 & 0.28 & 0.33 & 0.98 & 2.08 \\
0.024 & 0.73 & 0.43 & 0.30 & 0.35 & 1.00 & 2.90 \\
0.033 & 0.74 & 0.44 & 0.31 & 0.36 & 1.01 & 2.19 \\
0.046 & 0.76 & 0.46 & 0.33 & 0.38 & 1.03 & 2.13 \\
0.15 & 0.89 & 0.59 & 0.46 & 0.51 & 1.16 & 2.26
\end{tabular}

* This is for a temperature difference across the specimen of $27.8^{\circ} \mathrm{C}$ and for two-sided operation of the NBS $1-\mathrm{m}$ Guarded Hot Plate. 
Table 6 - Total Apparatus Uncertainty for a Specimen Thickness, L, of $304.8 \mathrm{~mm}$, as a Function of Specimen Mean Temperature, $\mathrm{T}_{\mathrm{m}}$, and Specimen Apparent Thermal Conductivity, $\mathrm{k}_{\mathrm{s}}$.

\begin{tabular}{ccccccc}
$\mathrm{k}_{\mathrm{S}}$ & \multicolumn{5}{c}{ Mean Temperature } \\
$(\mathrm{W} / \mathrm{m} \cdot \mathrm{C})$ & $-30^{\circ} \mathrm{C}$ & $0^{\circ} \mathrm{C}$ & $24^{\circ} \mathrm{C}$ & $50^{\circ} \mathrm{C}$ & $120^{\circ} \mathrm{C}$ & $180^{\circ} \mathrm{C}$ \\
0.0086 & 1.07 & 0.79 & 0.68 & 0.71 & 1.31 & 2.36 \\
0.024 & 0.97 & 0.69 & 0.58 & 0.61 & 1.21 & 2.26 \\
0.033 & 0.92 & 0.64 & 0.53 & 0.56 & 1.16 & 2.21 \\
0.046 & 0.89 & 0.61 & 0.50 & 0.53 & 1.13 & 2.18
\end{tabular}

* This is for a temperature difference across the specimen of $27.8^{\circ} \mathrm{C}$ and for two-sided operation of the NBS $1-\mathrm{m}$ Guarded Hot Plate. 
Table 7 - Total Apparatus Uncertainty for a Specimen Thickness, L, of $381 \mathrm{~mm}$, as a Function of Specimen Mean Temperature, $\mathrm{T}_{\mathrm{m}}$, and Specimen Apparent Thermal Conductivity, $\mathrm{k}_{\mathrm{S}}$.

\begin{tabular}{ccccccc}
$\mathrm{k}_{\mathrm{S}}$ & \multicolumn{5}{c}{ Mean Temperature } \\
$\left(\mathrm{W} / \mathrm{m}{ }^{\circ} \mathrm{K}\right)$ & $-30^{\circ} \mathrm{C}$ & $0^{\circ} \mathrm{C}$ & $24^{\circ} \mathrm{C}$ & $50^{\circ} \mathrm{C}$ & $120^{\circ} \mathrm{C}$ & $180^{\circ} \mathrm{C}$ \\
0.0086 & 1.55 & 1.28 & 1.17 & 1.20 & 1.78 & 2.82 \\
0.024 & 1.41 & 1.14 & 1.03 & 1.06 & 1.64 & 2.68 \\
0.033 & 1.30 & 1.03 & 0.92 & 0.95 & 1.53 & 2.57 \\
0.046 & 1.27 & 1.00 & 0.89 & 0.92 & 1.50 & 2.54
\end{tabular}

* This is for a temperature difference across the specimen of $27.8^{\circ} \mathrm{C}$ and for two-sided operation of the NBS 1-m Guarded Hot Plate. 

Table 8 - Data of Apparent Thermal Conductivity as a Function of
Specimen Mean Temperature, $\mathrm{T}_{\mathrm{m}}$.

$\begin{array}{lccc}\text { Material } & \text { Density }\left(\mathrm{kg} / \mathrm{m}^{3}\right) & \mathrm{T}_{\mathrm{m}}\left({ }^{\circ} \mathrm{C}\right) & \mathrm{k} \text {-value }(\mathrm{W} / \mathrm{m} \cdot \mathrm{K}) \\ \text { Wood } & 415 & 37.5 & 0.12448 \\ & & 23.9 & 0.11133 \\ & & 10.0 & 0.09320 \\ \text { Polystyrene } & 17 & 37.4 & 0.04481 \\ & & 24.1 & 0.04286 \\ & & -6.3 & 0.03808 \\ \text { Glass-fiber } & 13 & 37.8 & 0.04012 \\ & & 15.6 & 0.03587 \\ & & 4.4 & 0.03378 \\ & & -8.8 & 0.03136 \\ \text { Polyisocyanurate } & 40 & 37.7 & 0.02571 \\ & & 30.0 & 0.02516 \\ & & 23.9 & 0.02448 \\ & & 15.5 & 0.02287\end{array}$


Table 9 - Apparent Thermal Conductivity as a Function of Specimen Mean Temperature, $\mathrm{T}_{m}$, Data Measured on the NBS 1-m GHP Apparatus.

\begin{tabular}{|c|c|c|c|c|}
\hline Material & Density $\left(\mathrm{kg} / \mathrm{m}^{3}\right)$ & $\mathrm{T}_{\mathrm{m}}\left({ }^{\circ} \mathrm{C}\right)$ & kovalue $\left(W / m^{\circ} K\right)$ & Pressure (mo \\
\hline Glass-fiber & 12 & $\begin{array}{r}37.8 \\
23.9 \\
0.1\end{array}$ & $\begin{array}{l}0.04681 \\
0.04265 \\
0.03638\end{array}$ & \\
\hline Glass-fiber & 15 & $\begin{array}{r}37.9 \\
23.9 \\
0.0\end{array}$ & $\begin{array}{l}0.04382 \\
0.04019 \\
0.03473\end{array}$ & \\
\hline
\end{tabular}

Expanded-

Polystyrene

25

37.7

23.9

0.03730

10.0

0.03558

0.0

0.03375

0.03247

High-density

Glass-fiber

114

37.7

0.03363

23.9

0.03195

10.0

0.02992

0.2

0.02941

Min-K

320

55.0

0.02663

38.9

0.02588

29.612

23.9

0.02541

29.454

$-0.4$

0.02462

29.437

29.574

Polyisocyanurate 40

46.6

0.02718

37.7

0.02571

15.5

0.02287

4.5

0.02234

$-8.7$

0.02391 
Table 10 - Apparent Thermal Conductivity as a Function of Specimen Thickness, L, Data Measured on the NBS 1-m GHP Apparatus for a Mean Temperature of $23.9^{\circ} \mathrm{C}$ and a Temperature Difference of $27.8^{\circ} \mathrm{C}$.

Bulk

Material

Glass-fiber

Glass-fiber

Extruded

Polystyrene
Density

$\left(\mathrm{kg} / \mathrm{m}^{3}\right)$

9.6

19.2

32

\begin{tabular}{|c|c|c|}
\hline$(\mathrm{mm})^{\mathrm{Th}}$ & Thickness & $\begin{array}{l}k-v a l u e \\
(W / m \cdot K)\end{array}$ \\
\hline $\begin{array}{r}152.4 \\
76.2 \\
25.0\end{array}$ & $\begin{array}{l}6 \\
3 \\
1\end{array}$ & $\begin{array}{l}0.04752 \\
0.04721 \\
0.04554\end{array}$ \\
\hline $\begin{array}{r}101.6 \\
76.2 \\
50.8 \\
25.4\end{array}$ & $\begin{array}{l}4 \\
3 \\
2 \\
1\end{array}$ & $\begin{array}{l}0.0377 \\
0.0376 \\
0.0377 \\
0.0374\end{array}$ \\
\hline
\end{tabular}

$$
\begin{array}{r}
381.0 \\
342.9 \\
304.8 \\
254.0 \\
203.2 \\
152.4 \\
101.6 \\
50.8
\end{array}
$$

15
$13 \cdot 5$
12
10
8
6
4
2

0.02929

0.02917

0.02905

0.02884

0.02911

0.02901

0.02890

0.02873 
Table 11 - Data of the Percent Difference Between the Average $k$-value of the Individual Layers in a Stacked Specimen and the Actually Measured kovalue of the Stacked Specimen.

\begin{tabular}{ccc}
\multicolumn{2}{c}{ Thickness } \\
$(\mathrm{mm})$ & (in) & $\frac{\mathrm{R}_{0}-\mathrm{R}_{\mathrm{m}}}{\mathrm{R}_{\mathrm{e}}} \times 100$ \\
102 & 4 & $0.2 \%$ \\
154 & 6 & $0.3 \%$ \\
205 & 8 & $0.6 \%$ \\
257 & 10 & $-0.5 \%$ \\
309 & 12 & $0.2 \%$ \\
345 & 13.5 & $0.6 \%$ \\
389 & 15 & $0.6 \%$
\end{tabular}





\section{Appendix 1}

Copy of reference [4]. 
THE NBS LINE-HEAT-SOURCE GUARDED ROT PLATE FOR THICK MATERIALS

Frank J. Powell

Brian G. Rennex

\section{ABSTRACT}

The use of thicker thermal insulation material with greater themal resistance resulted in a need for the National Bureau of Standards to produce new apparatus for absolute measurement of the themal resistance of thick insulation samples to be used as transfer standards. These standards are used to calibrate or verify heat-flowneter (ASTM C-518) or guarded-hot-plate (ASTM 6-177) equipment.

This paper gives the background and description of the line-source heater in the hot plate and discusses the need to measure thick samples. The actually constructed apparatus is described, with emphasis given to innovative features. The data-acquisition system is discussed and data are presented. Finally. a sumary of the error analysis is presented, indicat. ing an overall absolute uncertainty of less than +18 in the measured themal conductivity.

The hot plate is made of aluminum and has a 40-in. (1-m) diameter and a 16-in. (406 m) measuring diameter, and contains circular line-source electric resistance heaters. The plates are housed in an environmental chamber that can be rotaked for vertical or horizontal measurements on a pair of specimens up to $15-i n .(380-m)$ thick. The range of material themal conductivity that can be measured is 0.14 to $2.1 \mathrm{Btu} \cdot \mathrm{in} / \mathrm{hr} \cdot \mathrm{ft} 2 .^{\circ} \mathrm{F}(0.02$ to $0.30 \mathrm{~W} / \mathrm{m} \cdot \mathrm{K})$. The hot plate can be controlled over the temperature range of -4 to $302^{\circ} \mathrm{F}\left(-20\right.$ to $\left.150^{\circ} \mathrm{C}\right)$ and the cold plates cover a range from -40 to $212^{\circ} \mathrm{F}\left(-40\right.$ to $\left.100^{\circ} \mathrm{C}\right)$.

\section{INTRODUCTION}

The purpose of this paper is to briefly describe the 40-in. (1016-m) National Bureau of Standards (NBS) guarded-hot-plate (GHP) apparatus in terms of its actual construction. its data acquisition capability, and its absolute accuracy. Earlier papers have presented a detailed analysis of the temperature distribution expected with the line-source heaterl and a detailed error analysis.?

The guarded-hot-plate apparatus is used worldwide to determine themal conductivity and themal resistance of themal insulation and building materials. The first apparatus at NES was designed in 1909 and construction was completed in 1912.3 The test method has been standardized in several countries 4,5,6 and the International Standards Organization (ISO). technical cormittee 163, thermal insulation. is in the process of producing an international standard method of test.

Many guarded-hot-plate apparatuses are made by uniformly distributing an electric resistance heater winding over a square or rectangular laminated metal hot plate. This construction has several disadvantages: (1) construction and repair are complicated and difficult. (2) differential thermal expansion can cause warpage of the plate, resulting in inaccurate measurement of specimen thickness and nonuniform themal contact between the specimen and the plate. (3) repeated thenmal cycling can'lead to permanent plate deformation.

Frank J. Powell and Brian G. Rennex. Mational Bureau of Standards, Washington, DC 20234. 
(4) the location of the gap themopile for one-sided tests is problematical, and (5) square corners make nathendical ana?ysis difficult.

Ideas to overcone these difficulties were presented by Robinson in 1964.7 These Ideas involvec the use of a circular metal hot plate containing a line-source electric resistance heaier. Analysis was glven to show that the circular line-source heater could be located at such a racius that the temperature at the outside edge of the meter area (on the meter side of the $g a p)$ wold be equal to the average temperature of the entire meter areas. Thus. plate surface temperature measurements would not be necessary.

In 1971. under the sponsorship of KBS. Hahn completed an in-depth analysis of these ideas and examined several design options. 8 The concept, mathenatical analysis, and proposed design-fex:ures were published in Ref. 2. The development of a prototype line-source apparatus and its description and results of measureinents were reported 10 before undertaking the design and construction of the 40-in. (10:6 mm) apparatus under discussion here.

Many guarded-hot-plate apparatuses were designed to accommodate test samples of 1 or 2-in. (25 or $50-m)$ thicknesses. Such equipment was satisfactory, provided the value of themal resistance obtained for a $1-i n$. $(25-\mathrm{mm})$ thick sample could be used to calculate the value of themal resistance for thicker materials by linear extrapolation. With the use of greater thicknesses of insulation to reduce building heating and cooling energy consumption, it becane necessary to know more precisely the thermal resistance of thick insulations (up to 12-in. [300 $\mathrm{m}$ ] thick products are available). In the case of low-density fiberglass insulation, there were indications that linear extrapolation from a $1-1 \mathrm{n}$. (25-m) thick sample could be in error. The themal testing community and manufacturing industry required thick specimens to calibrate their guarded-hot-plate and heat flowneter apparatuses. Furthermore, the test methods of the Anerican Society for Testing and Materials (ASTM) required calibration with transfer standards traceable to a national standards laboratory, and the Federal Trade Comission promulgated a rule requiring that advertised themal resistance values be derived from a "representative thickness" of the material. Representative thickness was defined as the thickness of material whose measured themal resistance can be extrapolated linearly to obtain a themal resistance at a greater thickness that is within $\pm 2 \%$ of the measured value of the thick material.

This paper presents a technical description of the as-bullt NBS line-source, 40-in. (1015-m) dianeter guarded-hot-plate apparatus, with emphasis given to innovative features. Sanple results and data that indicate that the absolute uncertainty of measured thermal resistance values is +1\% are given. The development of the equipment was jointly sponsored by the National Bureau of Standards and the Department of Energy and was supported by a research associate from the Mineral Insulation Manufacturers Assoctation.

\section{PRINCIPLE OF MEASUREMENT}

The principle of measurenent of a guarded-hot-plate is 11 lustrated in Fig. 1. Electric power is supplied to the meter heater and guard heaters to mainta in constant and equal temperatures of each of these plates. The guard and meter sections of the hot plate are separated by an air gap. Differential themocouples are connected across the air gap to indicate whether heat is flowing radially across the gap. The electric power to the guard heaters is controlled to maintain net gap heat flow as nearly as possible to zero. The cold plates are controlled to produce a constant, uniform surface temperature. Under these steady conditions heat flows unidirectionally from the meter plate to the cold plates. A layer of themal insulation surrounds the peripheral edges of the specimens. If none of the heat produced by the meter plate is lost to the guard heater (or gained from the guard plate) or transferred from or to the environnent surrounding the plates, the following steady-state relationship can be used to detemine the total themal resistance of both specimens (assuming the heater power. Q, is split evenly between the two sides):

$$
R=\frac{A\left(T_{h}-T_{c}\right)}{(Q / 2)}
$$

mere

$$
\begin{aligned}
& R=\text { total sample themal resistance of thickness } L^{n} \text { in. }(m), f t^{2} \cdot h r \cdot \bullet F / B t u\left(m^{2} / K \cdot H\right) \\
& A=\text { metered area, in. }{ }^{\circ}\left(m^{2}\right) \\
& T_{h}=\text { average temperature over the meter section of the hot plate, } \bullet F(K)
\end{aligned}
$$


$T_{c}=$ average cold plate temperature ${ }^{\circ} F(K)$

$\checkmark$ - electrical energy consumed by the meter plate to maintain its temperature, $W$

By definition, the apparent themal conductivity, $\lambda_{3}$ is

$$
\lambda=L / R
$$

It is possible to operate the hot-plate apparatus with one of the cooled plates maintained at the same temperature as the hot plate. In this case, a single specimen is measured instead of a pair of specimens. This brief explanation of the principle of measurement was given to enable to reader to see the various sources of measurenent uncertainty surmarized later.

\section{DESCRIPTION OF APPARATUS}

Hot Plate

The hot plate is circular and has a uniform thickness of $0.635 \mathrm{in}$. (16.13 mm). it is made of type 6061-T6 aluminum, Fig. 2. The center part is a solid diameter 11.299 in. $(287.0 \mathrm{~mm})$. A comercially available nichrome ribbon heater $(-4 \mathrm{mil}[0.1 \mathrm{~mm}$ ] thick and $160 \mathrm{mil}$ [4 mm wide]) encased in plastic surrounds the edge of the center. The circular ribbon heater is referred to as a line-heat-source hot-plate design. The section surrounding the center part has an inside dianeter of $11.299 \mathrm{in}$. $(287.0 \mathrm{~mm})$ and an outside diameter of $15.970 \mathrm{in}$. (405.6 $\mathrm{mm})$. These two inner sections comprise the heated, metered area of the hot plate. When fabricated, the center part was cooled to liquid nitrogen temperature and placed inside the outer section (held at room temperature), with the nichrone heater between, forming a shrinkofit assembly. Three equally spaced pins (120 mil [3 $\mathrm{mm}]$ dianeter stainless-steel) are used to support the meter-area part within the guard ring as shown in Fig. 2. The guard ring has an inner diameter of $16.040 \mathrm{in} .(407.4 \mathrm{~mm}$ ) and an outer dianeter of 40.000 in. (1016 mm). The gap between the guard and meter-area parts is $35 \mathrm{mil}(0.9 \mathrm{~mm})$ wide. There are two circulap heaters on each side of the guard surface at dianeters of $20.658 \mathrm{in}$. $(524.7 \mathrm{~mm})$ and $31.584 \mathrm{in}$. ( $(2 . \mathrm{mm})$. These are located in circular grooves, cut into the guard surface, and are embe: " in epoxy. Several holes (160 mil [4 $\mathrm{mm}$ ] in dianeter) penetrate the guard ring from its ol: : ese to the gap to permit access for themistor, heater leads, platinum resistance themome: $r_{\text {, }}$ and themocouple wires. The plate thickness of $0.635 \mathrm{in}$. $(16.13 \mathrm{~mm})$ was selected as a balance between a desired large thickness with great structural pigidity and a small thickness with less heat capacity. The plate surfaces are black anodized to achieve a nomal, visible emittance value of $0.89 \pm 0.01$.

The gap shape was chosen to allow maximum gap volume and a greater thermal reststance across the gap. without having too large a plate-surface gap separation with its accompanying potential for a larger uncertainty in meter-area value. The measured flatness of the meterarea is $\pm 1 \mathrm{mil}(25 \mathrm{Lm})$ across its diameter.

The design mathematical analysis, and experimental results related to the line heat source are discussed in Refs 1 and 2. For a $1-i n$. $(25-\mathrm{mm})$ thick sample with a heat flowrate per unit area of $-28 \mathrm{Btu} / \mathrm{hr} \cdot \mathrm{ft} 2\left(90 \mathrm{~W} / \mathrm{m}^{2}\right)$ and a hot-to-cold-plate temperature difference of $50^{\circ} \mathrm{F}$ $(28 \mathrm{~K})$, the measured temperature difference between that of the hot plate surface at the linesource-heater location and that of the plate center was $180 \mathrm{mF}(60 \mathrm{mK})$. Thus, the results given in Ref $I$ indicate the plate temperature is quite uniform. In addition, the temperature at the outside edge of the meter section (at a radius of 7.985 in. [202.8 mm]) was equal to the average temperature over the entire meter area, within the 1 imits of the measurenent accuracy $(\sim 27 \mathrm{mF}$ or $15 \mathrm{mK})$. This result justifies the use of a platinum resistance thermometer at the edge of the meter section (inside the gap on the meter side) to determine the average absolute temperature of the meter area.

\section{Cold Plates}

The construction of the liquid (ethylene glycol) cooled cold plates is show in Fig. 3. Each aluminum plate is $1 \mathrm{in.}(25.4 \mathrm{~mm})$ thick and consists of a $0.25 \mathrm{in}$. $(6.4 \mathrm{~mm})$ thick cover plate bonded with epoxy to a $0.75 \mathrm{in}$. $(19.0 \mathrm{~mm})$ thick base plate. The base plate contains milled grooves $0.375 \mathrm{in}$. $(9.5 \mathrm{~mm})$ deep and $0.375 \mathrm{in} .(9.5 \mathrm{~mm})$ wide arranged in a double-spiral configuration. This arrangement allows leak-tight counterflow channels in wich the incoming coolant passes next to outgoing coolant for a more uniform temperature distribution over the cold-plate surface. A $0.125-i n$. $(3.2-\mathrm{mm})$ dfameter hole was bored from the side to within $2.5 \mathrm{in}$. $(63 \mathrm{~mm})$ of the plate center to provide access for platinum resistance themometer. 
which is used to measure the absolute temperature of the cold plates. The backs and edges of the cold plates are insulated with $4 \mathrm{in}$. (102 m) thick expanded polystyrene.

Sugforting Structure

Figures 4 and 5 show how the three plates are supported by four stainiess-steel rods of 2-in. $(51-m)$ diameter. The rods are mounted in an airtight insulated chamber for enviromental control.

The hot plate is rigidly and permanently mounted on the four support rods. Each cold plate is supported at its center, and, at the point of support, has a load cell to measure the force that the sample exerts on the plate. This support has a ball joint so that the plate can tilt to conform to a nonparallel rigid sample. The cold plates are constrained in the radial direction by steel cables attached to four spring loaded bearings mounted on the hotplate support rods. This construction ensures that the plates remain aligned when the whole of the apparatus is rotated $180^{\circ}$ in either direction.

Environnental Chamber

The enviromental chanber is cube-shaped and $5.2 \mathrm{ft}(1.6 \mathrm{~m})$ on an inner side (see Fig. 4). The inside and outside surfaces are of sheet aluminum, and the core consists of $3 \mathrm{in}$. (75 m) thick expanded polystyrene insulation. Rigidity is provided by $2-i n$. $(50-m)$ square box-bean menbers. The plate-support rods are secured at the top only, to hang within the chamber. Axles extending fron the center of two opposite sides are mounted on gimbals, allowing $180^{\circ}$ rotasion of the entire apparatus. Full access to the plates is allowed by doors on both the front and back of the chamber. The temperature within the chamber is maintained at the desired value $\left( \pm 2^{\circ} \mathrm{F}\right.$ or $\left.1 \mathrm{~K}\right)$ using a platinum resistance themoneter and a feedback circuit to control a heater that loads a constant cooling heat exchanger. The present operating range is 0 to $150^{\circ} \mathrm{F}(273$ to $340 \mathrm{~K})$.

\section{Thickness Measurement}

The thickness, L, in Eq 2 is the average, over the meter area, of the spacing between the hot and cold plates. The basic calibration methodl involves measuring the hot-to-cold spacings at the outside edges of the cold plates at four equally spaced positions. The four spacings are correlated with a "known meter-area plate separation," which is detemined with a direct measurement of the thickness in the center of the plates, using an independent set of temporarily mounted thickness transducers accurate to within $0.3 \mathrm{mils}(7 \mathrm{~mm})$.

The outside cold-plate positions are measured using four permanently mounted thickness transducers on each plate. These thickness transducers measure any change in position relative to the initial reference point. The calibration must be done for each plate orientation and for compressible and rigid samples.

These four permanently mounted thickness transducers are mounted on Invar bars to minimize error resulting from ambient temperature variation and measure the average spacing with a repeatability of $0.2 \mathrm{mils}(5 \mathrm{~mm})$. Thus, the thickness can be measured continuously during a test as temperature testing conditions change, an improvenent over the procedure of measuring thicknesses only at the beginning and end of each test.

\section{Plate Temperature Control}

The plate temperatures are controlled with feedback circults. Thermistors are used in these circuits because of their large change in resistance with temperature. A thermistor is located in each of the hot and cold plates. In addition, pairs of themistors are used to control the temperatures between the gap and the outer guard. (The "gap" readout, however, is accomplished with a thermopile.) For the NBS/GHP apparatus the hot-plate temperature can be controlled to within a range of $2 \mathrm{mF}(1 \mathrm{mK})$. the cold plate temperatures to within $12 \mathrm{mF}(6 \mathrm{mK})$, and the average temperature difference across the gap to within $2 \mathrm{mF}(1 \mathrm{mK})$. A microprocessor is used in conjunction with the feedback circuit to automatically bring the plate temperatures to a desired value. The use of thermistor control circuits makes it possible to achieve steady-state test conditions within 3 hours for low-density, 6-in. (150-min) thick samples.

The steady-state value of apparent thermal conductivity is achieved in the constant hot. plate temperature mode, rather than a constant meter-area-heater power mode. This factor is important for the reduction of test times. Note that because the control range of the hot-plate 
temperature and the corresponding control range of the meter pover is very small. the accuracy of the final steady-state value of the apparent themal conductivity is not compromised by using the consiant-temperature mode.

DATA ACQUISITION AND DOCUMENTATION

\section{Automatic Data Acquisition}

The control of plate temperatures and data acquisition is acconplished with microprocessor. The selected plate temperatures are entered, and the computer reads tenperatures as measured with platinum resistance themoneters. These values and a control algorithm are used to bring the temperatures to the desired values. Raw data consist of readings of number of voltages. A scanner selects the voltage to be read by digital voltmeter. When complete scan is made of all the required voltages, the infomation is transmitted to desk calculator-computer and stored on a cassette tape.

The desk calculator also produces plots of the important dats as function of time, such as plate temperatures or hot-plate power. Figs. 6-10. Note that the steady-state values on these figures lie within a narrow band (for example. $0.05 \%$ for the apparent themal conduc. tivity, i). This short-tem scatter is mostly due to the power change requiped by the meter. area heater to maintain the hot plate at a constant temperature. The hot plate is in turn responding to the short-term changes in the cold-plate baths, ultimately causing most of the short-term scatter in $\lambda$. However, the mean value of $\lambda$ over several hours is known much better than within the $0.05 \%$ band (drifts in mean value of $-0.01 \%$ can be detected). Stated differently, the short-term scatter contributes a negligible amount to the uncertainty in $\lambda$. as long as the steady-state interval is several hours long. Rather, it is the data drifts over a period of about one day or more, as well as the systenatic errors, that contribute significantly to the uncertainty in $\lambda$. The time piots are invaluable for ascertaining that the test is in steady state. meaning that there is no monotonic change over time in the measured mean value of $\lambda$.

\section{Sample Report}

A sample of reported data, shown in Fig. 11, illustrates the standard data that are transmitted to a user when an insulation standard is measured at the National Bureau of Standards. This includes infomation on sample identification and on test conditions that should be reproduced by the user laboratory undertaking equipment verification or calibration.

\section{SUMMARY OF ERROR ANALYSIS}

\section{Method of Suming Individual Uncertainties}

The apparent themal conductivity and the themal resistance of an insulation sample are calculated quantities based on several measured parameters. Each of these measured parameters has an associated uncertainty. In turn, this uncertainty has a random and a systematic part. It is possible to estimate the uncertainty of each parameter by an independent test. For example, the apparatus thickness readout can be compared with a thickness gauge placed between the plates. It is less straightforward to estimate the overall uncertainty of the calculated quantity. because there is usually not sufficient information on the breakdown between the random and systematic parts of the uncertainty for each individual parameter. In principle, it is possible to gather this information, but in practice it would be too time consuming.

A more simple and practical approach was used in this error analysis. The tndividual paraneters. such as the thickness or temperature distribution over the meter area, were measured with an independent detector under test conditions. A comparison of the apparatus readout with these independent measured values made possible the estimate of the upper bound on the total uncertainty for each parameter. Since there is not sufficient information to assure that the measured values are randomly distributed about a "true" mean value, the upper bounds for each individual parameter are simply sumed to arrive at the overall uncertainty. This approach differs from an alternative approach in wich the uncertainties are treated as standard deviations that are then added in quadrature. 1.e.. the total uncertainty is the square root of the sum of the squares of the individual uncertainties. The method of simple addition results in a sonewhat larger estimate of the overall uncertainty (by as much as 30\%) as compared with the method to sum in quadrature). but it eliminates the need to make an inordinate number of checkup measurements to assure that there are no outlier values. This more conservative approach is thought by the authors to be appropriate for use by a national insulation standards iaboratory. 
The following phllosophy was used with regard to the estimate of upper bounds. Even if an unceriainty might have been expected to be smaller. based on theoretical considerations and manufacturer specifications, the uncertainty value actually used was that of the detector making the independent check. For example, the plate temperature might very well be known within 10 or $20 \mathrm{mF}$ ( 5 or $10 \mathrm{mK}$ ). The uncertainty value actually used--44 mF (22 mK)--was associated with the thermopile used independently to check the plate temperature.

It is posstble to estimate the overall random uncertainty, as the range of values of repeated measurenents on the saine sample with the same apparatus. This range within a period of several months for the NBS 40-in. (1016-mm) GHP apparatus at a thickness of 4 in. (100 um) was within 0.12 .

Generally speaking, the data on a single test are of two parts. The transient part at the beginning of the test shows an increasing or decreasing curve. When there is no monotonic trend, the steady-state condition has been achieved. There is st 111 a scatter of data points, due mostly to the cycling of the bath temperatures. The scatter band is about $2 \mathrm{mF}$ ( $1 \mathrm{mK}$ ) for the hot-plate temperature, $12 \mathrm{mF}(6 \mathrm{mK})$ for the cold-plate temperatures, and $1 \mathrm{~mW}$ for the power. The scatter in the calculated $\lambda$-value is about $0.01 \%$ for a two-sided. 1 in. (25 mm) sample and 0.03: for a two-sided, 6-in. $(150-\mathrm{mm})$ sample. The mean $\lambda$-value is known even better. The scatter in the data points, after the steady-state condition has been attained, is negligible compared to the estimated systenatic errors in $\lambda$.

\section{Individual Contributions to the Apparatus Uncertainty}

Table I shows the contributions to uncertainty for the individual measured parameters such as the thickness or heat flow; the overall uncertainty values are also shown for various thicknesses. The methods of estimating these uncertainties are discussed in detail in Ref 10 . This sumary of uncertainties is for the case of compressible insulation samples at a mean temperature of $75^{\circ} \mathrm{F}(297 \mathrm{~K})$ and a plate-temperature difference of $50^{\circ} \mathrm{F}(27 \mathrm{~K})$. Note that at a thickness of $1 \mathrm{in.}(25 \mathrm{~mm})$. the temperature and thickness uncertainties are largest. At $6 \mathrm{in.}(150 \mathrm{~mm})$, the temperature is the only large uncertainty. At $12 \mathrm{in.}$ ( $300 \mathrm{~mm}$ ) the edge uncertainty is dominant. The gap-voltage uncertainty was kept small, even at $12 \mathrm{in}$. (300 m). by using an 18-stage gap themopile, low-themal wiring, and a highly accurate voltmeter. The overall uncertainty value is about 0.37 up to a 6 -in. (150 mm) thickness. At 12 in. $(300 \mathrm{~mm})$. it should be possible to decrease the uncertainty with further edge studies.

\section{CONCLUSIONS}

A description of the as-built NBS I ine-source guarded-hot-plate apparatus capable of measuring the thermal resistance of specimens of themal insulation and building materials up to 15 in. (380 $\mathrm{mm})$ thick is presented. The apparatus conforms to ASTM Standard C-177-76. "Standard Test Meihod for Steady-State Thermal Transmission Properties by means of the Guarced Hot Plate." Experience with the apparatus and the results of uncertainty analyses justifies the conclusion that the KBS apparatus is a viable means for measuring absolute values of thermal resistance to an uncertainty of \pm 18 .

\section{REFERENCES}

1. B. Rennex, Error Analysis for the NBS $1016 \mathrm{~mm}$ Guarded Hot Plate, National Bureau of St andards Report KESIR-65-20/4 (hashingion: KES, 1983).

2. M. H. Hahn, H. E. Robinson, and D. R. Flynn, -Robinson Line-Heat-Source Guarded-Hot-Plate Apparatus. - Special Technical Publication 544 (Philadelphia: American Society for Testing and Materials, 1974), p. 167-192.

3. Paul R. Achenbach, Building Research at the National Bureau of Standards Through 1968. MBS Bullding Science Series, BSS O (washington: NBS, 1970). P. 11.

4. American Society for Testing and Materials, 1982 Annual Book of ASTM Standards, (Philadelphia: Anerican Society for Testing and Materials, 1982), part 18, p. $20-53$.

5. British Standards Institute, Methods for Determining Thermal Propertles. B.5. 874 (London: British Standards Institute).

6. Bestimung der Harmeleitfahigkelt inft der Plattengerat, OIN 52612 (Berlin: Deutsch Nomenausschusst. 
7. R. P. Tye, Nature 204 (1964).

8. M. H. Hahn, The Line Heat Source Guardeo Hot Plate for Measuring the Themal Conductivity of Building and Insulating Materials" Ph.D. dissertation, Catholic University of Anerica, 1971.

9. F. J. Powell and M. C. I. Siu, "Development of the Robinson Line-Heat-Source Guarded-HotPlate Apparatus for Measurement of Themal Conductivity. Proceedings of XIV International Congress of Refrigeration (Hoscow: International Institute of Refrigeration. 1975)。

10. M. Go I. Stu and C. Bulik. National Bureau of Standards Line Heat Source Guarded Hot Plate Apparatus, Review of Seientific Instruments 52:11 (Novo 1981) P. 1709-1716. 
TABLE 1

Percentage Estimate of Uncertainties in the Measured Apparent Thermal Conductivity for the IBS Cuarded Hot Plate

\begin{tabular}{|c|c|c|c|c|}
\hline \multirow{3}{*}{$\begin{array}{c}\text { Quentitative } \\
\text { Value }\end{array}$} & \multicolumn{4}{|c|}{ Thickness } \\
\hline & $\begin{array}{l}1 \text { in. } \\
(25 \mathrm{~mm})\end{array}$ & $\begin{array}{l}3 \mathrm{in.} \\
(75 \mathrm{~min})\end{array}$ & $\begin{array}{c}6 \mathrm{in} \\
(150 \mathrm{~mm})\end{array}$ & $\begin{array}{c}12 \text { in. } \\
(300 \mathrm{~mm})\end{array}$ \\
\hline & \multicolumn{4}{|c|}{ Uncertainty, } \\
\hline $\begin{array}{l}\text { Area } \\
(0.5 \text { mil or } 12 \text { w } \\
\text { in radius })\end{array}$ & 0.01 & 0.01 & 0.01 & 0.01 \\
\hline $\begin{array}{l}\text { Thickness } \\
(1.0 \mathrm{mil} \text { or } 25 \mathrm{~mm})\end{array}$ & 0.1 & 0.03 & 0.02 & 0.01 \\
\hline Meter power & 0.04 & 0.04 & 0.04 & 0.04 \\
\hline $\begin{array}{l}\text { Meter resistive } \\
\text { Device }(0.4 \mathrm{~mW})\end{array}$ & 0.00 & 0.01 & 0.02 & 0.04 \\
\hline $\begin{array}{l}\text { Gap heat flow } \\
(0.3 \mathrm{~mW} \text {, or } 0.5 \mathrm{uV} \\
\text { in gap voltage) }\end{array}$ & 0.00 & 0.01 & 0.02 & 0.03 \\
\hline Edge heat flow & 0.00 & 0.00 & 0.00 & 0.50 \\
\hline $\begin{array}{l}\text { Hot, cold-plate } \\
\text { temperature } \\
\text { difference } \\
\left(79 \mathrm{~m}^{\circ} \mathrm{F} \text { or } 44 \mathrm{mk}\right)\end{array}$ & 0.16 & 0.16 & 0.26 & 0.16 \\
\hline TOTAL & 0.31 & 0.26 & 0.27 & 0.79 \\
\hline
\end{tabular}


Figure 1. Principle of measurenent

Figure 2. Hot plate

Figure 3. Cold plate

Figure 4. Drawing showing rotatable support system for hot and cold piates

Figure 5: Photo of support systems for hot and cold plates

Figure 6. Hot plate temperature

Figure 7. Cold plate temperature

Figure 8. Meter-area power

Figure 9. Gap voltage

Figure 10. Apparent themal conductivity

Figure 11. Sample report 


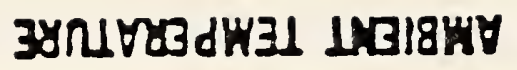

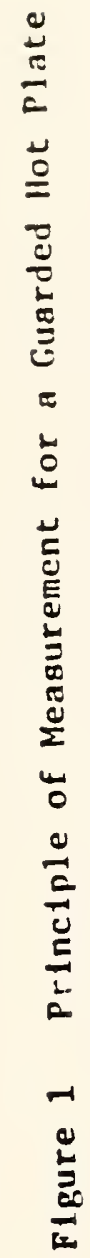

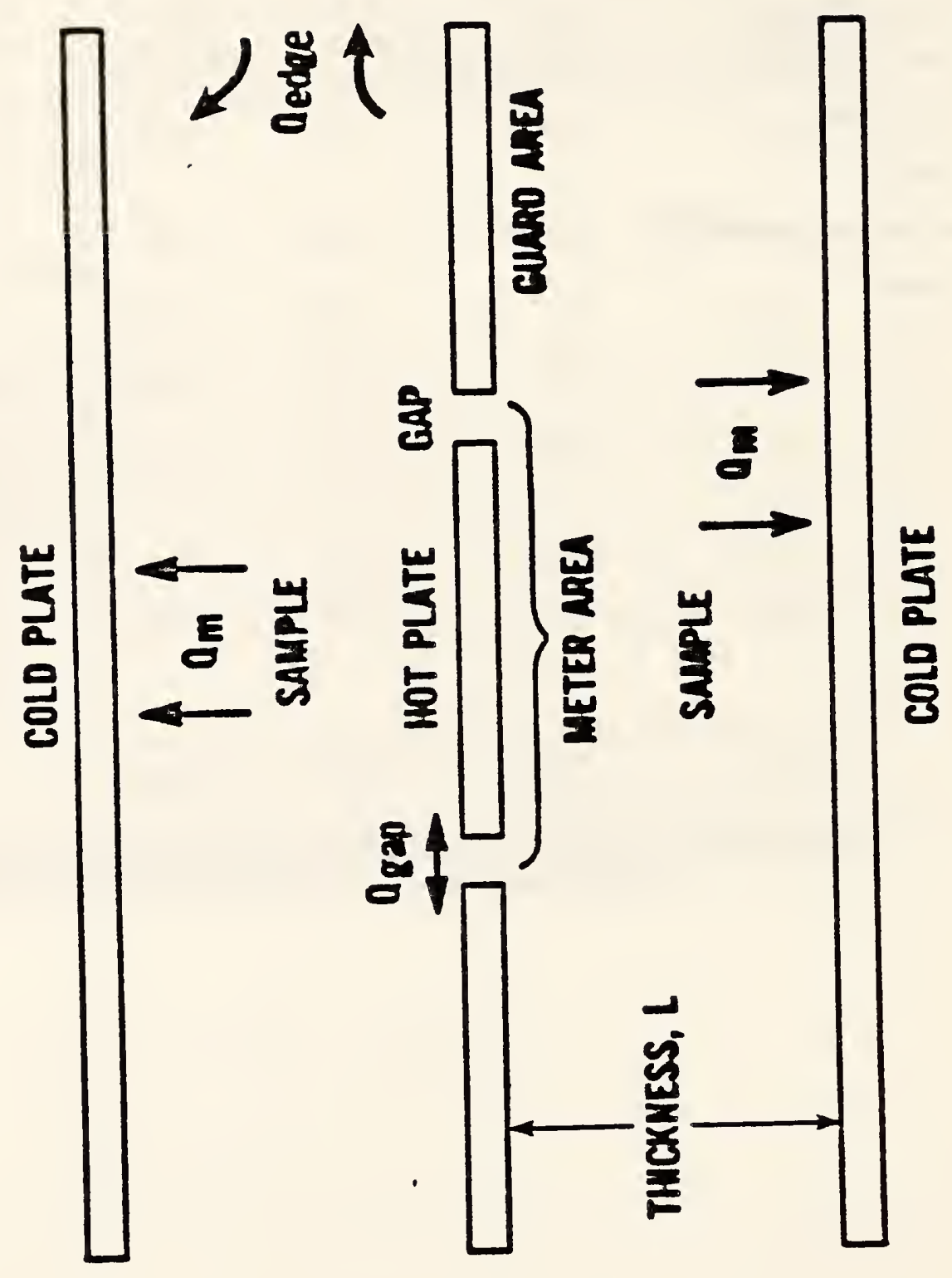

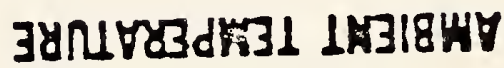


Figure 2 Hot Plate Construction for the NBS 1016m Guarded Hot Plate

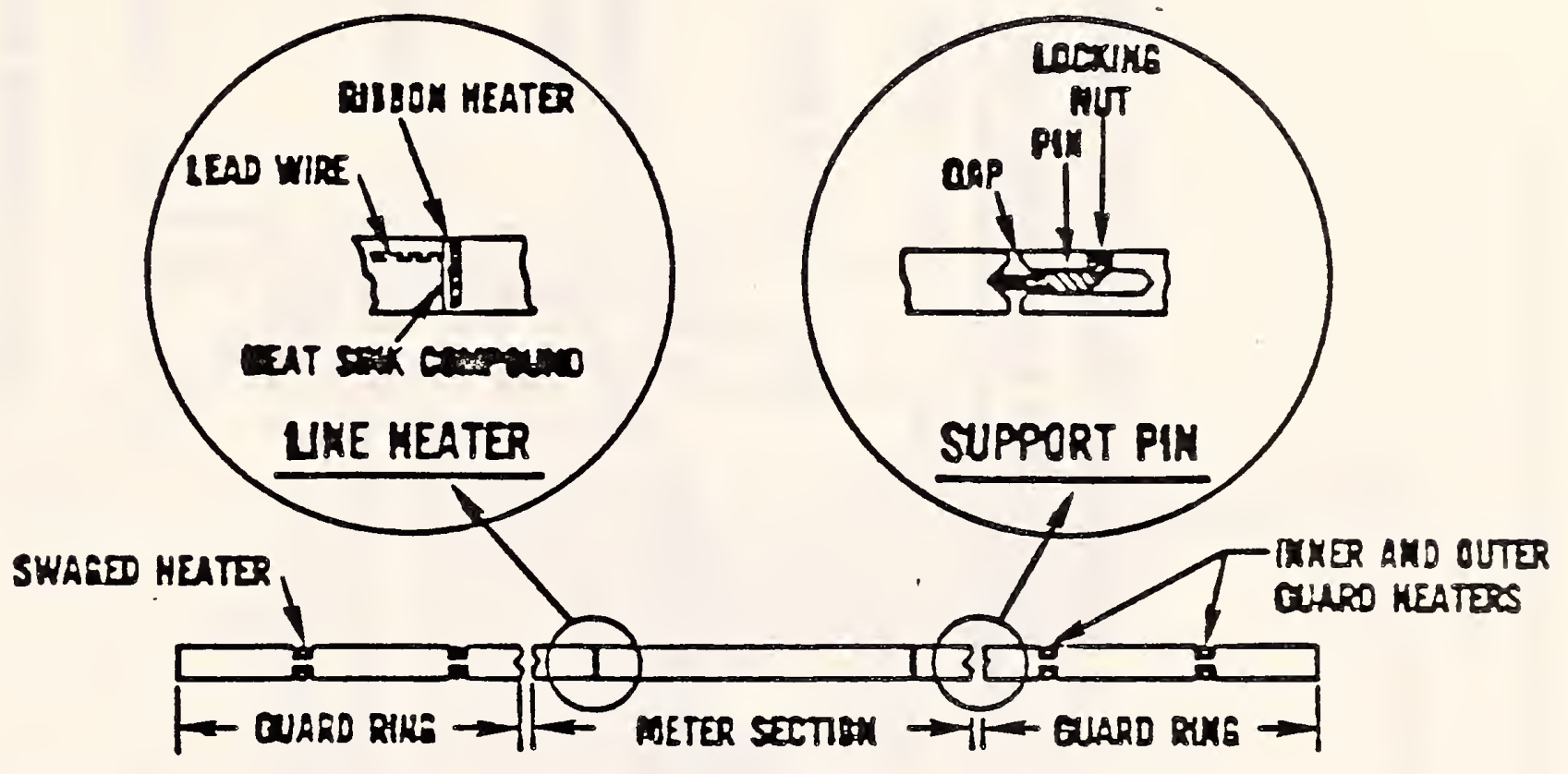

A - RIBBOX KEATER

B - GAP

C - GUARO KEATERS

D - SUPPORT PIN

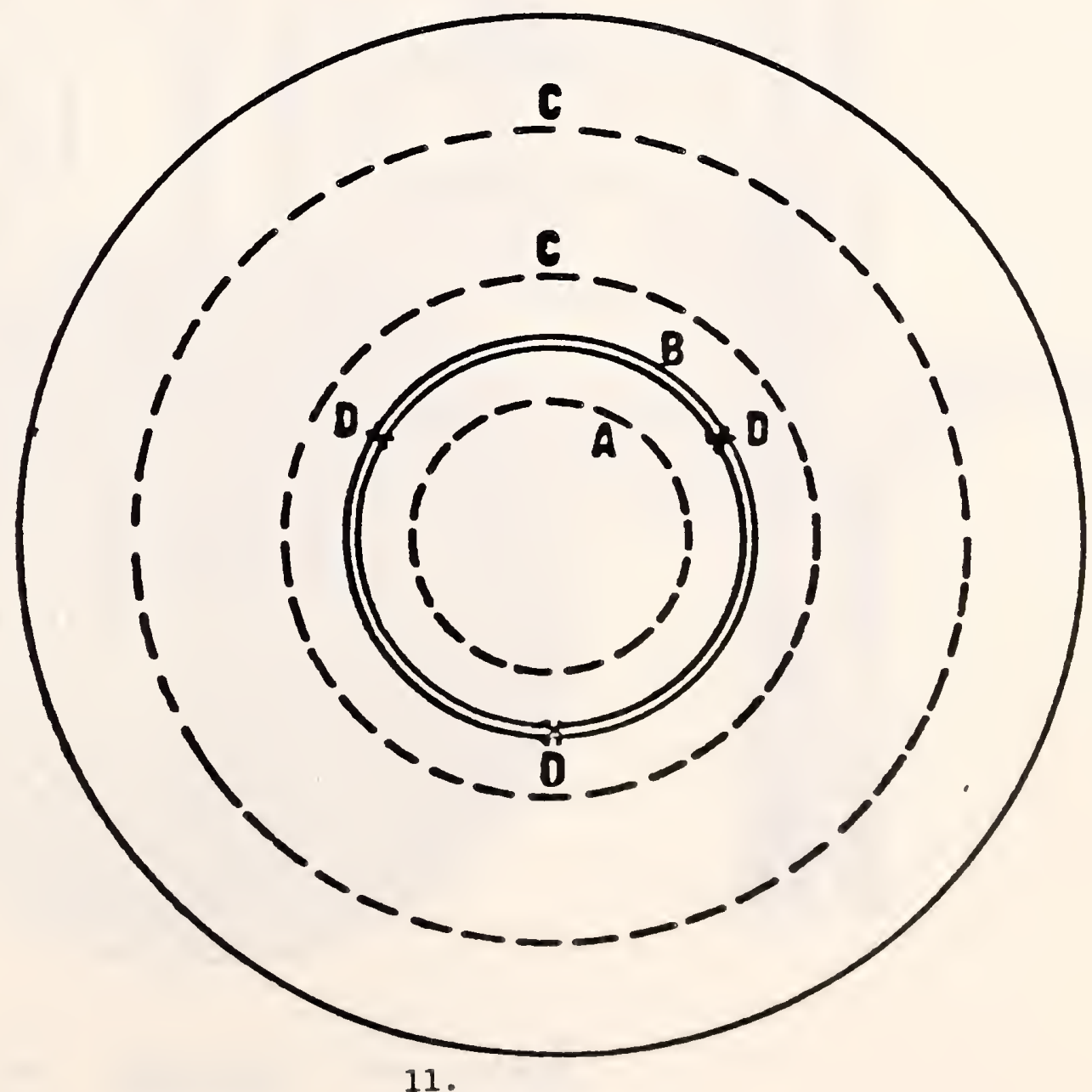




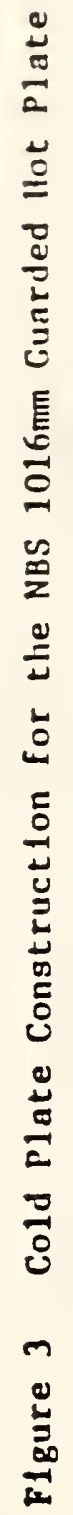

Figure 4 Drawing of the NBS 1016 Guarded Eot Plate Showing the Support System of the Hot and Cold Plates and Showing the Rotatable Enclosure for Environental Control




DATA ON HOT PLATE TEMP FROM OT/89 1981 AT 19:27:11 T0 07/18 1981 AT 08:57:11 ELAPSED TIME FROM FIRST TO LAST READINE IS 13.50 HOURS
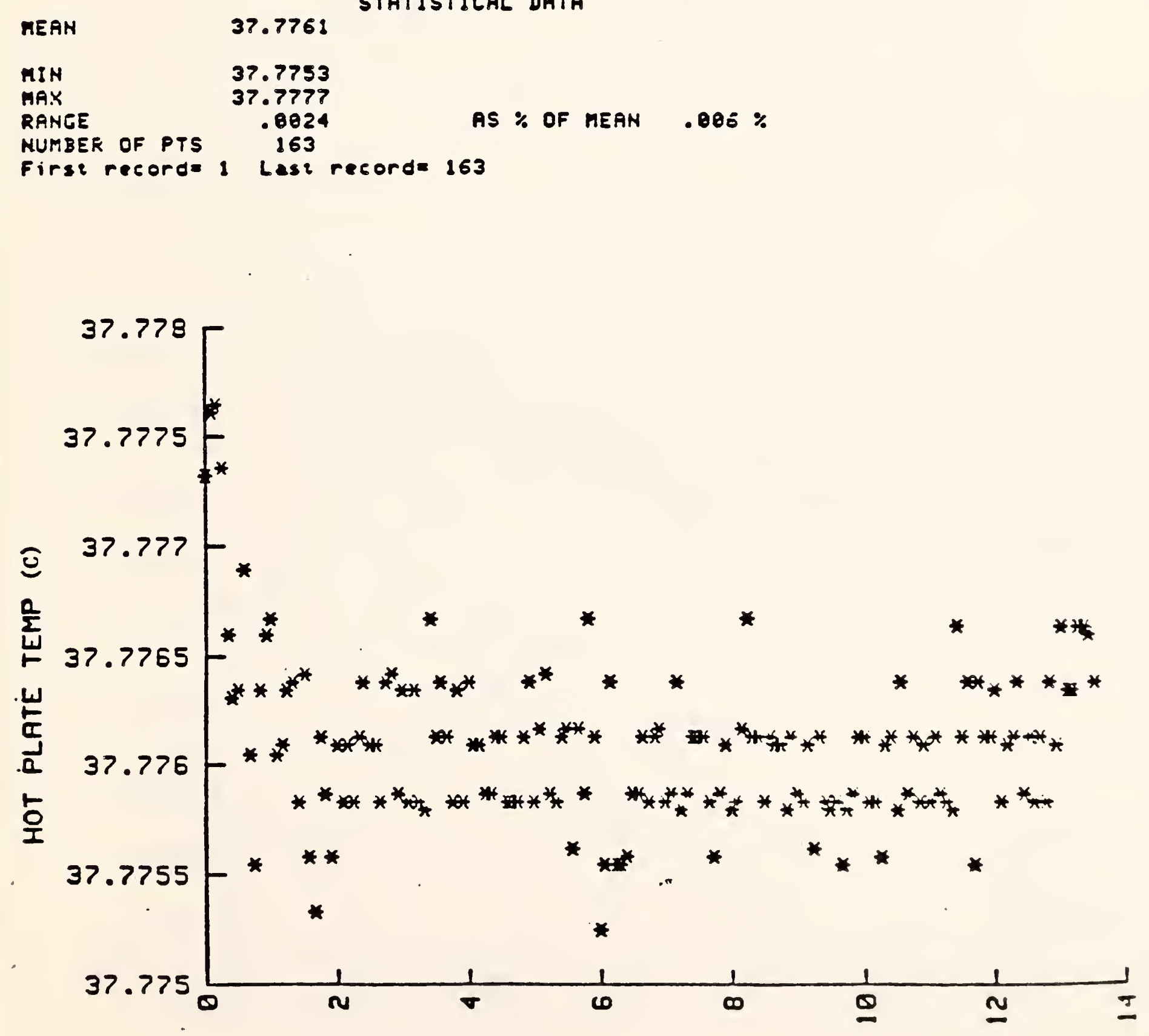

TIME (HOURS) 
FIGURE 7. Typical Data for the Cold-Plate Temperature as a Function of IIme for the NBS 1016mom Guarded Hot Plate

DATA ON UPPER COLD FLATE FROM OT/09 1981 AT 19:27:11 T0 87110.1981 AT 08:5T:11 ELAPSED TIME FROM FIRST TO LAST REFIINC IS 13.50 HOURS

MERN

MIN

MAX

RANCE

NUMEER OF PTS

Firse recorda 1
10.0018

18.0001

10.0044

.0842

163
AS \% OF MEAN $.842 \%$

STATISTICAL DATA

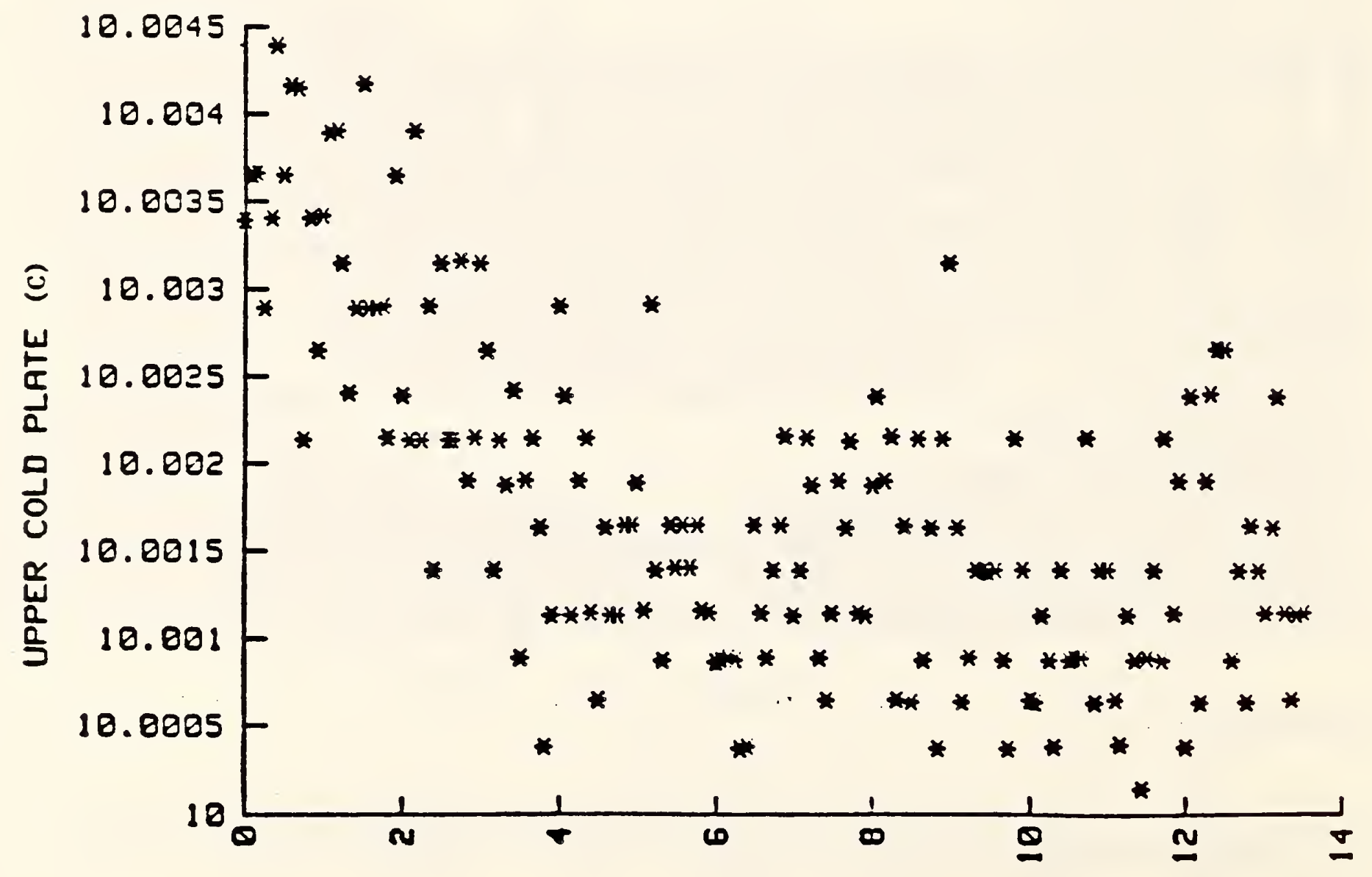

TIME (HOURS)

16. 
FIGURE 8. Typlcal Data for the Center Hot Plate Power as a Function of Irme for the NBS 1016m Guarded Hor Plate

ATA ON POWER EROM OT/B9 1981 AT 19:27:11 TO 07/18 1981 AT 98:57:11 LLAPSED T.IME FROM FIRST TO LAST READINE IS 13.50 HOURS


TIME (HOURS) 
FICURE 9. Typical Data for the Gap Voltage as a Function of I1me for the NBS 1016m Guarded Hot Plate

DATA ON CAP VOLTACE FROM OT/28 1981 AT 17:89:87 TO 07/29 1981 AT 88:48:87

ELAPSED TIME FROM FIRST TO LAST READINE IS 15.52 HOURS

MEAN

$$
.812388
$$

STATISTICAL DATA

$\operatorname{m!N}$

י.:-

$$
-.280000
$$

.460008

NUMBER OF PTS

134

Firse recorda 1 Lase record $=134$

PRT TEST

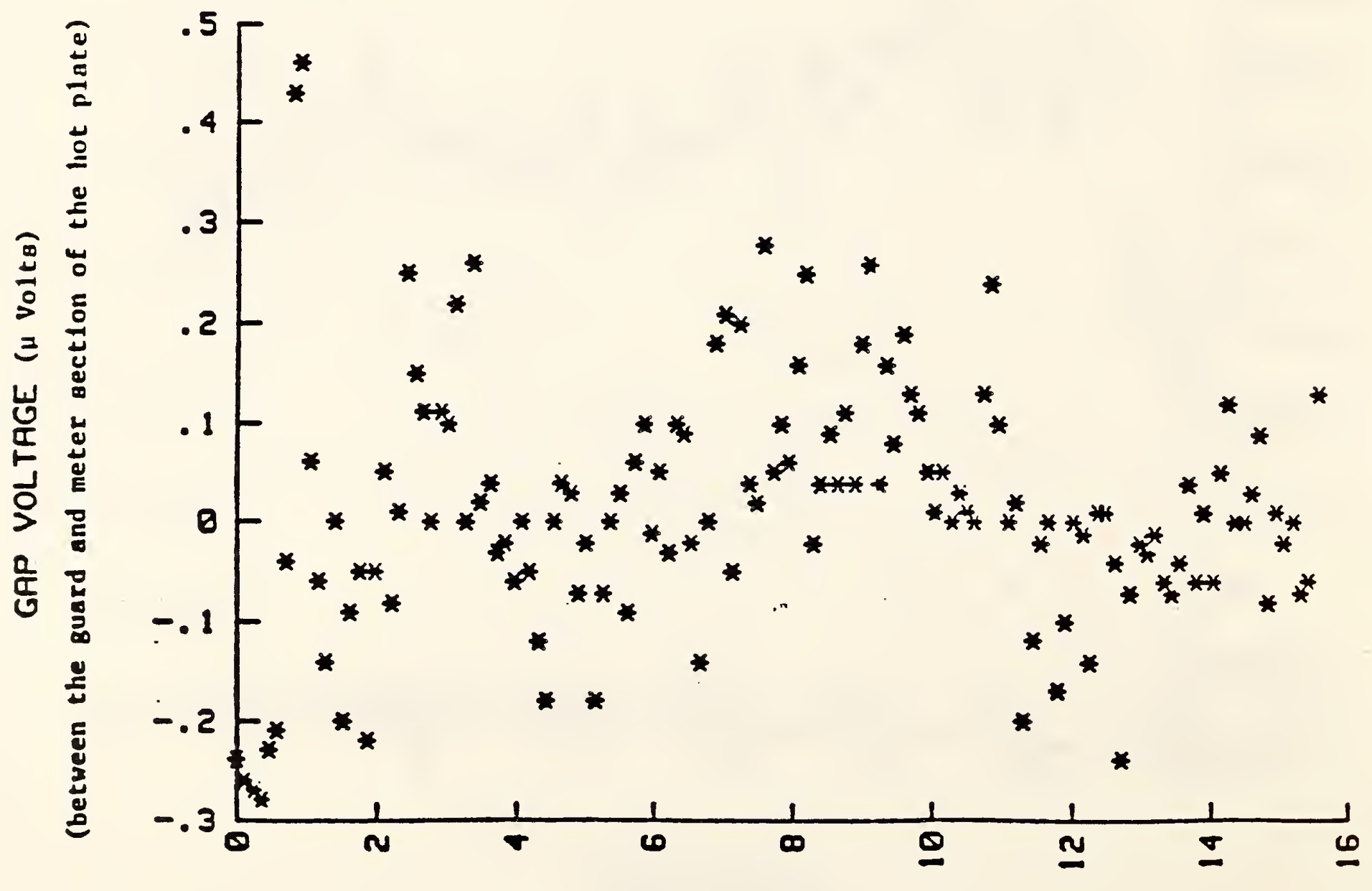


FIGURE 10. Typical Data for the Apparent Thermal Conductivieg as Function of Ilde for the NBS 1016 Guarded

Hot Plate

DATA ONK (AdS. CONd.) FROM OT/O9 1981 AT 19:27:11 T0 OT/18 1981 AT 08:\$7: \$1 ELAPSED TIME FROM FIRST TO LAST READINC IS 13.50 HOURS
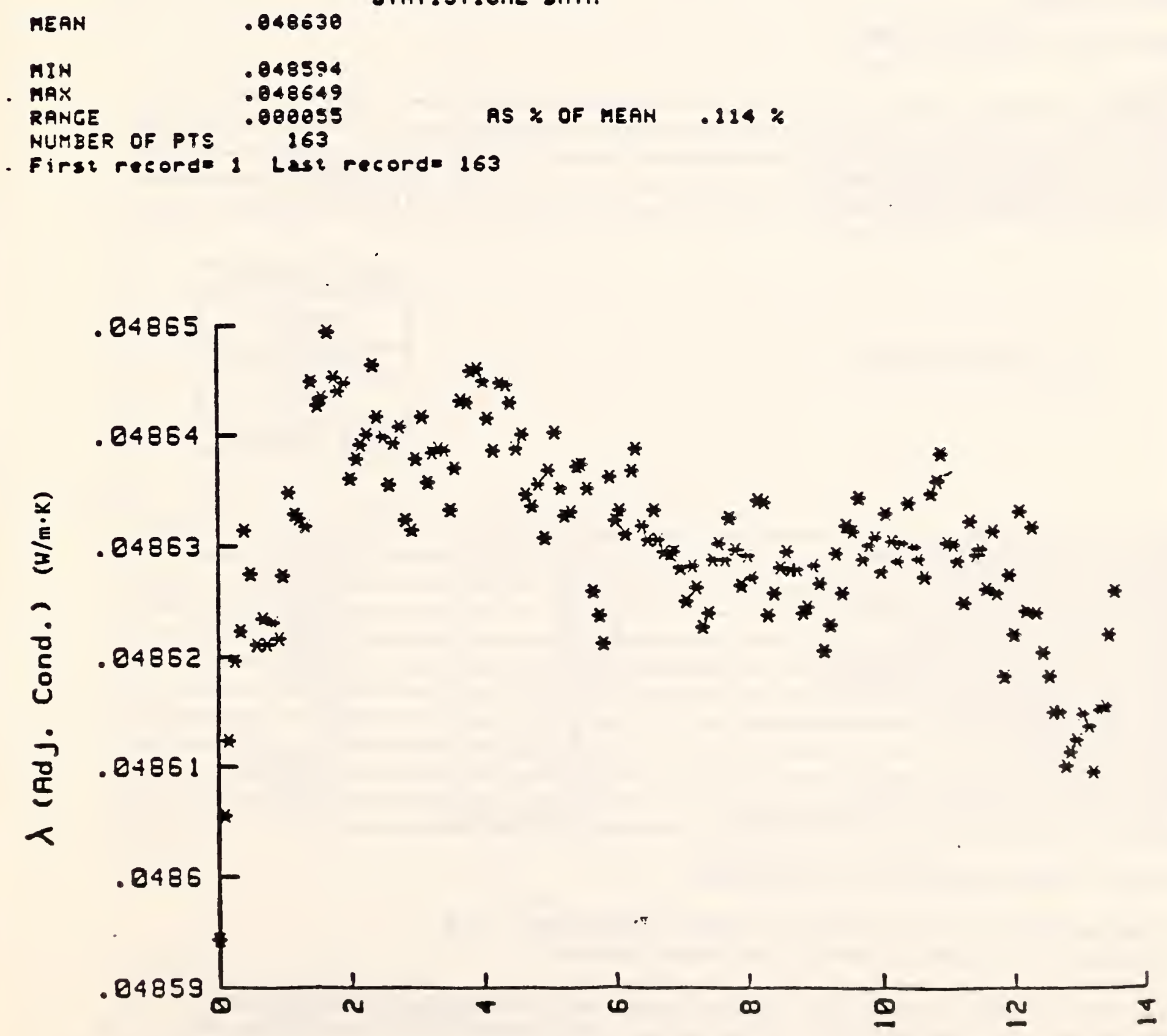

TIME (HOURS) 
Figure 11 Sample Test Report for NBS 1016m Guarded Hot Plate

Iest Results

Apparazus: RBS-CHP-1000

Iable 1

Tesino.

Speciden 1dentification no.

\begin{tabular}{|l|l}
\hline Piate orfentation during test & Horlzontal \\
\hline
\end{tabular}

\begin{tabular}{|l|l|}
\hline plrection of heat flow & Vertical (up) \\
\hline
\end{tabular}

Test Configuration

\begin{tabular}{|c|}
\hline Cold Plate $\# 1$ \\
\hline Sample \\
\hline Hot Plate \\
\hline Sample \\
\hline Cold Plate $\# 2$ \\
\hline
\end{tabular}

Lest thickness (average)

Thernal resistance

Cold plate \#I tezperature

Hot plaie terperature

Cold plate $\| 2$ tezperature

Speciden (mean) tesperature

A=blent reaperature

Asbient huaidity

Heier area

Pover Input to weter area

Edge Insulation theraal resistance

\begin{tabular}{|c|c|}
\hline$m$ & 152.35 \\
\hline$\left(E^{2} \cdot K\right) / W$ & 3.2554 \\
\hline${ }^{\circ} \mathrm{C}$ & 10.00 \\
\hline${ }^{\circ} \mathrm{C}$ & 37.78 \\
\hline${ }^{\circ} \mathrm{C}$ & 37,78 \\
\hline${ }^{\circ} \mathrm{C}$ & 23.89 \\
\hline${ }^{\circ} \mathrm{C}$ & 24 \\
\hline z Ih & 30 \\
\hline$m^{2}$ & 0.1209 \\
\hline$W$ & 2.108 \\
\hline$\left(n^{2} \cdot k\right) / h$ & 2.3 \\
\hline
\end{tabular}

a) Last diglt Included for rounding

b) Enisivity of the surface at room temperature: 0.9

c) Xominal $R$-ralue of insulation around plates

The thermal resistance value in the above table vas deterwined for that portion of the speclmen within the weter area (central 406.4-m diadeter region) of the NBS $-6 \mathrm{HP}-1000$. The uncertalnty in this thermal resistance value 1s estimated to be not wore than $\pm 3 / 4$ percent; this uncertainty Includes apparatus systemitic error and apparatus repeatabilicy. 


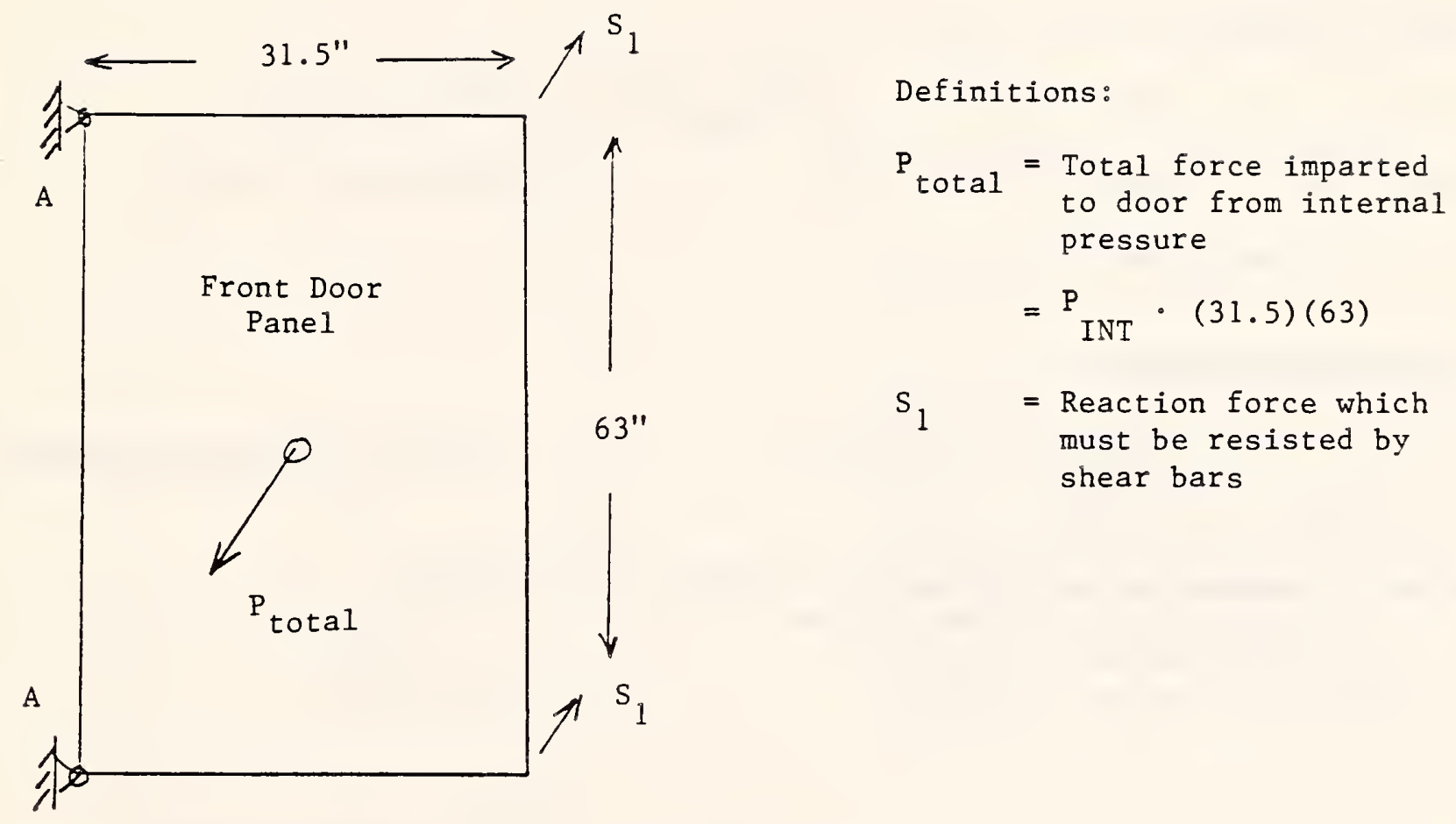

$$
\begin{aligned}
& \text { Definitions: } \\
& \qquad \begin{aligned}
P_{\text {total }}= & \begin{array}{l}
\text { Total force imparted } \\
\text { to door from internal } \\
\\
\text { pressure }
\end{array} \\
= & P_{\text {INT }} \cdot(31.5)(63) \\
= & \text { Reaction force which } \\
& \begin{array}{l}
\text { must be resisted by } \\
\text { shear bars }
\end{array}
\end{aligned} \\
& S_{1}
\end{aligned}
$$

$$
\text { Assume: Shear bar material = } \begin{aligned}
& 6061-\mathrm{T} 6 \text { Aluminum } \\
& \sigma_{\mathrm{ult}}=38 \mathrm{psi}
\end{aligned}
$$

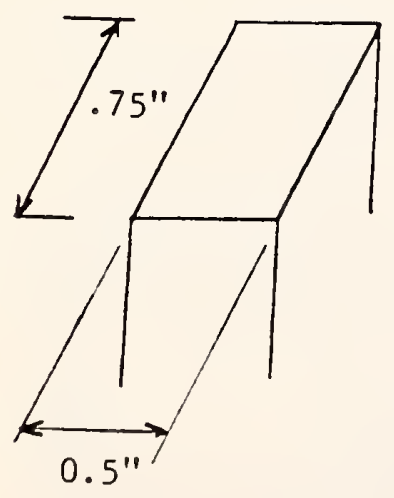

1. Pin shear criterion:

$$
\mathrm{S}_{\mathrm{l}_{\text {MAX }}}=\sigma_{\mathrm{ult}} \cdot \mathrm{A}=38(.75)(.5)=14.25 \mathrm{~K} \text { shear }
$$

2. Clevis shear:

$$
\mathrm{S}_{\mathrm{MAX}}=38(.5)(.625)(2)=23.75 \mathrm{~K} \text { shear }
$$



$0.75^{\prime \prime} \mathrm{TYP}$

3. Clevis tension:

$$
\mathrm{S}_{1_{\text {MAX }}}=38(.5)(.75)(2)=28.5 \mathrm{~K} \text { Tension }
$$


$\therefore \quad$ Pin Shear Controls and $\mathrm{s}_{1_{\mathrm{MAX}}}=14.25 \mathrm{~K}$

Moment Equilibrium about Hinge A - A:

$$
\begin{gathered}
\sum \mathrm{M}_{\mathrm{A}-\mathrm{A}}=0 \mathrm{P}_{\text {total }}\left(\frac{31.5}{2}\right)-2 \cdot \mathrm{S}_{1_{\mathrm{MAX}}}(31.5)=0 \\
\mathrm{P}_{\text {total }}=57 \mathrm{~K}
\end{gathered}
$$

Max Internal Pressure

$$
\mathrm{P}_{\text {INT }}=\frac{\mathrm{P}_{\text {total }}}{(31.5)(63)}=28 \mathrm{psi}^{\text {** }}
$$

**Note: Leakage due to bending in the panel will probably limit this to a lower value. 


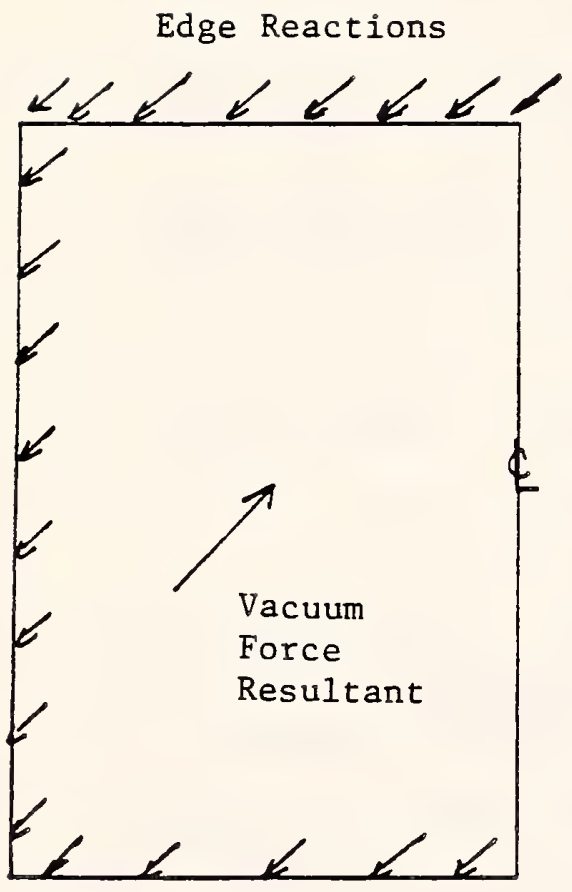

For the purposes of this analysis, the following assumptions can be made:

1. The door is simply supported along its edges as shown.

2. Although some 2-way panel action will occur in the proximity of the left hinge, we assume that a conservative estimate of the door's resistance to load can be calculated by considering a $1^{\prime \prime}$ vertical strip, simply supported at its ends and subjected to a pressure loading equal to the difference between atmospheric pressure and the internal pressure.

$14.7 \mathrm{lb} /$ in $^{2}$ (atmospheric pressure)

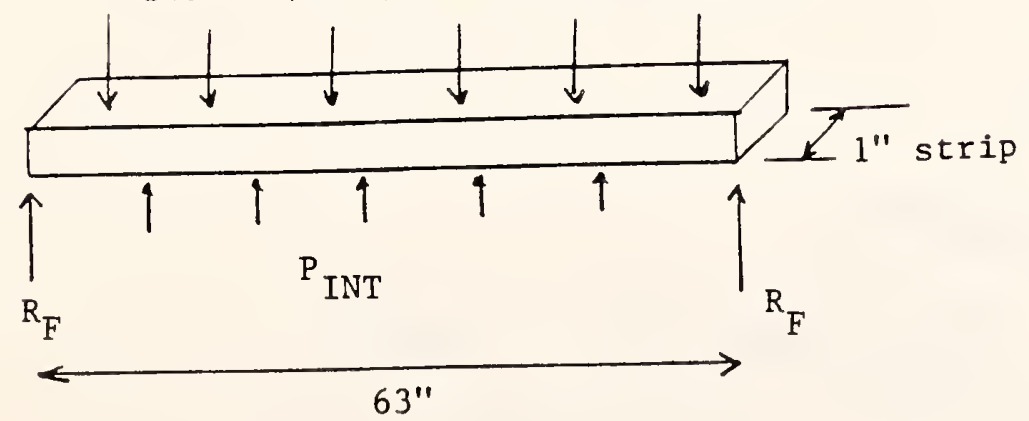

Vertical Force Equilibrium requires

$$
\begin{gathered}
\sum F_{y}=0: 2 R_{F}+P_{\text {INT }} \cdot 63-14.7 \cdot(63)=0 \\
R_{F}=\frac{63}{2}\left(14.7-P_{\text {INT }}\right)
\end{gathered}
$$




$$
M_{\text {MAX }}=R_{F}\left(\frac{63}{2}\right)-14.7\left(\frac{63}{2}\right)\left(\frac{63}{4}\right)=P_{I N T}\left(\frac{63}{2}\right)\left(\frac{63}{4}\right)
$$

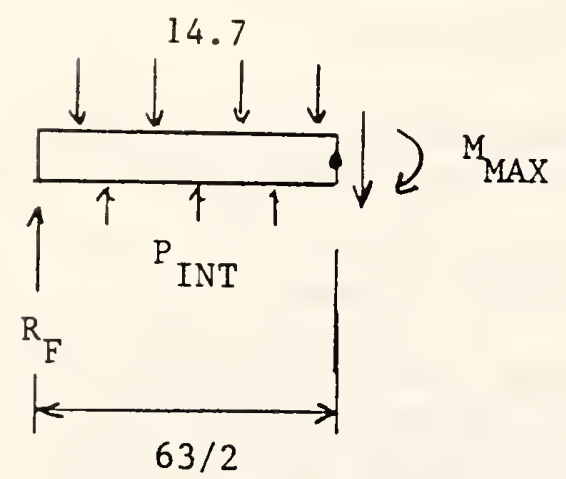

Substituting (EQ 1)

$$
\begin{aligned}
M_{\text {MAX }} & =\left(\frac{63}{2}\right)\left(14.7-P_{\text {INT }}\right)\left(\frac{63}{2}\right) \\
& +\left(P_{\text {INT }}-14.7\right)\left(\frac{63}{2}\right)\left(\frac{63}{4}\right) \\
M_{\text {MAX }} & =14586-992.25 P_{\text {INT }}
\end{aligned}
$$

\section{Calculate Section Properties}

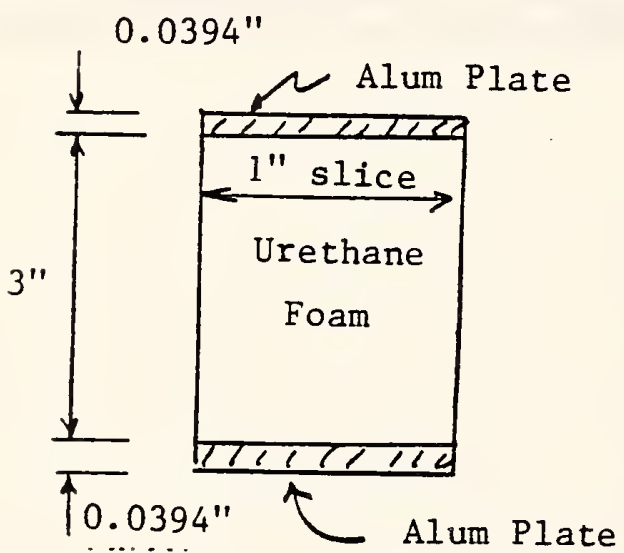

$$
\begin{aligned}
& I \sim \mathrm{Ad}^{2} \text { Aluminum }=1(0.0394)(1.5)^{2} \\
& =0.1773 \text { in }^{4} \\
& \sigma_{\text {MAX }}^{\sigma \text { (urethane shear) }}=0.217 \mathrm{MPa} \\
& =31.44 \mathrm{psi} \\
& \sigma_{\text {MAX }} \\
& \text { (aluminum) } \\
& =30 \mathrm{Ksi} \\
& \text { (standard alum. plate) }
\end{aligned}
$$

\section{Check Flexural Strength of Composite}

$$
\begin{gathered}
\sigma_{S}=\frac{M C}{I}=\frac{\left(14586-992.25 \mathrm{P}_{\text {INT }}\right)(1.5)}{0.1773}=30,000 \\
\frac{\text { Minimum }}{P_{I N T}}=\frac{14586(1.5)-30,000(.1773)}{1.5(992.25)} \\
P_{\text {INT }}=11.126 \text { absolute psi }
\end{gathered}
$$


Check Max Urethane Shear

$\sigma_{S}=\frac{V Q}{I B}=31.44$ psi $=\frac{3}{2} \frac{V}{A}$ for rectangular sections

$A=(1)(3.079)=3.079$

$\mathrm{V}=\left(14.7-\mathrm{P}_{\mathrm{INT}}\right)\left(\frac{63}{2}\right)$

$\sigma_{S}=31.44=\frac{3}{2} \frac{\left(14.7-P_{\text {INT }}\right)\left(\frac{63}{2}\right)}{3.079}$

$14.7-3.079(31.44)\left(\frac{2}{3}\right)\left(\frac{2}{63}\right)=\mathrm{P}_{\mathrm{INT}}$

$\mathrm{P}_{\text {INT }}=12.65$ psi min. (absolute)

$\therefore$ this controls

The chamber rating is therefore:

$12.65<\mathrm{P}_{\text {INT }}<42$ absolute

or

$-2.05<\mathrm{P}_{\text {INT }}<28$ (relative change WRT atmospheric) 



\section{Appendix 4 \\ Calculation of Percentage Uncertainty \\ in the Measured Metered-Area Heater Power \\ for a $152.4 \mathrm{~mm}$ Thick, Low k-Value Insulation Specimen [5]}

The term, $Q_{m}$, is the power produced by the meter heater. A known standard shunt resistor, $R_{S}$, of approximately $0.1 \AA$, that is maintained in an oil bath, is used to determine the current. Voltage taps across the meter heater lead wires in the center of the gap are used to measure the voltage corresponding to the power that flows one-dimensionally from the hot plate to the cold plates.

$$
\begin{aligned}
& Q_{m}=\frac{V_{\text {heater }} V_{s}}{R_{s}} \\
& R_{S}=0.1000700 \Omega \pm 5 \mathrm{ppm} \text { at } 25.0^{\circ} \mathrm{C}
\end{aligned}
$$

An additional uncertainty of $20 \mathrm{ppm}$ is included since the resistor is in a bath at $28^{\circ} \mathrm{C}$. The uncertainty of $25 \mathrm{ppm}$ corresponds to a 0.0025 percent uncertainty, which is negligible compared with other uncertainties.

If the heater voltage taps were not in the center of the gap, there would be an error in the measurement of $V_{\text {heater }}$. The 28 gauge nichrome wire has a resistance value of $42 \Omega / 305 \mathrm{~m}(1000 \mathrm{ft}$ ). Assuming (conservatively) that the taps might be misplaced by half the gap width of $6 \mathrm{~mm}(0.23 \mathrm{in})$, then the error in $R_{\text {heater }}$ is $8 \times 10^{-4} \Omega$. This is negligible when compared with the value of $R_{\text {heater }}$ of approximately $56 \Omega$.

As a worst-case example, the following calculation is for a thick two-sided specimen with a k-value that is at the low extreme of what would be expected $\left(k_{s}=0.0086 \mathrm{~W} / \mathrm{m}^{\circ} \mathrm{K}\right)$. The following equation expresses the metered-area heater power required to maintain a temperature difference, 
$\triangle \mathrm{T}$, of $27.8^{\circ} \mathrm{C}$ across the $152.4 \mathrm{~mm}$ thick specimen, for the NBS $1-\mathrm{m}$ GHP. The metered-area is $0.1299 \mathrm{~m}^{2}$.

$$
\begin{aligned}
Q_{m} & =\left(2 k_{s} \Delta T A\right) / L \\
& =0.408 \mathrm{~W}
\end{aligned}
$$

Given that the metered-area heater resistance, $R_{h}$, is $-560 \Omega$ and the shunt resistance, $R_{S}$, is $\sim 0.1 \Omega$, the shunt voltage is calculated as follows:

$$
\begin{aligned}
V_{s} & =R_{s}\left(Q_{m} / R_{h}\right)^{1 / 2} \\
& =8.5 \mathrm{mV}
\end{aligned}
$$

Thus $V_{h}=4.7 \mathrm{~V}$.

These order-of-magnitude estimates are necessary to calculate the percentage errors in $V_{\text {heater }}$ and $V_{s}$. As an example, for the $10 \mathrm{~V}$ range of the digital voltmeter and for a 90-day period, the manufacturer's specifications give the following formula to calculate the voltage uncertainty, $\Delta v$.

$$
3 \Delta \mathbf{v}=\left(\frac{0.0023}{100} \mathrm{v}+2 \text { counts } \mathrm{x} \text { count value }\right)
$$

This is for a 6-digit readout and an average over 10 power line cycles. The count value is somewhat larger than the minimum detectable signal and has a value of $10 \mu \mathrm{V}$. If $\mathrm{V}=4.7 \mathrm{~V}, \Delta \mathrm{V}=.0000004=0.00004$ percent. This is obviously negligible compared to other voltage errors.

The more significant contribution to uncertainty results from the reading of the shunt voltage, $v_{S}$, on the $0.1 \mathrm{~V}$ scale. $v_{s}=8.5 \mathrm{mV}$, which is a worst-case value. The manufacturer's uncertainty formula for this range is:

$$
\begin{aligned}
3 \Delta \mathrm{v} & =\left(\frac{0.0034}{100} \times 8.5 \mathrm{mV}+24 \text { counts } \times 0.1 \mu \mathrm{V}\right) \\
& =2.7 \mu \mathrm{V} \\
\frac{3 \Delta \mathrm{v}}{V_{s}} & =0.0003=0.03 \%
\end{aligned}
$$


This $\Delta v$ uncertainty is the only contributor to the uncertainty in $Q_{m}$ that is not negligible, and it is mostly due to the "24 counts". 



\section{Appendix 5 \\ Test Thickness Limitations Due to Edge Effect Oncertainties}

Figures 8 and 9 show the $A$ and $B$ edge effect coefficlents for the NBS $9=$ II GHP apparatus parameters. These are a metered-are radius equal to $200 \mathrm{~mm}$ and a guard-area radius equal to $400 \mathrm{~mm}$. The and $B$ coefficients indicate the magnitude of the edge effect as is shown in equations (1), (2) and (3) in the text. Eacb curve shows the dependence of $A$ and $B$ on specimen thickness, L. The set of curves demonstrates parametric dependence on the parameter $h_{e} / k_{s}$. Here, $h_{e}$ is the effective surface f1lm coefficient between the specimen edge and the ambient, and $k_{9}$ is the specimen apparent thermal conductivity.

The effective surface film coefficient, $b_{e}$, is calculated in terms of the thermal resistance of edge insulation, $R_{e d}$ and the surface film coefficient between this edge insulation and the ambient, $h$.

$$
b_{e}=\left(R_{e d}+1 / h\right)^{-1}
$$

A typical value for $R_{e d}$ is $1.75 \mathrm{~m}^{2} \cdot \mathrm{K} / \mathrm{W}$ and for $\mathrm{b}$ is $5.67 \mathrm{~W} / \mathrm{m}^{2} \cdot \mathrm{K}$. Then, $\mathrm{be}$ is equal to $0.52 \mathrm{~W} / \mathrm{m}^{2} \cdot \mathrm{K}$.

Typlcal values of $h_{e} / k_{s}$ are $11.3 \mathrm{~m}^{-1}$ for a low-density, glass-fiber material $\left(\mathrm{k}_{3}=0.046 \mathrm{~W} / \mathrm{m} \cdot \mathrm{K}\right), 15.8 \mathrm{~m}^{-1}$ for a high-density glass-fiber material $\left(k_{s}=0.033 \mathrm{~W} / \mathrm{m} \cdot \mathrm{K}\right)$, and $21.7 \mathrm{~m}^{-1}$ for an extruded polystyrene material $\left(k_{s}=0.024 \mathrm{w} / \mathrm{m} \cdot \mathrm{K}\right)$. For the low extreme value for $\mathrm{k}_{\mathrm{g}}$ of 0.0086 $W / m \cdot R, h_{e} / k_{3}$ is equal to $60.5 \mathrm{~m}^{-1}$.

Figure 8 shows $A(X)$ for various values of $h_{e} / k_{s}$. The term $A$ is the 
intercept value, $Y(0)$, when $X=0$, or equivalently when the ambient temperature equals the mean temperature (refer to Equation (2)). There are two approaches to estimate edge error. One is to consider A the uncertainty. Another is to rely on the edge-effect model to adjust to the value of $Y$ at which $Y=0$, which implies a knowledge of $R_{0}$, the onedimensional or "true" thermal resistance of the thick specimen. For the sake of brevity, the first approach is adopted here.

For a typical specimen, with $k_{s}=0.046 \mathrm{~W} / \mathrm{m}^{\circ} \mathrm{K}$ and $\mathrm{h}_{\mathrm{e}} / \mathrm{k}_{\mathrm{s}}=11.3 \mathrm{~m}^{-1}$, and for a tolerance of $0.2 \%$, the error curve in figure 8 exceeds the tolerance at a thickness of $-325 \mathrm{~mm}$. Whereas, for $\mathrm{k}_{\mathrm{s}}=0.0086 \mathrm{~W} / \mathrm{m} \cdot \mathrm{K}$ and $\mathrm{h}_{\mathrm{e}} / \mathrm{k}_{\mathrm{s}}=60.5 \mathrm{~m}^{-1}$, the curve exceeds the same tolerance at a thickness of $-310 \mathrm{~mm}$. Thus, a decrease in $k_{s}$ by a factor of 5 to the extreme low value $0.0086 \mathrm{~W} / \mathrm{m} \cdot \mathrm{K}$, does not result in a significant decrease in the thickness operating range.

At the maximum operating thickness of $381 \mathrm{~mm}$, the $\mathrm{A}$ value is $-0.5 \%$ for $\mathrm{k}_{\mathrm{s}}=$ $0.046 \mathrm{~W} / \mathrm{m} \cdot \mathrm{K}$, and $0.8 \%$ for $\mathrm{k}_{\mathrm{s}}=0.0086 \mathrm{~W} / \mathrm{m} \cdot \mathrm{K}$. Again, please note that the uncertainty would be smaller if the model were used to adjust the measured k-value. For example, if there were a $25 \%$ confidence in the model predictions, these values of $0.5 \%$ and $0.8 \%$ would be smaller by a factor of 4.

Figure 9 shows the curves of $B(L)$ for various values of $h_{e} / k_{s}$ (refer to equations (1), (2) and (3)). The B term is the slope of the edge effect term, $Y$, plotted as a function of the dimensionless ambient temperature unbalance, $X$. This slope is easy to determine empirically, by measuring change in the thermal resistance as the ambient temperature is varied. 
Then, to estimate the uncertainty in $R$-value due to $B$, multiply the empirically determined value of $B$ times the uncertainty in $\mathrm{X}, \Delta \mathrm{X}$. If $\left(\mathrm{T}_{\mathrm{h}}=\right.$ $\left.T_{c}\right)=27.8^{\circ} \mathrm{C}$ and if the uncertainty in $\left(T_{m}-T_{A}\right)$ is $1^{\circ} \mathrm{C}$, then $\Delta X-0.036$. The term, B $\Delta \mathrm{X}$, gives the uncertainty in the measured R-value.

For the two k-values used in the discussion of the $A$ term, $k_{s}=0.046 \mathrm{~W} / \mathrm{m}^{\circ} \mathrm{K}$ and $k_{s}=0.0086 \mathrm{~W} / \mathrm{m} \cdot \mathrm{K}$, the values of $B \Delta X$ are equal to $0.2 \%$ at thicknesses of $-295 \mathrm{~mm}$ and $-282 \mathrm{~mm}$. The same conclusion holds, as for the case of A, that a decrease in $\mathrm{k}-\mathrm{value}$ to the low extreme expected in practice, does not affect the thickness operating range significantly.

The reason for this conclusion is that the curves of $A(L)$ and $B(L)$ are highly unlinear. They are essentially zero until L $200 \mathrm{~mm}$. Between $\mathrm{L}=$ $200 \mathrm{~mm}$ and $L=300 \mathrm{~mm}$, the slope increases rapidly, and above $300 \mathrm{~mm}$ it is approximately constant. As a result, small changes in the curve, such as those due to the parametrical dependence on $h_{e} / k_{s}$, do not significantly affect the operating thickness threshold. 
Appendix 6

Contact Resistance

Contact resistance is the resistance to heat flow resulting from the air gaps between a specimen and the apparatus plates.

To estimate the error that could result if contact resistance were not taken into account, consider a 25.4 mm thick specimen with an air gap of 25.4 microns on each side. The heat transferred through the gap considering conductive and radiative heat transfer is given by the following equation [8].

$$
q=k_{a} \frac{\Delta T}{I_{g}}+\frac{4 \sigma \bar{T} \frac{3}{s} \Delta T}{2 / \epsilon-0.9343+3 / 4 T_{0}}
$$

where $k_{a}$ is the thermal conductivity of air $(0.0259 \mathrm{~W} / m \cdot K), \epsilon$ is the plate emittance $(0.9), T$ is approximately equal to the average air-gap temperature, $\Delta \mathrm{T}$ is the temperature difference across the air gap, and ${ }^{T_{0}}$ is the optical depth. It is defined as:

$$
\tau_{0}=\beta \mathrm{L}_{\mathrm{g}}
$$

where $\beta$ is the extinction coefficient and $\mathrm{L}_{\mathrm{g}}$ is the air-gap thickness. Since both $\beta$ (for $a i r$ ) and $L_{g}$ are small, the value of ${ }^{\top}$ is negligible.

The gap average temperature, $\bar{T}$, is different on the hot-plate and coldplate sides. The $\overline{\mathrm{T}}$ value of the hot-plate air gap, $35^{\circ} \mathrm{C}(308.15 \mathrm{~K})$, is used because the radiation heat transfer contribution is slightly larger. 
In general, the thermal resistance is defined as $R=T / q$. Using this and equation (5-1), the contact resistance, $r$, is the following.

$$
r=\frac{1}{k_{a} / I_{g}+\left[\left(4 \sigma \overline{\mathrm{T}}^{3}\right) /(2 / \epsilon-0.9343)\right]}
$$

The relative values of the two terms in the denominator are the following.

$$
\begin{aligned}
\frac{4 \sigma \bar{T}^{3}}{2 / \epsilon-0.9343} & =5.7024 \mathrm{~W} / \mathrm{m}^{2} \cdot \mathrm{K} \\
\mathrm{k}_{\mathrm{a}} / \mathrm{L}_{\mathrm{g}} & =510.59 \mathrm{~W} / \mathrm{m}^{2} \cdot \mathrm{K}
\end{aligned}
$$

From equation $(6-3)$ the contact resistance is the following.

$$
r=\frac{1}{510.59+5.7024}=0.00194 \mathrm{~m} \cdot \mathrm{K} / \mathrm{W}
$$

Thus, the radiation contribution to the thermal resistance is very sma 11 (approximate ly $1 \%$ ).

The ratio of $r$ to the thermal resistance of a $25.4 \mathrm{~mm}$ specimen is used to indicate the order of magnitude of error due to contact resistance. Table 1 shows the percent value of this ratio for a range of $k$-values from 0.02 to $0.30 \mathrm{~W} / \mathrm{m} \cdot \mathrm{R}$. 
NES-T14K. E. $2 \rightarrow C$

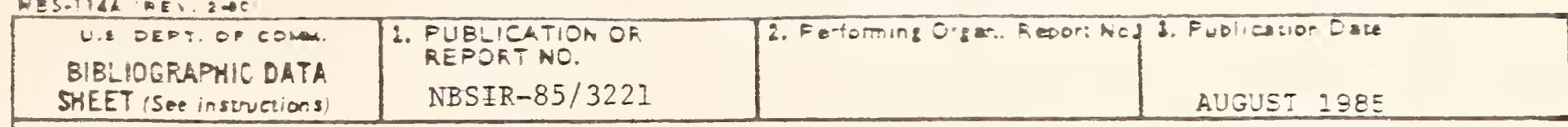

4. TITLE AND SUBTITLE

An Assessment of the NBS 1-m Guarded-Hot-Plate Limits

5. AUTHOR(S)

BItan. Reanex.

6. PERFORMING ORGANIZATION (If joint or other thon NBS. see instructions,

MATIONAL BUREAU OF STAMDARDS

DEFARTMENT OF COMUERCE

TASHILGTOK, D.C. 20234

7. Contract G-an! Ne.

DE-AIOS-85OR2:513

Task ce5/i

1. Type of Redori \& Periot Covered Final

3. SDONSORING ORGANIZATION NAME AND COMPLETE ADDRESS (STPCL CITY, SLOTE, ZIP)

Departwent of Energy

Oak Ridge Operations Office

10. SUPPLEMENTARYY NOTES

- Document oescribes compute program: SF-185. FipS Software Suman, is attached.

11. A.ESTRACT (A 200-wore or less foctwal summory of mosi significont information. If ciocument incluces o significons

bitutgrophy of ilereure surver. mention is mere,

The report evaluates the Katioral Bureau of Stancards i-meter Guarjec Eor Fiate in rezas of the range of velues of operating pazemerezs. Ine zanges of opergitor are ciscussed according to three kinds of limiting factors. The first is the Iimits of tempezature over which the various epparazus components cad be used uthou: sufierine cimage. The second kind is the limits of plate cemperatures, specimez thisiness, atmospheric pressure, anc reiative humidity achievabie with the existing controi systems. The third kind is any limite on the values of epparent thermel conductivity, chermal resistance, or specimen thichness due to measurement error considerations. The current operating range is oocumented by dats of apparent thermal conductivity versus specimet mean temperature and thiciness. Ine current temperature $11 m i t s$ for the specimen mean temperacure are $-3{ }^{\circ} \mathrm{C}$ to $55^{\circ} \mathrm{C}$. Minor 1 mprovements can extend this range to $-30^{\circ} \mathrm{C}$ to $190^{\circ} \mathrm{C}$. There are no serlous 11 mits on thermal resistance or apparent thermal conductivity for typlcal specimens. There 18 no pressure control, and to provide such control would be a msjor expense. The thickness $11 \mathrm{mits}$ are $19 \mathrm{~m}$ and 381 wh. The current I1mits on relative humidity are from 22 to $35 \%$ at $24^{\circ} \mathrm{C}$. The upper Iimit can easily be extended. Ar estimate of apparatus uncertaints is made over the ranges of spectmen mean temperature, apparent therms conductivity, and thickness.

12. KEY WORDS (5ix to twelve entries: alphobelical order: copitalize only proper nomes; ond seporate ke, words by semicoions) epparent thermal conductivity; calfbration; error analys16; guarded hot plate; operat1ng ranges; otandard reference material (SRM); thermal insulat1on; thermal.

resistance.

13. AVAILABILITY

X. Unlimited

For Officisl Distribution. Do Not Release wo NTIS

Ordet From Suderintendent of Documents, U.S. Government Printing Office, Mashington. D.C. 20402.

Q Order From National Technical Information Service (NTIS). Springfield. VA 22161

\begin{tabular}{|} 
14. NO. OF \\
PRINTED PAGES \\
97 \\
15. Price \\
$\$ 11.50$
\end{tabular}




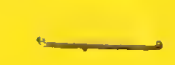

